Florida International University FIU Digital Commons

FIU Electronic Theses and Dissertations

University Graduate School

5-25-2016

\title{
Sulfur Based Electrode Materials For Secondary Batteries
}

Yong $\mathrm{HaO}$

Florida International University, yhao004@fiu.edu

DOI: 10.25148 /etd.FIDC000740

Follow this and additional works at: https://digitalcommons.fiu.edu/etd

Part of the Other Materials Science and Engineering Commons

\section{Recommended Citation}

Hao, Yong, "Sulfur Based Electrode Materials For Secondary Batteries" (2016). FIU Electronic Theses and Dissertations. 2582. https://digitalcommons.fiu.edu/etd/2582

This work is brought to you for free and open access by the University Graduate School at FIU Digital Commons. It has been accepted for inclusion in FIU Electronic Theses and Dissertations by an authorized administrator of FIU Digital Commons. For more information, please contact dcc@fiu.edu. 


\section{FLORIDA INTERNATIONAL UNIVERSITY}

Miami, Florida

SULFUR BASED ELECTRODE MATERIALS FOR SECONDARY BATTERIES

A dissertation submitted in partial fulfillment of the

requirements for the degree of

DOCTOR OF PHILOSOPHY

in

MATERIALS SCIENCE AND ENGINEERING

by

Yong Hao

2016 
To: Interim Dean Ranu Jung

College of Engineering and Computing

This dissertation, written by Yong Hao, and entitled Sulfur Based Electrode Materials for Secondary Batteries, having been approved in respect to style and intellectual content, is referred to you for judgment.

We have read this dissertation and recommend that it be approved.

Norman Munroe

Bilal El-Zahab

Nezih Pala

Yu Zhong

Arvind Agarwal, Co-Major Professor

Chunlei Wang, Co-Major Professor

Date of Defense: May 25, 2016

The dissertation of Yong Hao is approved.

Interim Dean Ranu Jung College of Engineering and Computing

Andrés G. Gil

Vice President for Research and Economic Development and Dean of the University Graduate School

Florida International University, 2016 
(C) Copyright 2016 by Yong Hao

All rights reserved. 


\section{DEDICATION}

Dedicated to my beloved parents, Zhenjiang Hao and Hua Sun. 


\section{ACKNOWLEDGMENTS}

My deepest gratitude dedicates to my esteemed advisor, Dr. Chunlei Wang, for her guidance, vision and support throughout my $\mathrm{PhD}$ research career. I truly appreciate her patience, understanding, inspiration and invaluable encouragement which assist me to overcome lots of obstacles during my study. I also appreciate her effort on reviewing my research work and providing constructive comments to improve the quality of my research.

I am grateful to my co-advisor, Dr. Arvind Agarwal and all the members of my dissertation committee, Dr. Norman Munroe, Dr. Nezih Pala, Dr. Bilal El-Zahab and Dr. Yu Zhong for their willingness to serve as my dissertation committee and for their invaluable support and encouragement. I would also like to thank Dr. Cesar Levy for his generous support and encouragement during my $\mathrm{PhD}$ study.

I sincerely thank my past and present research group members: Dr. Majid Beidaghi, Dr. Varun Penmatsa, Dr. Abirami Dhanabalan, Dr. Yin Song, Dr. Jun Wu, Dr. Jujun Yuan, Dr. Xianke Zhang, Dr. Jianwen Yang, Mr. Chunhui Chen, Ms. Richa Agrawal, Mr. Gautam Shan, Mr. Wladimir Valdenegro, Mr. Michael Page, Ms. Ali Henriques and Mr. Adelowo Dotun.

I also would like to appreciate the help from the staff in Advanced Materials Engineering Research Institute (AMERI) at FIU and all the collaborators outside FIU, Dr. Xueliang Sun, Dr. Xifei Li, Dr. Bo Zou, Dr. Xinyi Yang and Dr. Guangjun Xiao for their effort on my research work and valuable suggestions.

I acknowledge the Mechanical and Materials Engineering (MME) Department at FIU for supporting me through Graduate Assistantship and University Graduate School 
(UGS) at FIU for supporting me through Dissertation Evidence Acquisition (DEA) Fellowship. I also appreciate the funding from NSF and ASSIST for supporting my $\mathrm{PhD}$ program.

Last but not least, I feel blessed to have my friends and family for their unstoppable love and support. Thank you, Mom and Dad, for always believing in me no matter what choice I made, and I made it. 


\title{
ABSTRACT OF THE DISSERTATION
}

\section{SULFUR BASED ELECTRODE MATERIALS FOR SECONDARY BATTERIES}

by

Yong Hao

Florida International University, 2016

\author{
Miami, Florida \\ Professor Chunlei Wang, Co-Major Professor \\ Professor Arvind Agarwal, Co-Major Professor
}

Developing next generation secondary batteries has attracted much attention in recent years due to the increasing demand of high energy and high power density energy storage for portable electronics, electric vehicles and renewable sources of energy. This dissertation investigates sulfur based advanced electrode materials in Lithium/Sodium batteries. The electrochemical performances of the electrode materials have been enhanced due to their unique nano structures as well as the formation of novel composites.

First, a nitrogen-doped graphene nanosheets/sulfur (NGNSs/S) composite was synthesized via a facile chemical reaction deposition. In this composite, NGNSs were employed as a conductive host to entrap S/polysulfides in the cathode part. The NGNSs/S composite delivered an initial discharge capacity of $856.7 \mathrm{mAh} \mathrm{g}^{-1}$ and a reversible capacity of $319.3 \mathrm{mAh} \mathrm{g}^{-1}$ at $0.1 \mathrm{C}$ with good recoverable rate capability.

Second, NGNS/S nanocomposites, synthesized using chemical reactiondeposition method and low temperature heat treatment, were further studied as active cathode materials for room temperature Na-S batteries. Both high loading composite with 
$86 \%$ gamma-S8 and low loading composite with $25 \%$ gamma-S8 have been electrochemically evaluated and compared with both NGNS and S control electrodes. It was found that low loading NGNS/S composite exhibited better electrochemical performance with specific capacity of 110 and $48 \mathrm{mAh} \mathrm{g}^{-1}$ at $0.1 \mathrm{C}$ at the $1 \mathrm{st}$ and 300th cycle, respectively. The Coulombic efficiency of $100 \%$ was obtained at the 300 th cycle.

Third, high purity rock-salt (RS), zinc-blende (ZB) and wurtzite (WZ) MnS nanocrystals with different morphologies were successfully synthesized via a facile solvothermal method. RS-, ZB- and WZ-MnS electrodes showed the capacities of 232.5 $\mathrm{mAh} \mathrm{g}^{-1}, 287.9 \mathrm{mAh} \mathrm{g}^{-1}$ and $79.8 \mathrm{mAh} \mathrm{g}^{-1}$ at the 600th cycle, respectively. ZB-MnS displayed the best performance in terms of specific capacity and cyclability. Interestingly, MnS electrodes exhibited an unusual phenomenon of capacity increase upon cycling which was ascribed to the decreased cell resistance and enhanced interfacial charge storage.

In summary, this dissertation provides investigation of sulfur based electrode materials with sulfur/N-doped graphene composites and $\mathrm{MnS}$ nanocrystals. Their electrochemical performances have been evaluated and discussed. The understanding of their reaction mechanisms and electrochemical enhancement could make progress on development of secondary batteries. 


\section{TABLE OF CONTENTS}

CHAPTER

PAGE

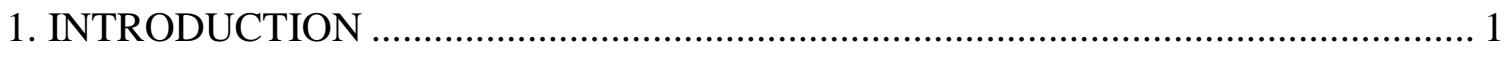

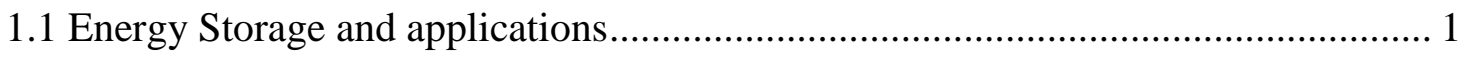

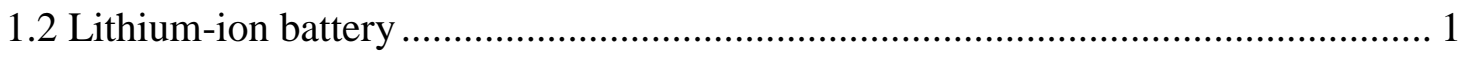

1.2.1 Historical Background and General working principle ................................. 2

1.2.2 Electrode Materials for Anodes ................................................................... 4

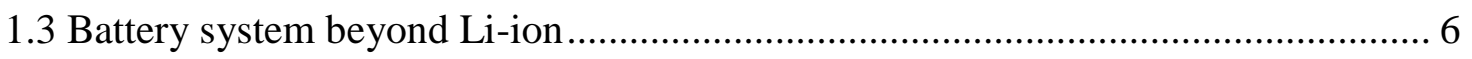

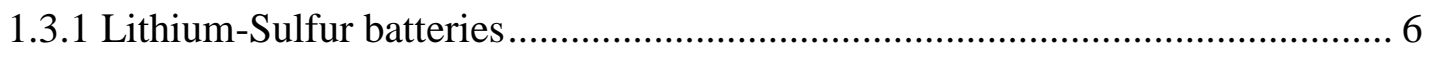

1.3.2 Room temperature Sodium-Sulfur Battery ................................................ 13

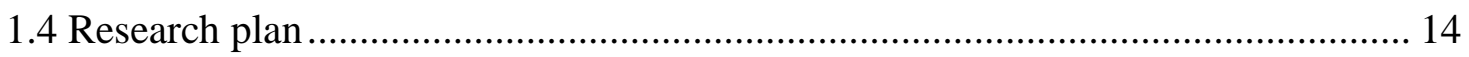

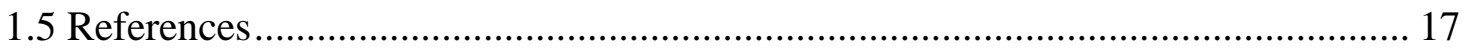

2. NITROGEN-DOPED GRAPHENE NANOSHEETS/SULFUR COMPOSITE AS

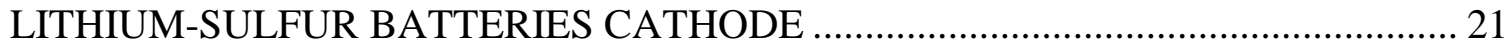

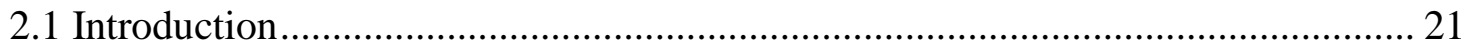

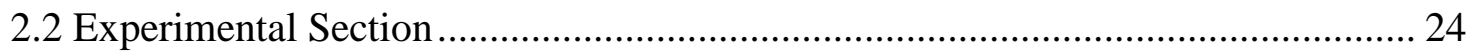

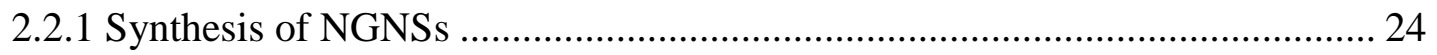

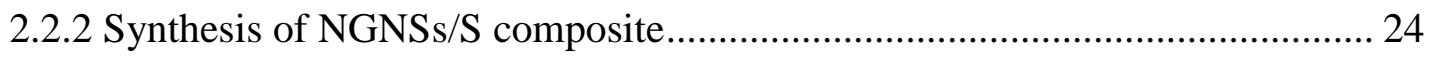

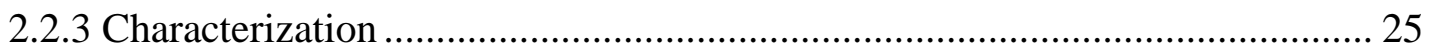

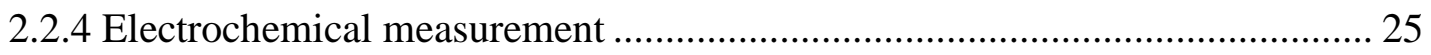

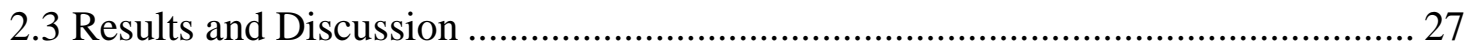

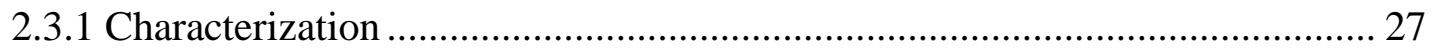

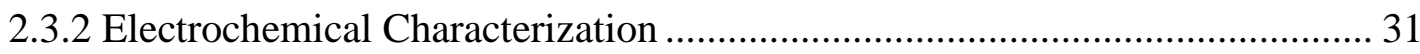

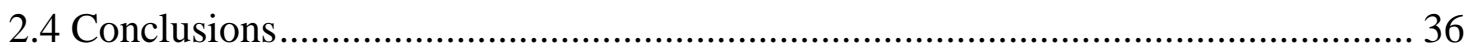

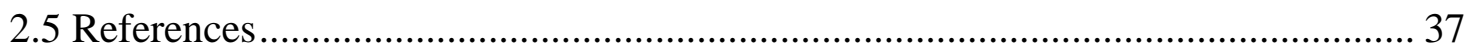

3. NITROGEN-DOPED GRAPHENE NANOSHEETS AND SULFUR COMPOSITE BASED CATHODE FOR ROOM-TEMPERATURE SODIUM-SULFUR BATTERY 42

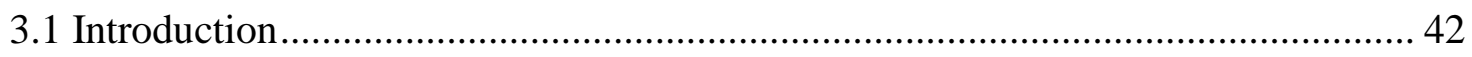

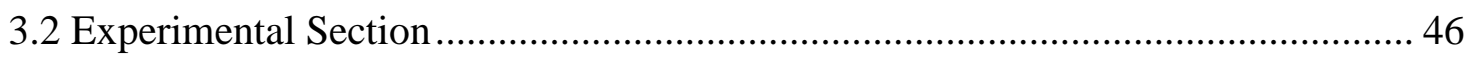

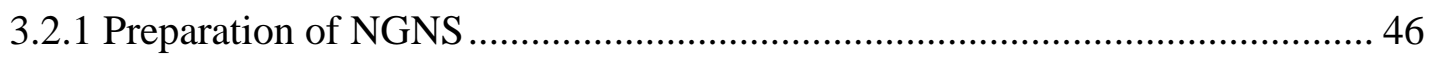

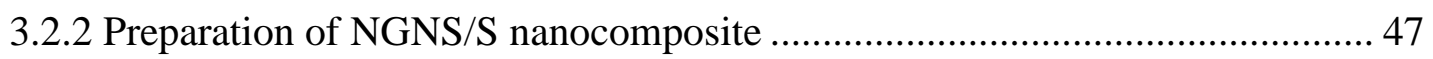




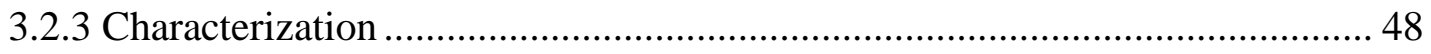

3.2.4 Electrochemical measurement ................................................................. 48

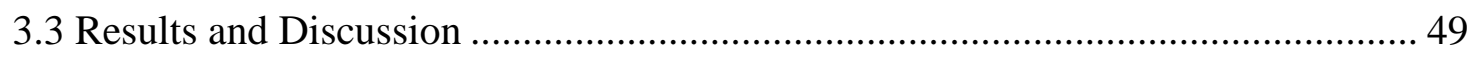

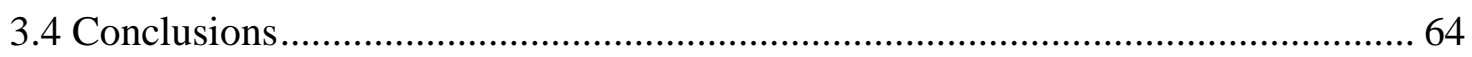

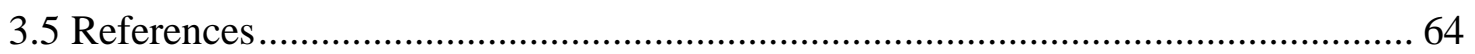

4. STUDIES ON INTRINSIC PHASE-DEPENDENT ELECTROCHEMICAL PROPERTIES OF MNS NANOCRYSTALS AS ANODES FOR LITHIUM-ION

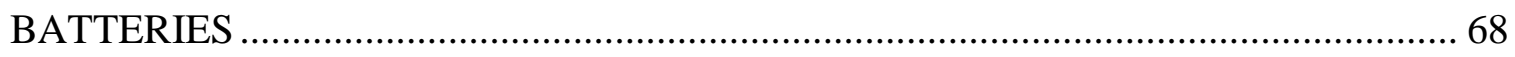

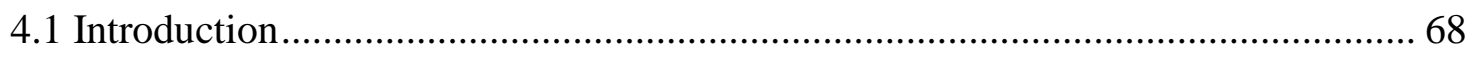

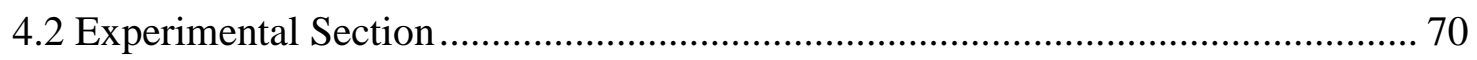

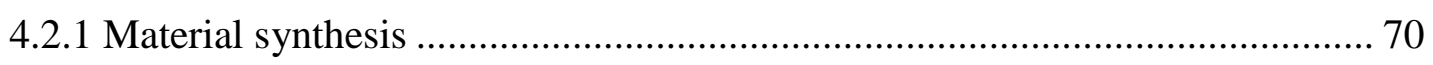

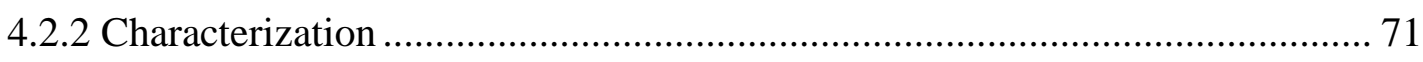

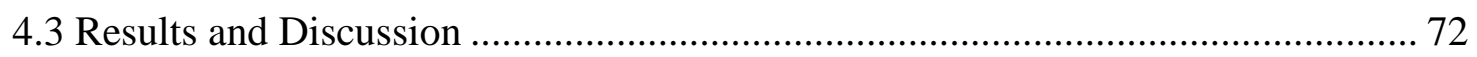

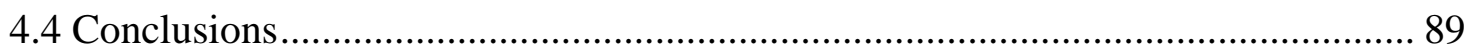

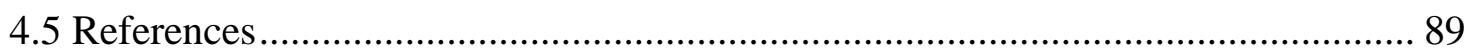

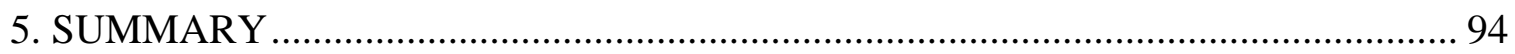

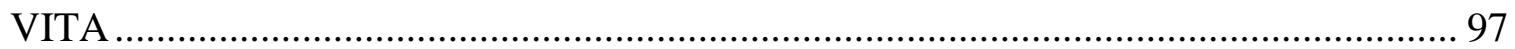




\section{LIST OF FIGURES}

FIGURE

PAGE

Figure 1.1 Working mechanism of Li-ion batteries............................................... 4

Figure 1.2 Schematic illustration of the reduction processes at the negative electrode

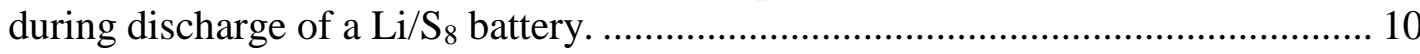

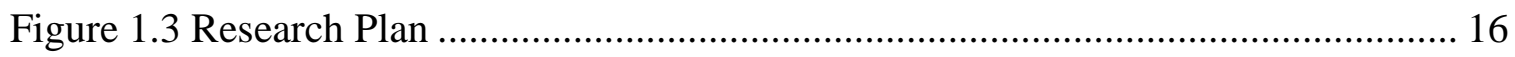

Figure 2.1 (a) Illustration of synthesis process of NGNSs/S composite; SEM images of (b) S particles, (c) NGNSs, (d) NGNSs/S composite (inset at low magnification) and (e) a typical TEM image of NGNSs.

Figure 2.2 XPS spectra of NGNSs: (a) wide scan and (b) N $1 \mathrm{~s}$. 28

Figure 2.3 (a) XRD patterns of Sulfur, NGNSs and NGNSs/S composite, (b) $\mathrm{N}_{2}$ adsorption-desorption isotherms of NGNSs and NGNSs/S composite, (c) FTIR spectra of NGNSs and (d) TGA analysis of NGNSs/S composite.

Figure 2.4 (a) Cyclic voltammograms of NGNSs/S composite as working electrode at a scan rate of $0.1 \mathrm{mV} \mathrm{s}^{-1}$ between 1.0 and $3.0 \mathrm{~V}\left(\mathrm{vs} . \mathrm{Li} / \mathrm{Li}^{+}\right),($b) the $1 \mathrm{st}, 2 \mathrm{nd}$ and 5 th cycles of discharge/charge profile of NGNSs/S composite at $0.1 \mathrm{C}$, (c) cycling performances of NGNSs/S composite, GNSs/S composite, NGNSs and S at 0.1C and (d) rate performance of NGNSs/S composite at various rates.

Figure 2.5 (a) Cyclic voltammograms of NGNSs as working electrode at a scan rate of $0.1 \mathrm{mV} \mathrm{s}^{-1}$ between 1.0 and $3.0 \mathrm{~V}\left(\mathrm{vs} . \mathrm{Li} / \mathrm{Li}^{+}\right)$and (b) Discharge/charge profile of NGNSs at $0.1 \mathrm{C}$ rate.

Figure 2.6 (a) Cyclic voltammograms of $\mathrm{S}$ particles as working electrode at a scan rate of $0.1 \mathrm{mV} \mathrm{s}^{-1}$ between 1.0 and $3.0 \mathrm{~V}\left(\mathrm{vs} . \mathrm{Li}^{-} / \mathrm{Li}^{+}\right.$) and (b) Discharge/charge profile of $\mathrm{S}$ particles at $0.1 \mathrm{C}$ rate.

Figure 2.7 Nyquist plots of the Li-S cell with NGNSs/S composite cathode before the 1 st, after the 1 st and 5 th cycles.

Figure 3.1 Schematic illustration of Nitrogen-doped Graphene nanosheets/Sulfur nanocomposites preparation and electrochemical testing as cathode material in room-temperature Sodium-Sulfur batteries and typical room-temperature sodiumsulfur batteries configuration with actual working electrode photo (middle). 46 
Figure 3.2 SEM images of (a) NGNSH, inset represents a typical layered structure of NGNSH and (c) NGNS/S-H25, (b) TEM image of NGNSH and (d) HRTEM image of NGNS/S-H25, respectively.

Figure 3.3 (a) SEM image of NGNS/S-H25 and corresponding EDS element mapping of (b) Carbon and (c) Sulfur.

Figure 3.4 (a) SEM image of NGNS/S-H86 and corresponding EDS element mapping of (b) Carbon and (c) Sulfur.

Figure 3.5 XRD patterns of GNS, NGNSH, NGNS/S-H25 nanocomposites, NGNS/SH86 nanocomposites and Sulfur, respectively.

Figure 3.6 $\mathrm{N}_{2}$ adsorption-desorption isotherms of (a) NGNS/S-H86 and Sulfur, and (b) NGNSH and NGNS/S-H25, respectively. TGA analysis of (c) NGNS/S-H86 and NGNS/s-90, and (d) NGNSH, NGNS/S-H25, and NGNS/S-30, respectively. 54

Figure 3.7 Electrochemical performance of NGNS/S-H25 and NGNS/S-H86 electrodes. CVs of (a) NGNS/S-H25 and (d) NGNS/S-H86 at a scan rate of $0.1 \mathrm{mV} \mathrm{s}^{-1}$ between 1.0 and $3.0 \mathrm{~V}$ vs. $\mathrm{Na} / \mathrm{Na}^{+}$; Galvanostatic discharge/charge profiles of (b) NGNS/S-H25 and (e)NGNS/S-H86 at 0.05C; Rate performances of (c) NGNS/S$\mathrm{H} 25$ at various $\mathrm{C}$ rates and (f) $\mathrm{NGNS} / \mathrm{S}-\mathrm{H} 86$ at $0.05 \mathrm{C}$ and $0.1 \mathrm{C}$.

Figure 3.8 Electrochemical performance of NGNSH electrodes in Na-S cells: (a) cyclic voltammograms at a scan rate of $0.1 \mathrm{mV} \mathrm{s}^{-1}$ between 1.0 and $3.0 \mathrm{~V}$, (b) discharge/charge profile at a current rate of $0.05 \mathrm{C}$ and (c) rate capability at various current rates.

Figure 3.9 Electrochemical performance of $\mathrm{S}$ electrodes in Na-S cells: (a) cyclic voltammograms at a scan rate of $0.1 \mathrm{mV} \mathrm{s}^{-1}$ between 1.0 and $3.0 \mathrm{~V}$ and (b) discharge/charge profile at a current rate of $0.05 \mathrm{C}$. 58

Figure 3.10 Cycling performances and Coulombic efficiencies of NGNSH, S, NGNS/S$\mathrm{H} 86$ and NGNS/S-H25 electrodes at $0.1 \mathrm{C}$, respectively.

Figure 3.11 (a) Nyquist plots of NGNS/S-H25 working electrode before 1st cycle and after 300 cycles. (b) Nyquist plots of NGNS/S-H86 working electrode before 1 st cycle and after 300 cycles.

Figure 3.12 SEM image of the surface of NGNS/S-H25 nanocomposite working electrode after 300 cycles.

Figure 3.13 TEM image of NGNS/S-H25 nanocomposite working electrode after 300 cycles. 
Figure 4.1 XRD patterns and corresponding JCPDS files of (a, b) RS-MnS, (c, d) ZB$\mathrm{MnS}$ and (e, f) WZ-MnS. The insets illustrate the crystalline structures of RS-, ZB- and WZ-MnS, respectively.

Figure 4.2 TEM images in low magnification of as-synthesized (a) RS-MnS, (c) ZB$\mathrm{MnS}$ and (e) WZ-MnS NCs before cycling, and disassembled (b) RS-MnS, (d) ZB-MnS and (f) WZ-MnS electrodes after cycling, respectively. (e inset) The schematic image illustrates a 3-branch multipod-like morphology of WZ-MnS. .... 74

Figure 4.3 TEM images, HRTEM images and SAED patterns of as-synthesized (a,b,c) RS-MnS, (d,e,f) ZB-MnS and (g,h,i) WZ-MnS, respectively. 76

Figure 4.4 (a-c) Cyclic voltammetry at a scanning rate of $0.2 \mathrm{mV} \mathrm{s}^{-1}$ and (d-f) galvanostatic discharge/charge curves at a current density of $0.1 \mathrm{~A} \mathrm{~g}^{-1}$ of RS-, ZBand $\mathrm{WZ}-\mathrm{MnS}$ in the voltage range of $0.01-3 \mathrm{~V}$ vs. $\mathrm{Li} / \mathrm{Li}^{+}$, respectively.

Figure 4.5 Rate capability of (a) RS-MnS, (b) ZB-MnS and (c) WZ-MnS at current densities of $0.1,0.2,0.5,1$ and $2 \mathrm{~A} \mathrm{~g} \mathrm{~g}^{-1}$, respectively.

Figure 4.6 (a) Cycling performance of RS-, ZB- and WZ-MnS electrodes and corresponding Coulombic efficiencies of RS- and ZB-MnS at a current density of $0.1 \mathrm{~A} \mathrm{~g}^{-1}$, respectively; (b) Nyquist plots of fresh cell and cell after cyclability test with ZB-MnS as anode in LIBs. Figure insets give equivalent circuit model for the fitting of the Nyquist plots and enlarged semicircles in high frequency range (below).

Figure 4.7 Nyquist plots of (a) RS-MnS and (b) WZ-MnS as anode materials in LIBs before and after cycling. Figure insets give equivalent circuit model for the fitting of the Nyquist plots and enlarged semicircles in high frequency range (below)...... 82

Figure 4.8 TEM and HRTEM images of disassembled $(\mathrm{a}, \mathrm{b}) \mathrm{RS}-\mathrm{MnS}$, (c,d) ZB-MnS and (e,f) WZ-MnS electrode materials after cycling (charged to $3 \mathrm{~V}$ ). 84

Figure 4.9 Cyclic voltammetry of (a) RS-, (b) ZB- and (c) WZ-MnS after cycling at the

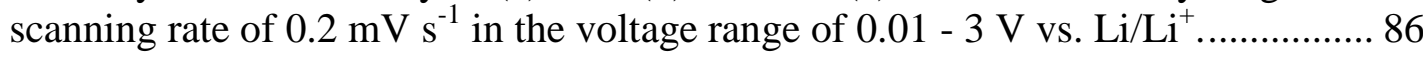

Figure 4.10 XRD patterns of disassembled (a) RS-MnS, (b) ZB-MnS and (c) WZ-MnS electrodes after cycling, charged to $3 \mathrm{~V}$. 


\section{INTRODUCTION}

\subsection{Energy Storage and applications}

Energy storage is becoming far more important in modern society today than any time in the past. Environmental pollution and global warming caused by burning fossil fuel and intense fossil fuel supplies around the globe have aroused tremendous interest in developing alternate, sustainable, clean energy technologies. On the one hand, renewable energy, such as solar, wave and wind, is attractive developable energy source, but hardly to control and intermittent, which needs to associate with reliable electrical energy storage (EES) system to deliver stable and consistent power. On the other hand, transformation from traditional vehicles powered by fossil fuels to electric vehicles is vital to reduce the $\mathrm{CO}_{2}$ emission and perhaps, the ultimate choice of vehicle technology. To date, rechargeable batteries are one of the most promising EES systems to cater the needs of new markets with their advantages such as high energy and power density.

\subsection{Lithium-ion battery}

The most challenging issue to design the rechargeable battery systems is high energy density and high power density requirement for energy applications. As the development of rechargeable batteries, it went through with lead acid batteries, Ni-Cd batteries and Ni-MH batteries. Compared to them, lithium-ion batteries (LIBs) show many advantages such as high working voltage ( 3.6 V), high energy density (125 Wh $\mathrm{kg}^{-1}$ ), long cycling life (more than 1000 cycles), and eco-friendliness [1-4]. LIBs have been widely used as a convenient power source for various electronic devices, such as digital watches, digital cameras and media players, etc. Besides, LIBs are also considered as one of the most promising energy storage technologies for application of low fuel 
consumption hybrid electrical vehicles (HEVs), plug-in hybrid electric vehicles (PHEVs) and zero fuel consumption pure electrical vehicles (EVs). In particular, the development and commercialization of HEVs and EVs have been regarded as the major driving force for the development of LIBs [5-6]. They are also being intensively studied for loadleveling stationary EES applications. The component materials used in LIB are the crucial factor to the success of Li-ion technology in the latter applications. However, the performance of LIB is not sufficient to meet growing demands in energy density, safety, durability, and cost. These factors absolutely depend on the electrode materials. To meet these requirements, substantial efforts have been devoted to developing new active materials and to designing new electrode structures.

\subsubsection{Historical Background and General working principle}

In 1976, M Stanley Whittingham et al. published the first report on lithium batteries. This work proposed one kind of lithium batteries which consists titanium (II) sulfide as cathode and lithium metal as anode [7]. As far as we know, lithium is the lightest metal that delivers the high theoretical capacity of $3860 \mathrm{mAh} \mathrm{g}^{-1}$. It also has the lowest electrochemical reduction potential of $-3.045 \mathrm{~V}$. However, the formation of lithium dendrite on the surface of lithium metal electrode during charge/discharge cycles results in safety issues and poor cycle life [8]. In 1977, Samar Basu et al. demonstrated the electrochemical intercalation of lithium in graphite [9]. Based on these work, Bell laboratories proposed a graphite-based anode [10]. In 1980, John Goodenough et al. proposed lithium batteries with lithium cobalt oxide $\left(\mathrm{LiCoO}_{2}\right)$ [11]. This work paved the way for using $\mathrm{LiCoO}_{2}$ as cathode material instead of lithium, which made lithium ion batteries possible. In 1983, Rachid Yazami et al. demonstrated that using solid electrolyte 
lithium undergoes reversible intercalation with graphite, which would allow these batteries to be rechargeable [12]. In 1985, Akira Yoshino et al. developed a LIB with carbon as anode and $\mathrm{LiCoO}_{2}$ as cathode. In 1990, Sony Company commercialized nonaqueous LIBs, introducing a "rocking chair" concept, which demonstrated the intercalation phenomenon that $\mathrm{Li}^{+}$insertion/deinsertion into active materials occurred during cycling [13]. In 1996, John Goodenough et al. proposed lithium iron phosphate and other phospo-olivines as the cathode materials. Since then, new material chemistry, nanotechnology, polymer electrolytes with improved stability and higher energy density have been the crucial concerns in LIB's evolution. Currently, the batteries market is a competitive pool with couples of developers. They mainly focus on LIBs for portable electronics, EVs, and HEVs.

For typical LIBs, they consist of cathode and anode, porous polypropylene membrane separator acting as electrical insulation and electrolyte of $\mathrm{LiPF}_{6}$ dissolved in a mixture of organic solvent. For a commercial $\mathrm{LIB}, \mathrm{LiCoO}_{2}$ and graphite are commonly used as cathode and anode materials, respectively. As it is depicted in Figure 1.1, the electrochemical potential difference between the anode and cathode drives $\mathrm{Li}^{+}$to move from $\mathrm{LiCoO}_{2}$ and simultaneously intercalate into graphite anode during charge process. Oppositely while discharging, $\mathrm{Li}^{+}$is reversing the direction of movement, leaving the anode, and intercalating into 3D lattice crystal structure of $\mathrm{LiCoO}_{2}$ cathode. The whole electrochemical insertion/extraction process is a solid-state redox reaction involving electrochemical charge-transfer and proceeding along with $\mathrm{Li}^{+}$insertion/extraction into/from the structure of cathode or anode. During the whole charge/discharge process, only $\mathrm{Li}^{+}$repeatedly transfers between the cathode and the anode. 


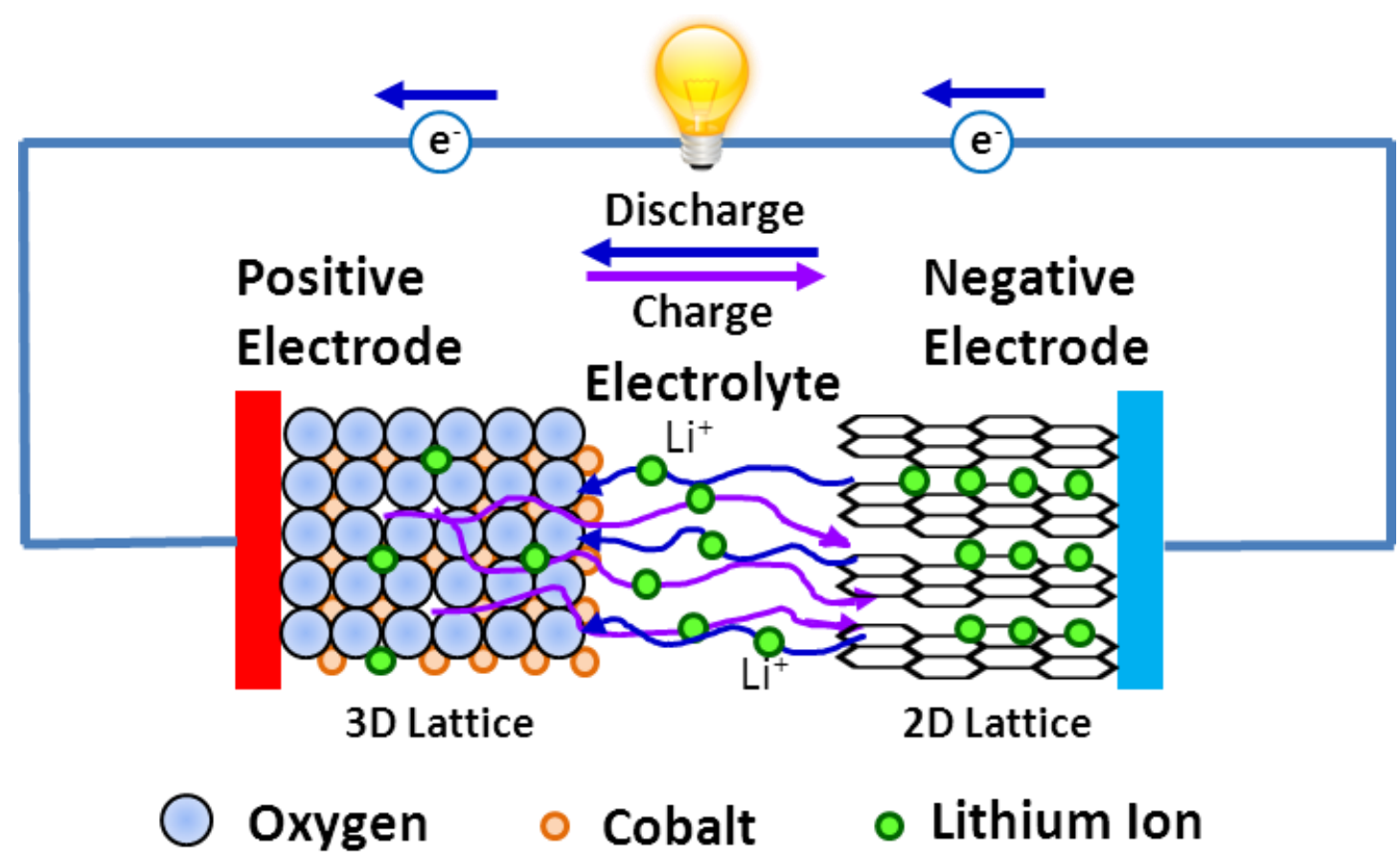

Figure 1.1 Working mechanism of Li-ion batteries.

\subsubsection{Electrode Materials for Anodes}

Graphite is the most widely used anode material in commercialized LIBs. It delivers theoretical capacity of $372 \mathrm{mAh} \mathrm{g}^{-1}$ when $\mathrm{Li}^{+}$intercalation proceeds and reaction product compound $\mathrm{LiC}_{6}$ forms. In addition to graphite and various natural or synthesized carbon-based anode materials, nano sized carbon materials such as carbon nanotubes and graphene have greater potential to make contributions to increase the specific capacities for LIBs. Besides carbon-based anodes, there are many other anode materials, such as Sibased, Sn-based, metal oxides and metal sulfides with relatively high theoretical capacities. Although challenges still exist to improve their electrochemical performance, some of these anode materials have been commercialized and used in LIBs with a small 
scale. In general, anode materials can be categorized into three groups according to their electrochemical reaction mechanism with $\mathrm{Li}^{+}$during cycling:

1) Intercalation/de-intercalation anodes. It includes compounds such as $\mathrm{TiS}_{2}$ and carbon based anodes such as graphite, CNTs, hard carbon, etc. [14]. In this type of anodes, lithium is stored between the graphitic layers. The reaction mechanism is as shown below:

$$
\mathrm{Li}^{+}+\mathrm{e}^{-}+\mathrm{MX} \leftrightarrow \mathrm{LiMX}
$$

2) Alloying/de-alloying anodes. The examples include $\mathrm{Si}, \mathrm{Sn}$, etc. [15]. During the $\mathrm{Li}^{+}$ reaction process, different amounts of $\mathrm{Li}^{+}$could react with $\mathrm{M}$ and form various $\mathrm{Li}_{\mathrm{x}} \mathrm{M}$ alloys. The reaction equation is as below:

$$
\mathrm{xLi}^{+}+\mathrm{xe}^{-}+\mathrm{M} \leftrightarrow \mathrm{Li}_{\mathrm{x}} \mathrm{M}
$$

3) Conversion reaction anodes. These kinds of anodes include transition metal oxides $\left(\mathrm{M}_{\mathrm{x}} \mathrm{O}_{\mathrm{y}}\right)$, such as $\mathrm{Fe}_{2} \mathrm{O}_{3}, \mathrm{CuO}, \mathrm{NiO}, \mathrm{Co}_{3} \mathrm{O}_{4}$, etc. [16] and transition metal sulfide $\left(\mathrm{M}_{\mathrm{x}} \mathrm{S}_{\mathrm{y}}\right)$. The reaction mechanism is different from classical lithium intercalation/de-intercalation in graphite or alloying/de-alloying reactions of metallic or semi metallic anodes with lithium. The reaction mechanism is as following:

$$
2 \mathrm{M}_{\mathrm{x}} \mathrm{X}_{\mathrm{y}}+2 \mathrm{yLi}^{+}+2 \mathrm{ye}^{-} \leftrightarrow 2 \mathrm{xM}+\mathrm{yLi}_{2} \mathrm{X}
$$

Transition metal sulfides (MSs) have been considered as the most promising candidates for LIBs in the past few decades, due to their advanced properties such as relatively high electrical conductivity, mechanical and thermal stability as well as the rich redox chemistry that contributes to their high specific capacity which are several times higher than those of carbon/graphite-based materials. However, the sluggish diffusivity of $\mathrm{Li}^{+}$into the MSs limits the rate of lithium insertion/extraction, and the low surface area 
of the bulk electrodes restrains their capacitive contribution. Therefore, moving from conventional bulk to nanostructures provides several advantages for LIBs. Tremendous research effort has been made in the nanostructure of electrode materials to improve their performance for LIBs. First, increasing in electrode/electrolyte contact area per unit mass permits a higher rate for $\mathrm{Li}^{+}$cross the interface for LIBs. Second, shorter path lengths for ionic and electronic transport result in a faster diffusion rate. Third, better accommodation of the mechanical strain and structural distortion generated from ion insertion/extraction and other reactions. The strong correlation between the nanostructures and their electrochemical properties has prompted a surge in research to perform the controlled synthesis of innovative electrode materials with tailored nanostructures.

\subsection{Battery system beyond Li-ion}

The capacities of these Li-ion intercalation materials are limited by their crystallographic structure and the present technology has virtually approached to the theoretical values. While acceptable for the applications in mobile consumer electronics, the relatively high cost and limited earth abundance of the transitional metals used in the Li-ion cathode materials become grand challenges for the transportation and stationary applications. In order to overcome the challenges of the performance and cost, new materials and concepts are necessary for the development and commercialization of the next generation rechargeable batteries.

\subsubsection{Lithium-Sulfur batteries}

With the increasing energy demands for portable electronic devices and transportation sector, the continued search for high capacity batteries drives the scientific 
and technological innovations in rechargeable lithium batteries. Among these secondary lithium batteries, Li-ion batteries are the state-of-the-art technology and are still one of the best energy storage solutions for a wide array of applications. However, since the first commercial Li-ion cell was released by Sony in 1991, the progress in the rechargeable battery was not remarkably striking afterward [17]. The major barrier to the development of high energy density battery technology lies in the limitation of the electrode materials, which determine the working voltage, capacity, and energy density of a battery. Therefore, changing the battery chemistry from current lithium intercalation reactions in transition metal oxides or metal phosphates or graphite to other promising reactions is an inevitable means to boost the performance of Li-ion batteries.

As one of the most abundant elements on earth, sulfur is a promising cathode candidate with the highest theoretical capacity of $1675 \mathrm{mAh} \mathrm{g}^{-1}$ among the solid elements. Switching from the traditional insertion cathodes $\left(\mathrm{LiCoO}_{2}, \mathrm{LiMn}_{2} \mathrm{O}_{4}\right.$, and $\mathrm{LiFePO}_{4}$ ) [18] to sulfur has many benefits besides the high capacity, such as the low operating voltage $\left(2.15 \mathrm{~V}\right.$ vs $\left.\mathrm{Li} / \mathrm{Li}^{+}\right)$improving the safety, the low-cost (\$160 USD per ton, 2012) [19], and environmentally friendly. Most of all, the practical energy density of a packaged lithium-sulfur (Li-S) cells could be as high as 400 to $600 \mathrm{Wh} \mathrm{kg}^{-1}$, which is two or three times higher than that of current Li-ion batteries. The low-cost and high energy density are also appealing for stationary storage for renewable energies such as solar and wind if long cycle life and high system efficiency can be achieved.

Nowadays, Li-S batteries are becoming attractive and promising next-generation Li batteries when compared to other batteries. Li-S batteries have an overwhelming advantage in energy density, with a theoretical value of about $2600 \mathrm{Wh} \mathrm{kg}^{-1}$ calculated on 
the basis of the Li anode and the $\mathrm{S}$ cathode, and is up to five times greater than that of commercial Li-ion batteries ( $387 \mathrm{Wh} \mathrm{kg}^{-1}$ for $\mathrm{LiCoO}_{2} / \mathrm{C}$ battery). Utilizing elemental sulfur as a cathode electrode material was first introduced by Herbet and Ulam in 1962 [20] and later developed by Argonne National Laboratory in 1967 [21]. However, research stopped in the 1990s with the triumph of Li-ion batteries [22]. After 2000, the rapid development of emerging applications, including military power supplies, civil transportation, and stationary storage, placed higher demands on the energy density of the batteries [23], which resulted in the resurgent of Li-S batteries. Since 2009, Li-S batteries have gained ever-increasing attention as promising candidates for the next-generation energy storage applications after Nazar et al. reported a Li-S battery with improved cycling performance [24-26]. Intensive efforts have been exerted in striving for significant breakthroughs in the core technology of Li-S batteries.

A typical Li-S battery is composed of a lithium anode, a sulfur cathode, and an electrolyte in between. At the open circuit state, the Li-S battery holds a maximum voltage. The value of this voltage is in direct proportion to the difference between the electrochemical potentials of the Li anode and the S cathode. Sulfur can exist in the form of polyatomic molecules with different structures, and octasulfur (cyclo-S8) is the most stable allotrope at room temperature. The electrochemical reactions occurring in the Li-S battery involve lithium, lithium ions, sulfur, and polysulfide ions. The redox reactions can be written as follows [Eqs. (1)-(3)]. A discharge/charge current can be applied to the cell resulting in reduction/oxidation at the positive electrode and the oxidation/reduction at the negative electrode.

Positive electrode: $\quad \mathrm{S}_{8}+16 \mathrm{Li}^{+}+16 \mathrm{e}^{-} \rightarrow 8 \mathrm{Li}_{2} \mathrm{~S}$ 
Negative electrode: $\quad 16 \mathrm{Li} \rightarrow 16 \mathrm{Li}^{+}+16 \mathrm{e}^{-}$

Overall reaction: $\quad \mathrm{S}_{8}+16 \mathrm{Li} \leftrightarrow 8 \mathrm{Li}_{2} \mathrm{~S}$

Although the reaction appears simple above, the actual reaction occurring at the cathode during discharge is far more complex than the intercalation reactions at transition metal oxide cathodes, proceeding through a series of reactions as described below [Eqs. (4)-(8)] [25, 26].

$$
\begin{aligned}
& \mathrm{S}_{8}+2 \mathrm{e}^{-} \rightarrow \mathrm{S}_{8}{ }^{2-} \\
& 3 \mathrm{~S}_{8}{ }^{2-}+2 \mathrm{e}^{-} \rightarrow 4 \mathrm{~S}_{6}{ }^{2-} \\
& 2 \mathrm{~S}_{6}{ }^{2-}+2 \mathrm{e}^{-} \rightarrow 3 \mathrm{~S}_{4}{ }^{2-} \\
& \mathrm{S}_{4}{ }^{2-}+4 \mathrm{Li}^{+}+2 \mathrm{e}^{-} \rightarrow 2 \mathrm{Li}_{2} \mathrm{~S}_{2} \\
& \mathrm{Li}_{2} \mathrm{~S}_{2}+2 \mathrm{Li}^{+}+2 \mathrm{e}^{-} \rightarrow 2 \mathrm{Li}_{2} \mathrm{~S}
\end{aligned}
$$

The first three steps [Eqs. (4)-(6)] correspond to the high plateau (2.15-2.4 V) in the voltage profile, and polysulfide species produced in these steps are soluble in the electrolyte. In the last two steps [Eqs. (7)-(8)], insoluble $\mathrm{Li}_{2} \mathrm{~S}_{2}$ and $\mathrm{Li}_{2} \mathrm{~S}$ are formed and they precipitate out at the cathode as shown in Figure 1.2. The corresponding voltage is lower with the long plateau at $2.1 \mathrm{~V}$. The first four steps have fast or moderate kinetics, while the last step of converting $\mathrm{Li}_{2} \mathrm{~S}_{2}$ to $\mathrm{Li}_{2} \mathrm{~S}$ is difficult and is impeded by slow solidstate diffusion. Consequently, the voltage drops rapidly once $\mathrm{Li}_{2} \mathrm{~S}$ covers the whole electrode framework, resulting in the termination of discharge. 


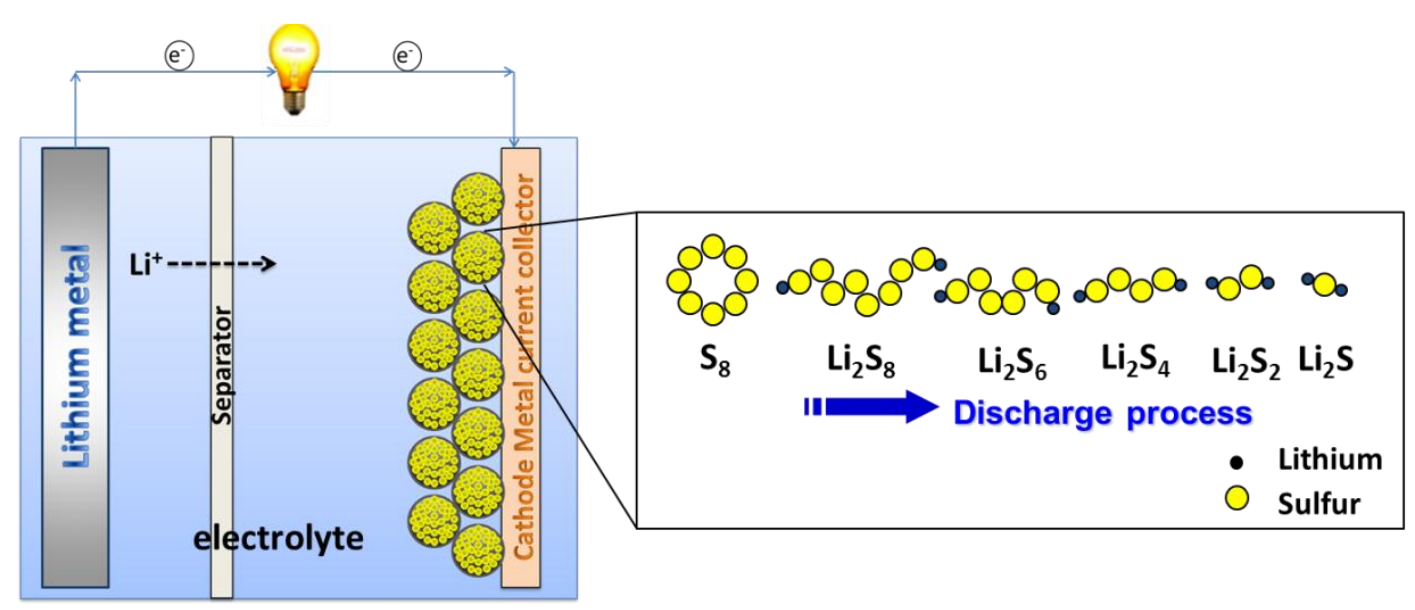

Figure 1.2 Schematic illustration of the reduction processes at the negative electrode during discharge of a $\mathrm{Li} / \mathrm{S}_{8}$ battery.

Although Li-S batteries possess many advantages, low active material utilization, capacity degradation, poor coulombic efficiency, poor cycle life, and electrode volume expansion are still the challenges remaining with the Li-S cells. These challenges are described in details in the following sections:

\section{- Insulating active materials}

Sulfur is an insulator with a very high electrical resistivity of $2 \times 10^{23} \mu \Omega \mathrm{cm}$ at 20 ${ }^{\circ} \mathrm{C}$. $\mathrm{Li}_{2} \mathrm{~S}$ as the end discharge product is highly insulating as well. The high resistance causes Li-S cells to output low specific capacities due to the low active utilization. Conductive agents need to be appropriately added, and well-dispersed active material is desired to ensure smooth electron transport between the interfaces of conductor/active material.

\section{- Polysulfide dissolution - Shuttle effect}

Polysulfides are soluble in the electrolyte. These soluble species can be reduced to $\mathrm{Li}_{2} \mathrm{~S}$ at the lithium anode surface, passivating the anode and leading to both material loss and an increase in impedance. Moreover, the dissolution and precipitation process alters 
the morphology of the cathode in each cycle, which induces strain inside the electrode and degrades the cycle life [27]. The dissolution of polysulfides also results in the so-called shuttle effect, where long chain polysulfides diffuse to the surface of the lithium anode and are reduced to short chain polysulfides. The short chain polysulfides can then move back to the cathode and be oxidized to long chain polysulfides. This parasitic process takes place continuously, creating an internal "shuttle" phenomenon. It decreases the active mass utilization in the discharge process and markedly reduces the coulombic efficiency.

\section{- $\quad$ Volume expansion}

On account of the density difference between sulfur ( $\alpha$ phase, $2.07 \mathrm{~g} \mathrm{~cm}^{-3}$ ) and $\mathrm{Li}_{2} \mathrm{~S}\left(1.66 \mathrm{~g} \mathrm{~cm}^{-3}\right)$, the volume change during cycling can be another problem for Li-S cells [28-29]. Severe volume expansion of the electrodes would lead to the failure of batteries due to huge crack formation. Flexible carbon materials can be used to buffer the volume change of the cathode. Utilizing partially-filled sulfur composites is also applicable to avoid the fracture of sulfur containers.

In the past five years, tremendous progress has been made in understanding and improving the performance of sulfur cathodes. Employing sulfur-carbon composites is the most effective way to improve the cathode performance. In 2009, Nazar et al. firstly reported the introduction of sulfur into a mesoporous carbon (CMK-3) to improve the cycling performance of the sulfur cathode. The major breakthrough relied on the optimal use of the ordered mesoporous carbon synthesized by using the ordered mesoporous template. Since then, many works have been reported on porous carbon systems for hosting sulfur, such as mesoporous carbon/sulfur [30-31], microporous carbon/sulfur [32- 
33], hierarchical porous carbon/sulfur [34], and hollow carbon/sulfur [35]. Guo et al. have developed an advanced hierarchical structured hollow porous carbon, which integrates micropores, mesopores and macroporous hollow cavity [36]. This sulfur cathode demonstrates a long lifespan of 600 discharge-charge cycles. Graphene, with its excellent conductivity, high surface area and good mechanical property, has also been widely used. Early work on graphene (oxide)-sulfur composite materials produced by the mixing and heating method was reported by Wang et al [37]. However, the results suggested that this approach is not very effective in trapping polysulfides since the composite does not have a closed structure and polysulfides diffused out easily. Since then, successive optimization of the synthesis methods resulted in diverse configurations of the graphene-sulfur composites: graphene-wrapped sulfur particles [38-41], sandwich type composites [4245], and sulfur coated graphene sheets [46-47]. Cui et al. have demonstrated a graphene oxide wrapped sulfur composite with stable specific capacities of around $600 \mathrm{mAh} \mathrm{g}{ }^{-1}$. Moreover, graphene can also be functionalized to enhance its affinity for sulfur and polysulfide. Ji et al. [48] have reported both epoxy and hydroxyl groups on graphene oxide can enhance the binding of sulfur and polysulfide with cycling of 50 cycles at $0.1 \mathrm{C}$. Carbon nanotubes $(\mathrm{CNT})$ and Carbon nanofibers $(\mathrm{CNF})$ are also good substrates to be impregnated with sulfur [49-51]. Zheng et al. reported a CNF network synthesized through a templating method using AAO membrane, and a specific capacity of about 730 $\mathrm{mAh} \mathrm{g}^{-1}$ was observed at $0.2 \mathrm{C}$ after 150 cycles [52]. Besides carbons, conductive polymers are also popular in using for the modification of sulfur cathodes. Conducting polymers such as polypyrrole (PPy) [53-54], polyaniline (PANI) [55-56], polythiophene (PT) [57-58], and poly (3,4-ethylenedioxythiophene) (PEDOT) [59], have been used for 
sulfur coating. Many core-shell structure sulfur composite have been prepared in which the polymer shell can facilitate electron transport, improving the active material utilization. Not only carbons and polymers but also other additive materials could be applied to the composite synthesis with sulfur as well. Various nano-sized metal oxides, such as manganese nickel oxide [60-61], alumina [62], silica [63-64], and titanium oxide [65] have been used. These nano additives function as adsorbing agents to improve cycle stability and reduce polysulfide shuttle. Seh et al. [65] designed a $\mathrm{TiO}_{2}$-sulfur yolk-shell composite that exhibits prolonged cyclability over 1000 cycles with $725 \mathrm{mAh} \mathrm{g}^{-1}$ at $1 \mathrm{C}$, showing that metal oxides might replace a portion of carbon to trap polysulfides. Recently, Li Sulfide $\left(\mathrm{Li}_{2} \mathrm{~S}\right)$, the final lithiation product of sulfur, has received increasing attention as a promising candidate for $\mathrm{Li}-\mathrm{S}$ batteries [66]. Cai et al have reported a combination of micrometer-sized $\mathrm{Li}_{2} \mathrm{~S}$ particles with carbon black nanoparticles by high energy ball milling. A high specific capacity of $1144 \mathrm{mAh} \mathrm{g}^{-1}$ is obtained at a high $\mathrm{Li}_{2} \mathrm{~S}$ content of 67.5 wt. \%.

\subsubsection{Room temperature Sodium-Sulfur Battery}

High-temperature sodium-sulfur battery systems operated at $>300{ }^{\circ} \mathrm{C}$ with molten

electrodes have been used to support stationary energy-storage systems for several decades. However, the high operating temperature of the molten $\mathrm{Na}-\mathrm{S}$ batteries poses serious safety, reliability, and maintenance issues, which limit their widespread application. The development of ambient- or room-temperature $\mathrm{Na}-\mathrm{S}$ (RT Na-S) batteries has been reported since 2006 [24]. However, operation of a Na-S battery at ambient temperatures faces many more challenges than for Li-S batteries, especially in terms of the electrochemical utilization of the sulfur active material and capacity retention during 
cycling. To date, RT Na-S battery has been hardly studied but the challenges will be quite similar to Li-S batteries. However, due to higher atomic mass of sodium, the theoretical energy density of a $\mathrm{Na} / \mathrm{S}$ cell is roughly smaller compared to the analogous $\mathrm{Li} / \mathrm{S}$ cell. Larger volume change of the sulfur electrode during cycling ( $170 \%$ for $\mathrm{Na}_{2} \mathrm{~S}$ formation compared to $80 \%$ for $\mathrm{Li}_{2} \mathrm{~S}$ formation) will pose additional problems. Compared to a $\mathrm{Li} / \mathrm{S}$ cell, substituting lithium by the more abundant sodium appears attractive, and the same strategies for improving $\mathrm{Li} / \mathrm{S}$ batteries (sulfur utilization, cycle life) might apply for $\mathrm{Na} / \mathrm{S}$ batteries. However, theoretical energy densities are lower and the larger volume expansion might lead to severe problems. Compared to a high-temperature $\mathrm{Na} / \mathrm{S}_{8}$ cell, decreasing the operating temperature would be attractive because safety and corrosion issues are reduced. In addition, if full reduction of sulfur to $\mathrm{Na}_{2} \mathrm{~S}$ can be accomplished, an increase in system's energy density might be possible.

\subsection{Research plan}

Based on literature studies and research carried on so far, it can be concluded that an ideal structure for sulfur electrode should have the following characteristics: (1) a welldesigned structure for efficient polysulfides confinement; (2) enhanced contact for sulfurelectrolyte; (3) sufficient space to accommodate sulfur volumetric expansion and small characteristic dimension of the sulfur electrode to avoid pulverization; and (4) a short transport pathway for both electrons and Li ions to achieve high capacity at a high power rate. To meet all these requirements mentioned above, it is very challenging to fabricate sulfur electrodes with high specific capacity and long cycle life.

The ultimate goal of this research is to confine sulfur in the electrode and further enhance the electrochemical performance of sulfur electrode for Li-S and Na-S batteries, 
aiming at batteries with high capacity, good rate capability and improved cycling lifetime. To achieve this goal, sulfur should be confined in the electrode efficiently. On the one hand, to achieve the physical confinement, sulfur loading will be carried out in designed matrix. Meanwhile, sufficient empty space needs to be present to allow for volume expansion. On the other hand, to achieve the chemical confinement, sulfur should have interconnections with the matrix. It has been found that surface functionalization can improve the binding between sulfur/polysulfides and its matrix. Therefore, functional groups which bind favorably with polysulfide anions need to be introduced to the matrix surface. Based on the requirement of sulfur electrode with high performance, we may have the hypothesis of research plan that if nitrogen defects are introduced to the graphene layer, those defects and functional groups will enhance binding formation between sulfur/polysulfides and the graphene layer, beneficially achieved high performance of Li-S and Na-S batteries.

This dissertation work progresses towards its goal by pursuing the following objectives (Figure 1.3):

$\mathrm{N}$-doped graphene/sulfur as composites: In addition to the physical confinement and physical adsorption, chemical adsorption has been found to effectively entrap sulfur species. It is reported that nitrogen-doped mesoporous carbon cathode exhibits much better sulfur immobilization capability than the undoped counterpart and sulfur can form binding with the oxygen in the functional group. In this work, $\mathrm{N}$-doped graphene has been introduced to the sulfur cathode to promote chemical confinement of sulfur. Low temperature heat treatment has been further applied for improving sulfur loading onto the 
graphene layers. The improvement of electrochemical performance of NGNS/S has been studied in both lithium cells and sodium cells.

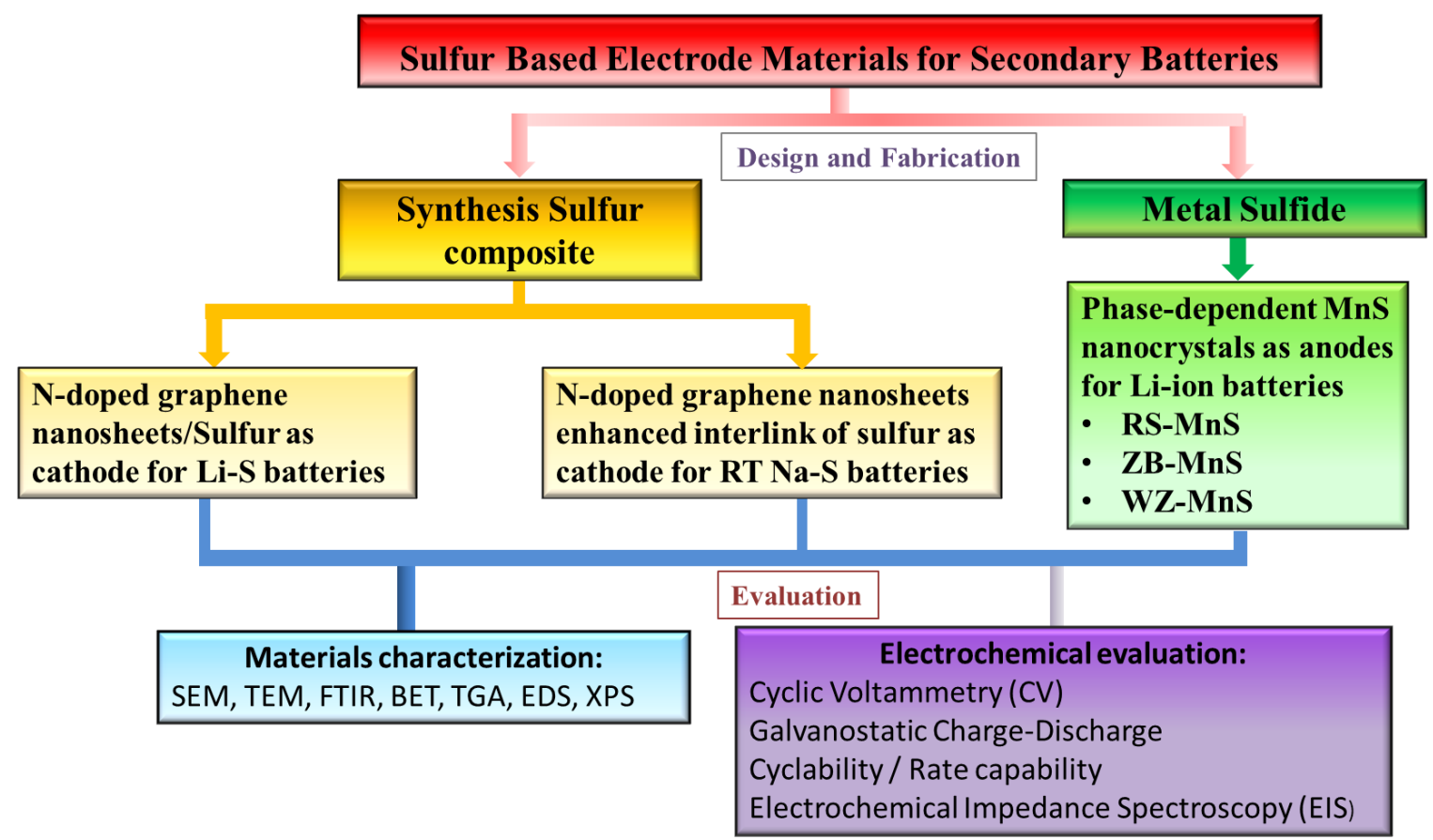

Figure 1.3 Research Plan

Metal sulfide as anode material: Among the various candidates for electrode materials, metal sulfides are known to be promising cathode materials for rechargeable batteries due to their low cost and high theoretical capacity. To the best of our knowledge, the electrochemical property of manganese sulfide has not been investigated so far. Herein, three different structural phases of $\mathrm{MnS}$ are successfully synthesized. The sizes of each kind of nanoparticles are controlled by the aging time. Electrochemical performance of three phases RS-, ZB- and WZ-MnS is evaluated in Li-ion batteries. 


\subsection{References}

[1] Y. Nishi, J. Power Sources, (2001) 100, 101.

[2] M. Winter and R. J. Brodd, Chem. Rev., (2004) 104, 4245.

[3] H. K. Liu, G. X. Wang, Z. P. Guo, J. Z. Wang, and K. Konstantinov, J. Nanosci. Nanotechnol. (2006) 6, 1.

[4] J. Chen and F. Cheng, Acc. Chem. Res., (2009) 42, 713.

[5] C. C. Chan, Proc. IEEE. (2002) 90, 247.

[6] Lu, Languang, et al. J. Power Sources, (2013) 226, 272.

[7] M.S. Whittingham, Science, (1976) 192, 1126.

[8] F. Orsini, A. Du Pasquier, B. Beaudoin, J. M. Tarascon, M. Trentin, N. Langenhuizen, E. De Beer, and P. Notten, J. Power Sources, (1998) 76, 19.

[9] M. Zanini, S. Basu, and J. E. Fischer, Carbon, (1978) 16, 211.

[10] S. Basu, US patent 4304825, (1981).

[11] Mizushima, K., P. C. Jones, P. J. Wiseman, and J. B. Goodenough. Mater. Res. Bull., (1980) 15, 783.

[12] R. Yazami, and Ph. Touzain, J. Power Sources, (1983) 9, 365.

[13] Sony Corporation, US4959281, (1990).

[14] D. Guerard and A. Herold, Carbon, (1975) 13, 337.

[15] U.Kasavajjula, C.S.Wang, and A.J. Appleby, J. of Power Sources, (2007) 163, 1003.

[16] Wu, Hao Bin, et al. Nanoscale, (2012) 4.8, 2526-2542.

[17] M. S. Whittingham, Chem. Rev., (2004) 104, 4271.

[18] J. B. Goodenough, Y. Kim, Chem. Mater., (2010) 22, 587. 
[19] "Mineral commodity summaries 2013: U.S. Geological Survey" (U.S.Geological Survey, Reston, Virginia, 2013).

[20] D. Herbert, J. Ulam, U.S. Patent 3043896, (1962).

[21] J. R. Birk, R. K. Steunenberg, Adv. Chem. Ser., (1975) 186.

[22] M. Armand, J. M. Tarascon, Nature, (2008) 451, 652.

[23] B. Dunn, H. Kamath, J.-M. Tarascon, Science, (2011) 334, 928.

[24] P. Adelhelm, P. Hartmann, et al., Journal of Nanotechnology, (2015) 6(1), 1016.

[25] X. Ji, L. F. Nazar, J. Mater. Chem., (2010) 20, 9821.

[26] X. Ji, K. T. Lee, L. F. Nazar, Nat. Mater., (2009) 8, 500.

[27] R. Elazari, et al., J. Electrochem. Soc., (2010) 157, A1131.

[28] X. M. He et al., J. Power Sources, (2009) 190, 154.

[29] A. Manthiram, et al., Chem. Rev., (2014) 114, 11751-11787.

[30] J. Wang et al., Carbon, (2008) 46, 229.

[31] G. He, X. L. Ji , L. Nazar, Energy Environ. Sci., (2011) 4, 2878.

[32] B. Zhang, X. Qin, G. R. Li and X. P. Gao, Energy Environ. Sci., (2010) 3, 1531.

[33] D. W. Wang et al., Phys. Chem. Chem. Phys., (2012) 14, 8703.

[34] B. Ding, C. Yuan, L. Shen, G. Xu, P. Nie and X. Zhang, Chem.-Eur. J., (2013) 19, 1013.

[35] N. Jayaprakash et al., Angew. Chem., Int. Ed., (2011) 50, 5904.

[36] S. Xin, Y.-X. Yin, L.-J.Wan, Y.-G. Guo, Part. Part. Syst. Charact. (2013) 30, 321.

[37] J.-Z. Wang et al., J. Power Sources, (2011) 196, 7030.

[38] F. f. Zhang et al., J. Mater. Chem., (2012) 22, 11452.

[39] H. Wang et al., Nano Lett., (2011) 11, 2644. 
[40] S. Evers and L. F. Nazar, Chem. Commun., (2012) 48, 1233.

[41] M. S. Park et al., Phys. Chem. Chem. Phys., (2012) 14, 6796.

[42] Y. Cao et al., Phys. Chem. Chem. Phys., (2011) 13, 7660.

[43] N. W. Li et al., Chem. Commun., (2012) 48, 4106.

[44] S. Li et al., Electrochem. Solid-State Lett., (2011) 14, A105.

[45] Y. X. Wang et al., J. Mater. Chem., (2012) 22, 4744.

[46] B. Wang, K. Li, D. Su, H. Ahn, G. Wang, Chem.-Asian J., (2012) 7, 1637.

[47] H. Sun et al., Nano Res., (2012) 5, 726.

[48] L. W. Ji et al., J. Am. Chem. Soc., (2011) 133, 18522.

[49] W. Zheng, Y. W. Liu, X. G. Hu and C. F. Zhang, Electrochim. Acta, (2006) 51, 1330.

[50] W. Ahn et al., J. Power Sources, (2012) 202, 394.

[51] L. X. Yuan et al., J. Power Sources, (2009) 189, 1141.

[52] G. Zheng, Y. Yang, J. J. Cha, S. S. Hong and Y. Cui, Nano Lett., (2011) 11, 4462.

[53] J. Wang et al., Electrochim. Acta, (2006) 51, 4634.

[54] Y. Z. Fu, A. Manthiram, J. Phys. Chem. C, (2012) 116, 8910.

[55] F. Wu, J. Z. Chen, L. Li, T. Zhao, R. J. Chen, J. Phys. Chem. C, (2011) 115, 24411

[56] L. Xiao et al., Adv. Mater., (2012) 24, 1176.

[57] F. Wu et al., J. Phys. Chem. C, (2011) 115, 6057.

[58] F. Wu et al., Electrochem. Solid State Lett., (2010) 13, A29.

[59] W. Y. Li et al., Proc. Natl. Acad. Sci. U. S. A., (2013) 110, 7148.

[60] M. S. Song et al., J. Electrochem. Soc., (2004) 151, A791.

[61] Y. G. Zhang, et al., J. Mater.Chem. A, (2013) 1, 295. 
[62] Y. J. Choi et al., Phys. Scr., (2007) T129, 62.

[63] X. L. Ji, S. Evers, R. Black, L. F. Nazar, Nat. Commun., (2011) 2.

[64] S. Evers, T. Yim, L. F. Nazar, J. Phys. Chem. C, (2012) 116, 19653.

[65] Z. W. Seh et al., Nat. Commun., (2013) 4.

[66] Y. Yang et al., J. Am. Chem. Soc. (2012) 134, 15387. 


\section{NITROGEN-DOPED GRAPHENE NANOSHEETS/SULFUR COMPOSITE AS LITHIUM-SULFUR BATTERIES CATHODE}

\subsection{Introduction}

Recently lithium-sulfur (Li-S) batteries are becoming one of the most attractive next-generation lithium batteries. As one of the most abundant, low-cost and environmental friendly elements on earth, sulfur has a theoretical capacity and energy density of $1675 \mathrm{mAh} \mathrm{g}^{-1}$ and $2600 \mathrm{Wh} \mathrm{kg}^{-1}$ (vs. $272 \mathrm{mAh} \mathrm{g}^{-1}$ and $387 \mathrm{Wh} \mathrm{kg}^{-1}$ for $\mathrm{LiCoO}_{2}$ ), respectively, which are much higher than typical commercial lithium-ion battery cathodes such as $\mathrm{LiCoO}_{2}, \mathrm{LiMn}_{2} \mathrm{O}_{4}$ and $\mathrm{LiFePO}_{4}[1,2]$. However, low active material utilization, capacity degradation, poor Coulombic efficiency and poor cycle life are the challenges of Li-S cells using sulfur cathodes. During the electrochemical reaction, both sulfur and its discharge product $\mathrm{Li}_{2} \mathrm{~S}$ have high electrical resistivities [3]. Moreover, dissolution of polysulfides in the electrolyte and precipitation of polysulfides on the electrodes result in the so-called shuttle effect [4], which leads to the decrease of the active mass utilization during discharge process and strain field which degrades the cycle life [5-7]. It was also reported that volume expansion and crack formation of the sulfur electrodes take place during cycling which could lead to the failure of batteries [8]. In recent years, intensive efforts have been exerted in improving Li-S batteries by developing sulfur composite cathode materials (such as sulfur/carbon materials composite [9-13], sulfur/conductive polymers composite [14-17] and sulfur/metal oxide additives composite [18-20]), modifying electrolytes to manipulate the solubility of polysulfides (such as changing lithium salt and solvent [21, 22], employing polymer electrolyte [23], adding electrolyte additive [24] and using polysulfides containing 
electrolyte $[25,26]$ ), and designing various cell configurations (such as placing carbonbased interlayer [27-30], coating modification of separator [31-33], fabricating lithium metal free anode [34], and binder or metal current collector free cathode [35-37]).

Graphene, a two-dimensional (2D) crystalline allotrope of carbon, has been considered as a promising conductive matrix for Li-S batteries due to its superior electrical conductivity, high specific surface area and excellent chemical tolerance. Graphene/sulfur composites with different structures such as graphene-wrapped sulfur particles [38-41] or sandwich type composites [42-44] have been reported. However, these close-type structures only provide physical barriers by which polysulfides dissolution in the electrolyte is hardly prevented in long term cycling and constrain $\mathrm{Li}^{+}$ transporting across graphene in the lateral direction. Chemical adsorption of sulfur and polysulfides by the host is another attractive strategy to effectively eliminate the polysulfide dissolution. Several studies have been reported on the chemical interactions between functional group (e.g. oxygen group or hydroxyl group) on graphene and polysulfides which are beneficial to the enhancement of polysulfides immobilization [45, 46]. Nitrogen- $(\mathrm{N}-)$ doping by introducing nitrogen groups and generating the extrinsic defects on carbon lattice is proved to be an effective way to improve the electrochemical performance of electrodes [47-54]. There are three major types of N-doped groups: pyridinic-N, pyrrolic-N and graphitic-N [55]. It has been found that these $\mathrm{N}$-doped active sites can adsorb $\mathrm{Li}^{+}$and also serve as tunnels for $\mathrm{Li}^{+}$transportation [56]. Recently, several studies have been reported on developing N-doped graphene/sulfur (NG/S) composite for Li-S batteries. X. Wang et al. synthesized two types of NG/S composite: pyridinic- $\mathrm{N}$ enriched and pyrrolic- $\mathrm{N}$ enriched, respectively. Pyridinic- $\mathrm{N}$ has been proved 
to contribute more efficiently on confining the diffusion of soluble polysulfides [57]. In another work, C. Wang et al. reported a NG/S composite with 3D structure. The NG with the pyridinic-, pyrrolic- and graphitic-N groups exhibited a better performance comparing to undoped graphene, which was attributed to the $3 \mathrm{D}$ conductive network and reactive $\mathrm{N}$ functional groups [58]. Y. Qiu et al. further studied the role of N-doping in immobilizing polysulfides and compared the binding energies for primitive-, pyridine- and pyrrolegraphene with atomic $\mathrm{Li}$ and polysulfides by a computational method. It has been revealed that the enhancement is mainly due to the ionic attractions between $\mathrm{N}$ and $\mathrm{Li}$ cations, instead of $\mathrm{N}$ and $\mathrm{S}$ anions [59]. The work mentioned above so far has been successfully introduced basic $\mathrm{N}$ functional groups in the NG sheets. It has to be noted that the performance of NG can be determined by several factors, such as the type of $\mathrm{N}$ functional groups, the $\mathrm{N}$ content in the NG, and structure and morphology of NG induced by $\mathrm{N}$-doping, indicating more studies related to $\mathrm{NG} / \mathrm{S}$ composites need to be further addressed.

In order to study the contribution of other N-doped functional groups, in this work, we have successfully synthesized the $\mathrm{N}$-doped graphene nanosheets with amino- $\mathrm{N}$ and pyridine-N-oxide functional groups. The $\mathrm{N}$-doped graphene nanosheets/sulfur (NGNSs/S) composite was prepared and evaluated as cathode materials in Li-S batteries. At $0.1 \mathrm{C}$, the NGNSs/S composite exhibited discharge capacities of $857 \mathrm{mAh} \mathrm{g}^{-1}$ and $319.3 \mathrm{mAh} \mathrm{g}^{-1}$ at the first and 20th circles, respectively. It is suggested that the NGNSs provided a conductive matrix with high surface area and high conductivity and $\mathrm{N}$ functional groups facilitated immobilization of the polysulfides. 


\subsection{Experimental Section}

\subsubsection{Synthesis of NGNSs}

NGNSs were synthesized from natural flake graphite, as reported in our previous work $[55,60]$. First, graphite oxide was obtained by the oxidation of natural graphite in a modified Hummers method [55]. The graphene nanosheets (GNSs) were obtained by the thermal exfoliation of graphite oxide at $1050{ }^{\circ} \mathrm{C}$ for $30 \mathrm{~s}$ under nitrogen atmosphere. NGNSs were produced by treating the pristine GNSs at the mixed gas of ammonia and argon at $900{ }^{\circ} \mathrm{C}$ for $5 \mathrm{~min}[60]$.

\subsubsection{Synthesis of NGNSs/S composite}

NGNSs/S composite was synthesized by a facile chemical reaction deposition method [58]. The procedures are as illustrated in Fig. 2.1a. First, a $0.04 \mathrm{M} \mathrm{Na}_{2} \mathrm{~S}_{2} \mathrm{O}_{3}$ solution was prepared by dissolving $1.58 \mathrm{~g} \mathrm{Na}_{2} \mathrm{~S}_{2} \mathrm{O}_{3}$ in $250 \mathrm{ml}$ distilled water, followed by magnetic stirring for $30 \mathrm{~min}$. Next, the as-synthesized $0.4 \mathrm{~g}$ NGNSs were dispersed in the $\mathrm{Na}_{2} \mathrm{~S}_{2} \mathrm{O}_{3}$ solution to produce composite. The mixture was under sonication for $1 \mathrm{~h}$ and it was continuously stirred. Then, $20 \mathrm{ml} 10 \mathrm{M}$ hydrochloric acid was dropped into the solution. After stirring for $24 \mathrm{~h}$ to let the reaction proceed completely, the product was filtered and washed with distilled water several times to eliminate salt products as well as until $\mathrm{pH}$ reached 7 and finally dried in a vacuum oven at $60{ }^{\circ} \mathrm{C}$ for $24 \mathrm{~h}$. GNSs/S composite was synthesized by the same procedures as NGNSs/S composite. Pure S particles were obtained via the same chemical reaction route as described above and in the chemical Equation (1) as below [61]:

$$
\mathrm{Na}_{2} \mathrm{~S}_{2} \mathrm{O}_{3}+2 \mathrm{HCl} \rightarrow 2 \mathrm{NaCl}+\mathrm{SO}_{2} \uparrow+\mathrm{H}_{2} \mathrm{O}+\mathrm{S} \downarrow
$$




\subsubsection{Characterization}

The microstructure and morphology characterization of obtained NGNSs, S particles and NGNSs/S composite was carried out by using a JEOL FE6330 field-emission scanning electron microscope (SEM). The nitrogen contents of NGNSs were determined by XPS analysis with a Kratos Axis Ultra Al $(\alpha)$ X-ray photoelectron spectroscopy at 14 $\mathrm{kV}$. The crystal structures of the products were examined by X-ray diffraction (XRD) on a Siemens D5000 X-ray diffractometer via $\mathrm{Cu} \mathrm{K \alpha}$ radiation between $10^{\circ}$ and $90^{\circ}$ at a scan rate of $2 \%$ min. The surface area was characterized by nitrogen adsorption/desorption isotherms at $77 \mathrm{~K}$ using a TriStar II Micromeritics and calculated by Brunauer-EmmettTeller (BET) measurement. Detailed surface information of NGNSs was obtained by using a JASCO Fourier transform-infrared spectrometer (FTIR)-4100. The weight percentage of sulfur in the composite was determined by thermogravimetric analysis (TGA) conducting on a SDT Q600 at a heating rate of $5{ }^{\circ} \mathrm{C} / \mathrm{min}$ from room temperature to $400^{\circ} \mathrm{C}$ under nitrogen protection.

\subsubsection{Electrochemical measurement}

Electrochemical characterization was carried out in CR2032-type coin cells. The NGNSs/S working electrodes were constructed from 80 wt. \% NGNSs/S composite, 10 wt. \% poly(vinylidene difluoride) (PVDF) binder, and $10 \mathrm{wt}$ \% Carbon black in an Nmethyl-2-pyrrolidinone (NMP) solution. GNSs/S, sulfur particles and NGNSs working electrodes were also prepared and evaluated as control samples. The well mixed slurry was uniformly casted onto aluminum foil current collectors and the electrodes were dried in a vacuum oven at $60{ }^{\circ} \mathrm{C}$ for $12 \mathrm{hrs}$. The coin cells were assembled in an argon-filled glove box with lithium metals as the counter and reference electrodes and Celgard 2400 
polypropylene film was used as separator. The electrolyte was a 1 M lithium bis(trifluoromethanesulfonyl)imide (LiTFSI) in 1,2-Dimethoxyethane (DME) and 1,3dioxolane (DOL) (1:1 v/v) with 1 wt. \% $\mathrm{LiNO}_{3}$ mixed solution. The cyclic voltammetry $(\mathrm{CV})$ data were collected with a biologic VMP3 potentiostat at a scan rate of $0.1 \mathrm{mV} \mathrm{s}^{-1}$ at $1.0-3.0 \mathrm{~V}\left(\mathrm{vs} . \mathrm{Li} / \mathrm{Li}^{+}\right)$. Galvanostatic Charge/Discharge cycling profiles of the cells with constant current densities and rate capability at various current densities were conducted at a cut-off potential of $1.0-3.0 \mathrm{~V}\left(\mathrm{vs} . \mathrm{Li} / \mathrm{Li}^{+}\right)$on a Neware BTS-610 instrument. Electrochemical impedance spectroscopy (EIS) was conducted on the VMP3 in the frequency range from $100 \mathrm{kHz}$ to $0.1 \mathrm{~Hz}$ with an input $\mathrm{AC}$ voltage amplitude of 10 $\mathrm{mV}$. All the electrochemical tests were performed at room temperature. 
2.3 Results and Discussion

2.3.1 Characterization
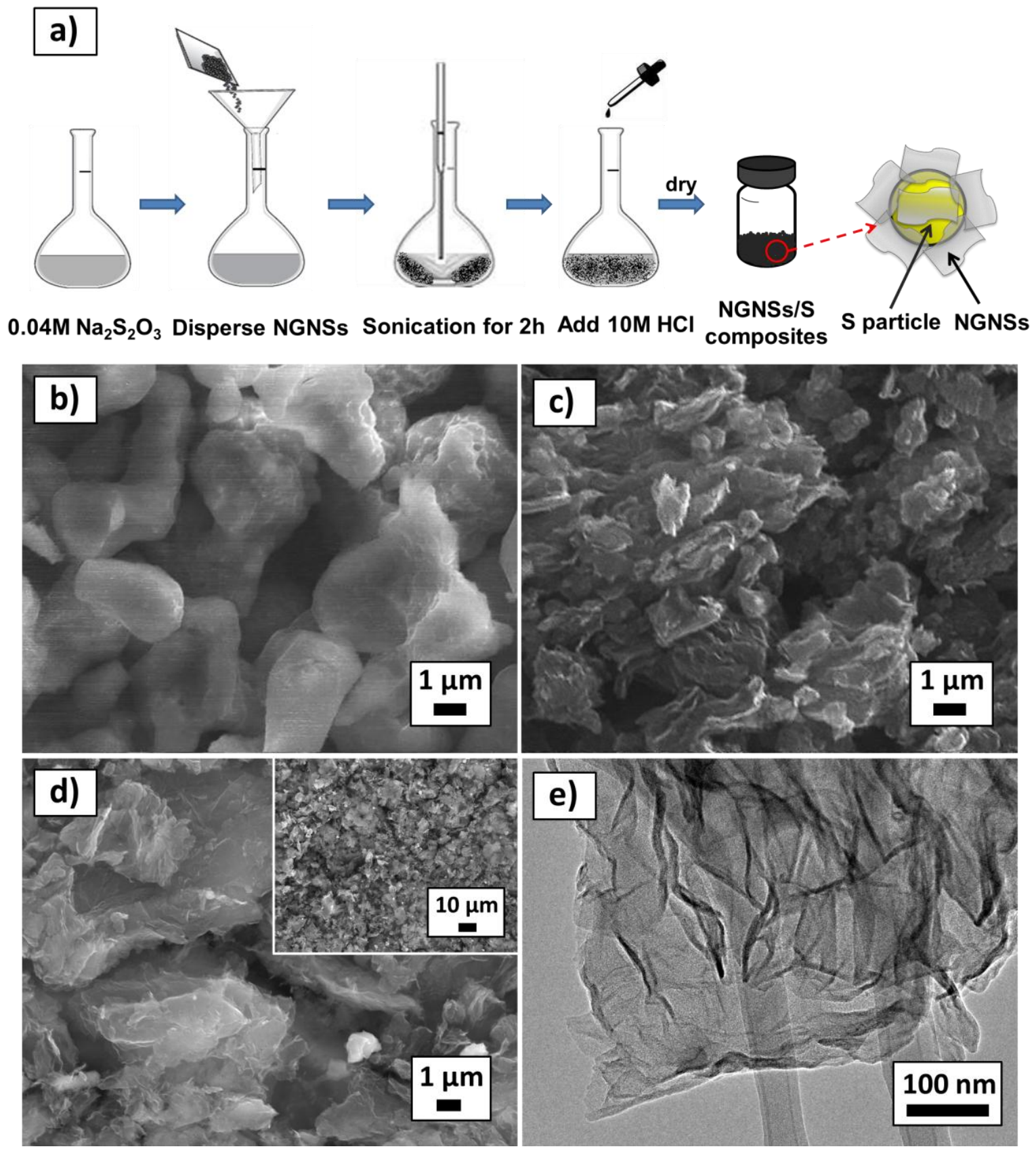

Figure 2.1 (a) Illustration of synthesis process of NGNSs/S composite; SEM images of (b) S particles, (c) NGNSs, (d) NGNSs/S composite (inset at low magnification) and (e) a typical TEM image of NGNSs. 
The SEM results of S particle, NGNSs and NGNSs/S composite are compared in Fig. 2.1b-d. It can be seen in Fig. 2.1b that irregular shaped sulfur particles formed by precipitation of chemical reaction are in the particle size of several microns. Fig. 2.1c displays the morphology of NGNSs which was randomly orientated agglomerate of planar sheets. Fig. 2.1d shows the morphologies of NGNSs/S composite at different magnifications. It can be observed that the sulfur particles are pretty homogenously mixed with the NGNSs together (Fig. 2.1d inset). Fig. 2.1e shows the TEM image of NGNSs, in which the 2D layered structure of NGNSs can be observed.
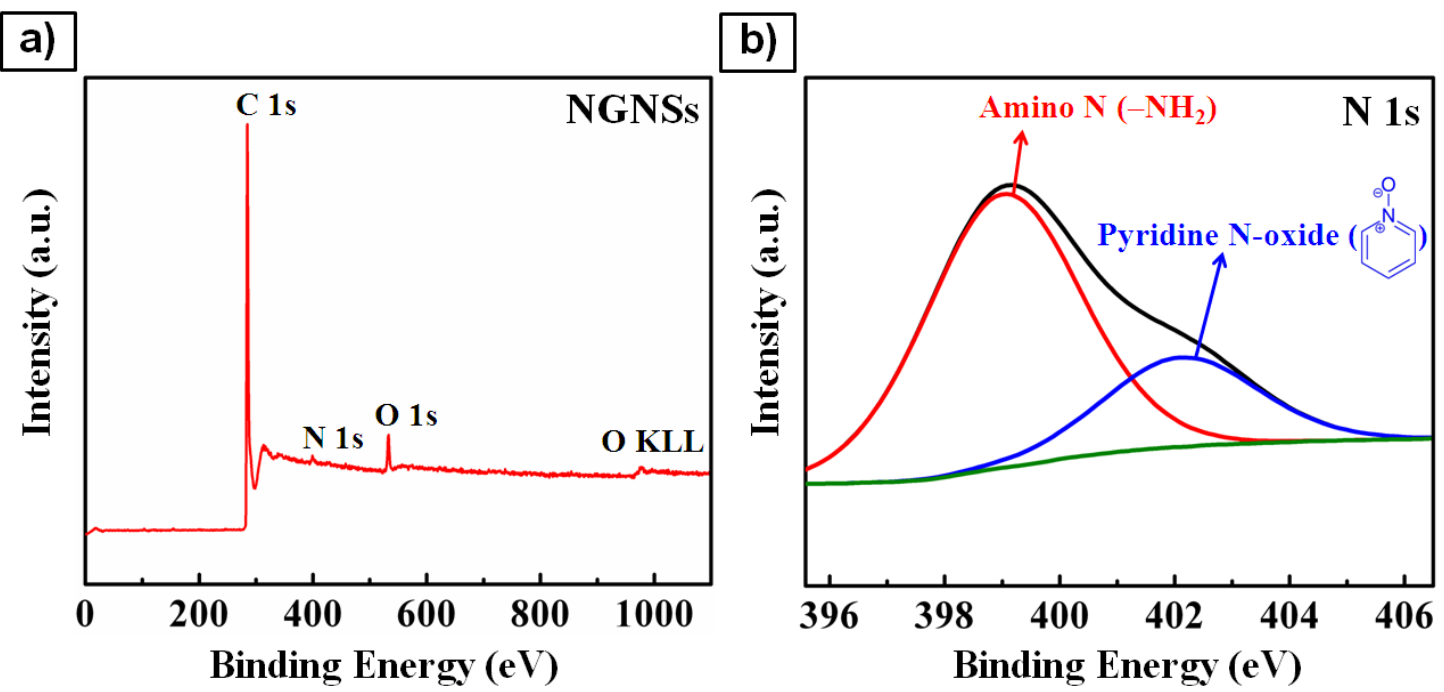

Figure 2.2 XPS spectra of NGNSs: (a) wide scan and (b) N 1s.

XPS was applied for analyzing the surface chemistry and measuring the elemental composition of NGNSs. Fig. 2.2a shows XPS analysis spectrum of NGNSs. It can be seen that there is one sharp peak at $284.35 \mathrm{eV}$, corresponding to $\mathrm{C} 1 \mathrm{~s}$ as expected. The peak at $399.15 \mathrm{eV}$ represents $\mathrm{N} 1 \mathrm{~s}$, indicating nitrogen has been successfully doped in the NGNSs. Besides the presence of $\mathrm{C} 1 \mathrm{~s}$ and $\mathrm{N} 1 \mathrm{~s}$, O1s peaks at $532.85 \mathrm{eV}$ can also be 
observed in the XPS spectrum of NGNSs. The relative atomic percentages of $\mathrm{C} 1 \mathrm{~s}, \mathrm{~N} 1 \mathrm{~s}$ and $\mathrm{O} 1 \mathrm{~s}$ are calculated from the XPS spectrum as $95.5 \%, 1.2 \%$ and $3.3 \%$, respectively. The coverage of $\mathrm{N}$ on the graphene surface could be estimated as about $1.3 \%$. The XPS $\mathrm{N}$ 1s spectrum of NGNSs is shown in Fig. 2.2b. It can be observed there are two fitting peaks in the $\mathrm{N} 1 \mathrm{~s}$ spectrum with binding energies of $399.02 \mathrm{eV}$ and $402.10 \mathrm{eV}$, corresponding to amino- $\mathrm{N}$ and pyridine- $\mathrm{N}$-oxide, respectively [49, 62].
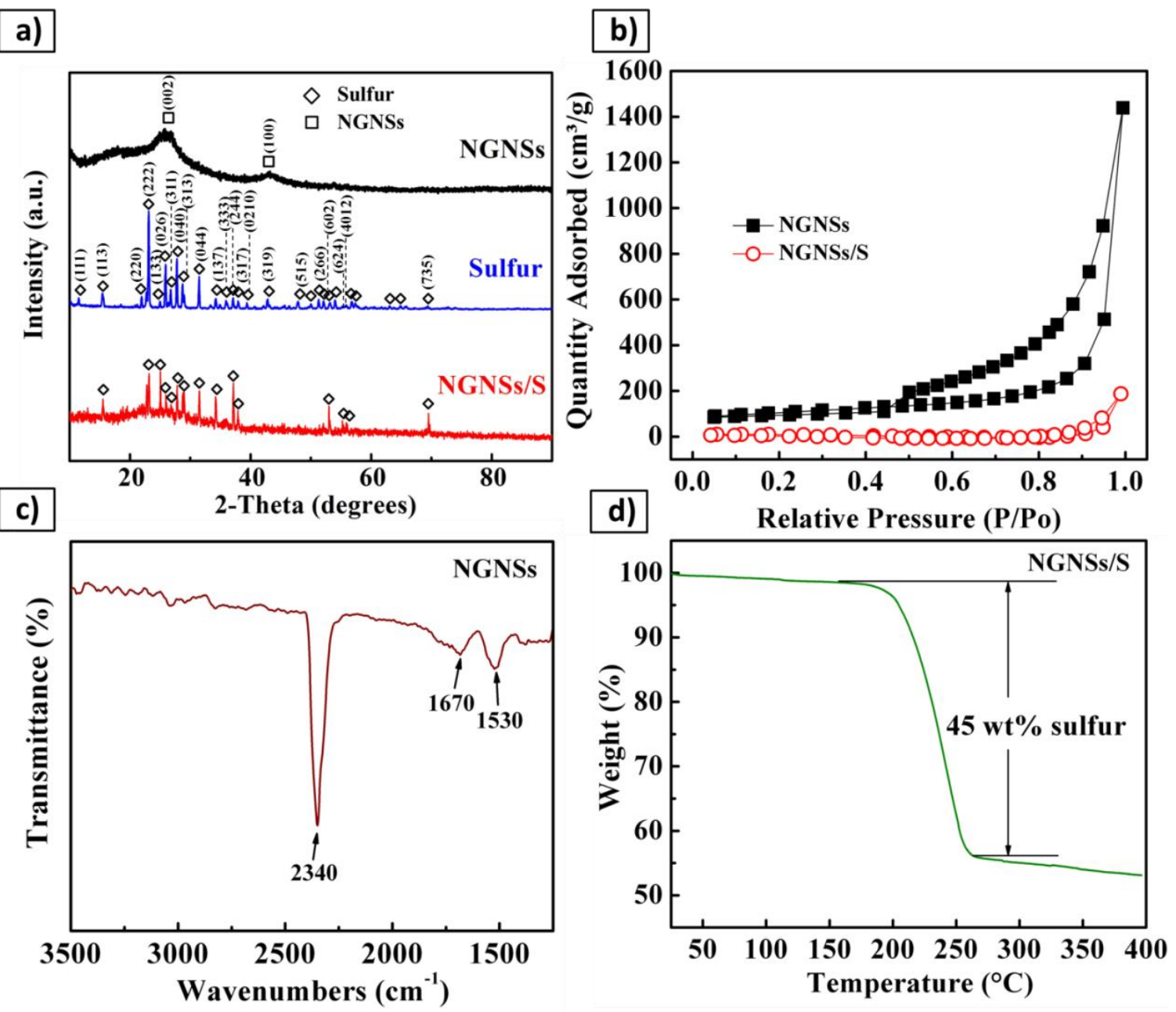

Figure 2.3 (a) XRD patterns of Sulfur, NGNSs and NGNSs/S composite, (b) $\mathrm{N}_{2}$ adsorption-desorption isotherms of NGNSs and NGNSs/S composite, (c) FTIR spectra of NGNSs and (d) TGA analysis of NGNSs/S composite. 
The XRD patterns of elemental sulfur particles, NGNSs and as-synthesized NGNSs/S composite are presented in Fig. 2.3a. It is observed that the pristine NGNSs exists two broad diffraction peaks around $26^{\circ}$ and $42^{\circ}$, corresponding to the general characteristic (002) and (100) diffraction peaks of multi-layered graphene. The XRD pattern of elemental sulfur particles generally exhibits a series of sharp and strong peaks, indicating a well-defined Fddd orthorhombic crystalline structure of sulfur (JCPDS\#: 080247). The XRD pattern of NGNSs/S composite shows most sharp and strong sulfur peaks as well, indicating the existing of sulfur in the composite. The broad peaks of NGNSs are barely obvious in the NGNSs/S composite with sulfur loading. Fig. 2.3b shows the surface area measurement results of NGNSs and NGNSs/S composite. For NGNSs, the surface area is around $330 \mathrm{~m}^{2} \mathrm{~g}^{-1}$. After sulfur loading, the surface area of NGNSs/S composite turns out to be $10 \mathrm{~m}^{2} \mathrm{~g}^{-1}$. This massive decrease after sulfur loading reveals that the loading of sulfur particles occupies the most surface area of NGNSs [50].

The nitrogen functionalization on NGNSs was also characterized by FTIR, as shown in Fig. 2.3c. It can be seen that there is a board band centered at $2340 \mathrm{~cm}^{-1}$, indicating the presence of adsorbed $\mathrm{CO}_{2}$ and/or vibration of $\mathrm{C}=\mathrm{N}=\mathrm{O}$ asymmetric stretching. The vibration peaks at $\sim 1530 \mathrm{~cm}^{-1}$ and $\sim 1670 \mathrm{~cm}^{-1}$ can be indexed to amine groups of $\mathrm{N}-\mathrm{H}$ stretching and scissoring [53,63]. The FTIR matches the obtained results of XPS analysis and further confirms that nitrogen has been successfully doped into graphene structure. TGA was conducted on as-synthesized NGNSs/S sample and the result is shown in Fig. 2.3d. The NGNSs/S composite has a weight loss of 45 wt. $\%$ with the temperature increasing from 150 to $250{ }^{\circ} \mathrm{C}$, indicating that there is a content of $45 \mathrm{wt}$. $\%$ sulfur in the NGNSs/S composite. 


\subsubsection{Electrochemical Characterization}

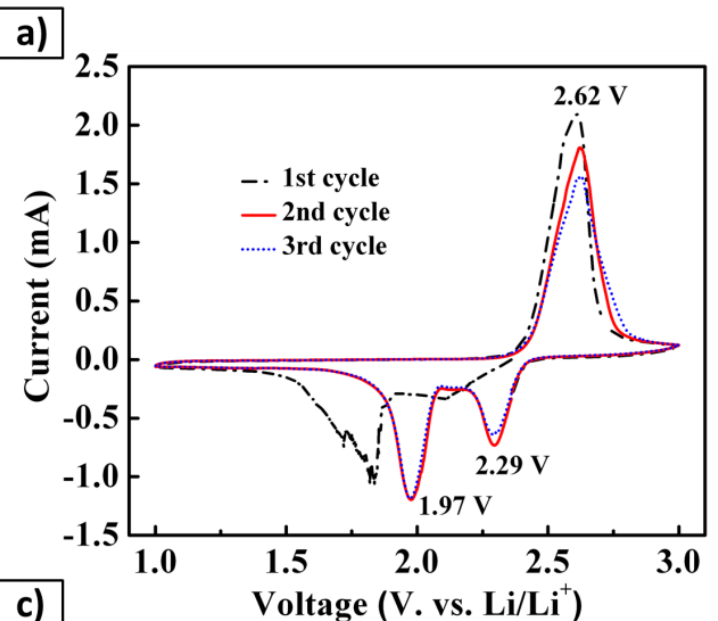

b)
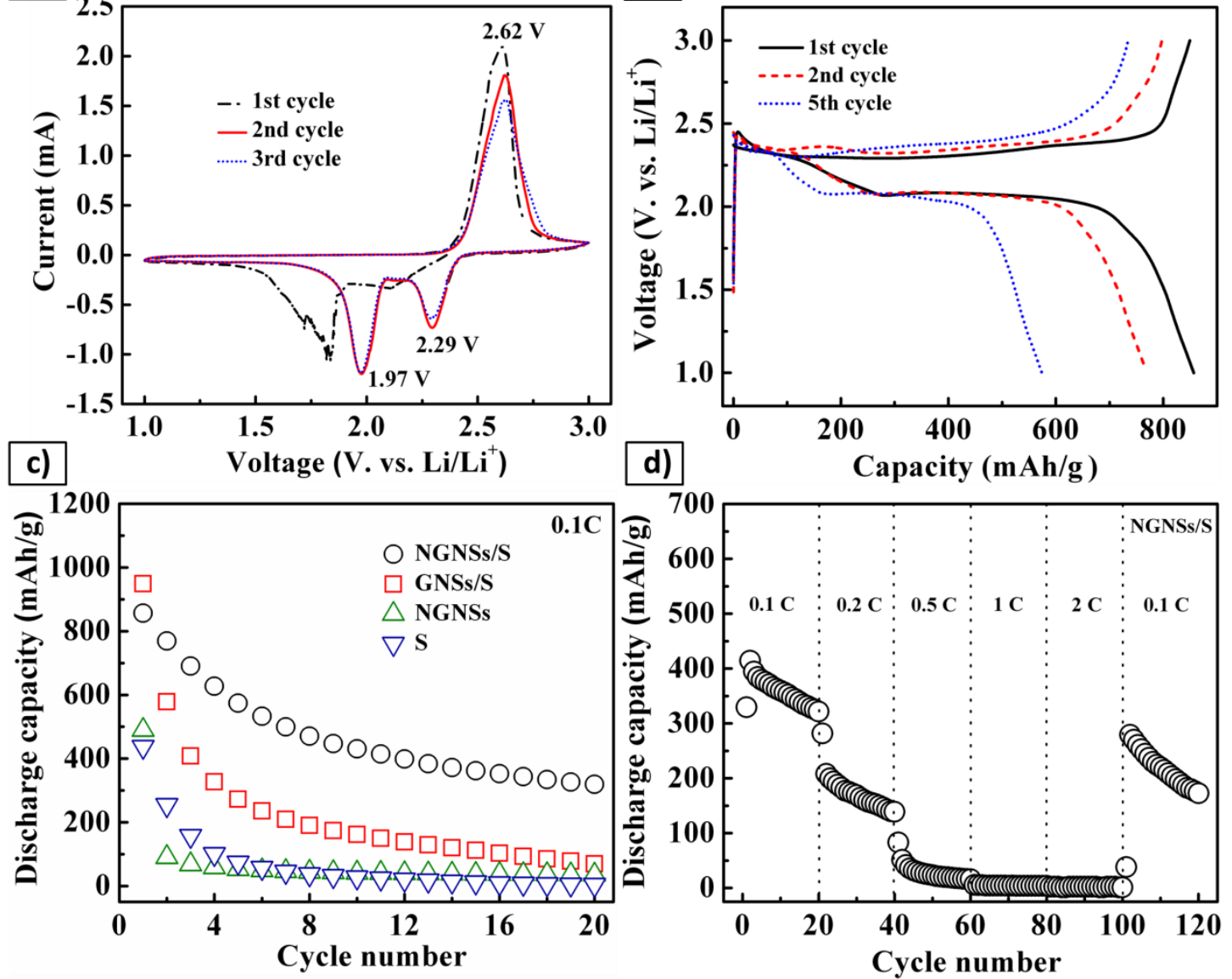

Figure 2.4 (a) Cyclic voltammograms of NGNSs/S composite as working electrode at a scan rate of $0.1 \mathrm{mV} \mathrm{s}^{-1}$ between 1.0 and $3.0 \mathrm{~V}$ (vs. $\mathrm{Li} / \mathrm{Li}^{+}$), (b) the $1 \mathrm{st}, 2$ nd and 5 th cycles of discharge/charge profile of NGNSs/S composite at $0.1 \mathrm{C}$, (c) cycling performances of NGNSs/S composite, GNSs/S composite, NGNSs and S at $0.1 \mathrm{C}$ and (d) rate performance of NGNSs/S composite at various rates.

The electrochemical properties of NGNSs/S composite were investigated as shown in Fig. 2.4. Fig. 2.4a shows the cyclic voltammetry (CV) profiles of the NGNSs/S cathode for the initial 1 st, 2 nd and 3rd cycles between 1.0 and $3.0 \mathrm{~V}$ (vs. $\mathrm{Li} / \mathrm{Li}^{+}$). In the cathodic scan of the first cycle, the NGNSs/S electrode exhibits a small shoulder at $2.11 \mathrm{~V}$ and a broad peak starting at $1.83 \mathrm{~V}$. The small shoulder around $2.11 \mathrm{~V}$ could be assigned to the formation of soluble polysulfides $\left(\mathrm{Li}_{2} \mathrm{~S}_{\mathrm{x}}, 4 \leq \mathrm{x} \leq 8\right)$ during lithiation, while the low voltage 
peak around $1.83 \mathrm{~V}$ is most likely associated to the formation of insoluble lithium disulfide $\mathrm{Li}_{2} \mathrm{~S}_{2}$ and lithium sulfide $\mathrm{Li}_{2} \mathrm{~S}$ [51]. During the anodic process, there is only one oxidation peak observed and $2.62 \mathrm{~V}$ (vs. $\mathrm{Li} / \mathrm{Li}^{+}$). This can be assigned to delithiation process of $\mathrm{Li}_{2} \mathrm{~S}$ back to polysulfides and eventually to $\mathrm{S}$ [57]. In the second and third cycle, there are two reduction peaks observed at $2.29 \mathrm{~V}$ and $1.97 \mathrm{~V}$, which shift toward more positive direction in comparison to the first cycle. The change of kinetics after the polysulfides formation could be related to the voltage shift. Meanwhile, similar voltage shift behavior was also reported and attributed to strain/stress generation during polysulfides formation [64]. Further study needs to be conducted to clarify the voltage shift mechanism. For the oxidation peaks in the second and third cycle, the currents of the peaks decrease which may be due to the dissolution of polysulfides. Fig. $2.4 \mathrm{~b}$ shows the galvanostatic charge/discharge curves of NGNSs/S composite cathode at the 1st, 2nd and 5th cycles. The first discharge curve suggests that there are two plateaus which correspond well with two apparent reduction peaks in $\mathrm{CV}$ results. The first plateau observed at $2.3 \mathrm{~V}$ is attributed to the formation of soluble polysulfides. The second plateau at $2.1 \mathrm{~V}$ corresponds to the reduction of soluble polysulfides to insoluble $\mathrm{Li}_{2} \mathrm{~S}_{2}$ and $\mathrm{Li}_{2} \mathrm{~S}$. In the following cycles, the discharge processes follow the steps as the first cycle. From the first charge curve, it can be observed that there is a sharp rise at the beginning and follow by a shallow dip. The initial sharp rise is due to the polarization of $\mathrm{Li}_{2} \mathrm{~S}$ passivation layer on the surface of cathode and the shallow dip may be attributed to the depolarization of insoluble $\mathrm{Li}_{2} \mathrm{~S}$ to soluble polysulfides by electrochemical oxidation $[6,65]$. The one major plateau is assigned to the oxidation of polysulfides to element $S[7,66]$. Based on the CV and charge/discharge profiles, the reaction occurring at NGNSs/S cathode during 
discharge proceeds through a series of steps can be described as below (Equations (2)-(6)) $[67,68]$.

$$
\begin{aligned}
& \mathrm{S}_{8}+2 \mathrm{e}^{-} \rightarrow \mathrm{S}_{8}{ }^{2-} \\
& 3 \mathrm{~S}_{8}{ }^{2-}+2 \mathrm{e}^{-} \rightarrow 4 \mathrm{~S}_{6}{ }^{2-} \\
& 2 \mathrm{~S}_{6}{ }^{2-}+2 \mathrm{e}^{-} \rightarrow 3 \mathrm{~S}_{4}{ }^{2-} \\
& \mathrm{S}_{4}{ }^{2-}+4 \mathrm{Li}^{+}+2 \mathrm{e}^{-} \rightarrow 2 \mathrm{Li}_{2} \mathrm{~S}_{2} \\
& \mathrm{Li}_{2} \mathrm{~S}_{2}+2 \mathrm{Li}^{+}+2 \mathrm{e}^{-} \rightarrow 2 \mathrm{Li}_{2} \mathrm{~S}
\end{aligned}
$$

Fig. 2.4c compares the cycling performance of the NGNSs/S composite, control samples GNSs/S composite, NGNSs and S (CV and charge/discharge profiles of NGNSs and $\mathrm{S}$ are shown in Fig. 2.5 and 2.6, respectively) at a current rate of 0.1C. The NGNSs/S shows a discharge capacity of $856.7 \mathrm{mAh} \mathrm{g}^{-1}$ in the first cycle which is higher than the capacity of $489.9 \mathrm{mAh} \mathrm{g}^{-1}$ of NGNSs and capacity of $437.1 \mathrm{mAh} \mathrm{g}^{-1}$ of S. The capacity of NGNSs/S fades to $319.2 \mathrm{mAh} \mathrm{g}^{-1}$ after 20 cycles while the capacity of bare sulfur electrode decreases to $4.1 \mathrm{mAh} \mathrm{g}^{-1}$. Although the GNSs/S exhibits the first discharge capacity of $949.2 \mathrm{mAh} \mathrm{g}^{-1}$, the capacity fades faster compared to the NGNSs/S composite and decreases to $69.3 \mathrm{mAh} \mathrm{g}^{-1}$ at the 20th cycle. The enhanced cycling performance could be attributed to the $\mathrm{N}$-doped functional groups, which has beneficial effect on the confinement of polysulfides in the NGNSs/S composite. However, the capacity fading with cycling still can be observed due to the polysulfides inevitably dissolving into the electrolyte. Fig. $2.4 \mathrm{~d}$ shows the rate performance of NGNSs/S at various $\mathrm{C}$ rates. The 20th cycle discharge capacities are 321.8, 139.0, 15.9, 4.1, 1.2 and 173.0 $\mathrm{mAh} \mathrm{g}^{-1}$, respectively, at discharge rates of $0.1,0.2,0.5,1,2$ and $0.1 \mathrm{C}$, respectively. For each rate performance, 
it can be seen that there is capacity fading during the cycling performance which may due to the polysulfides dissolve into the electrolyte discussed above. However, it is noticed that when the rate turns back to $0.1 \mathrm{C}$, the specific capacity recovers to $173.0 \mathrm{mAh} \mathrm{g}^{-1}$, indicating that NGNSs/S composite still presents a good rate capability. It has to be noted that there are only few published Li-S works using NGNSs/S composite. The enhanced electrochemical performance so far were mainly attributed to the three common types of $\mathrm{N}$-doped functional groups, which are pyridinic-N, pyrrolic-N and graphitic-N. In this work, we demonstrated that the NGNSs with amino-N and pyridine-N-oxide can also contribute to the enhancement of the electrochemical performance in Li-S cells. We believe that the electrochemical performance can be further improved by modifying the coverage of N-doped functional groups, which needs to be investigated in the future work.
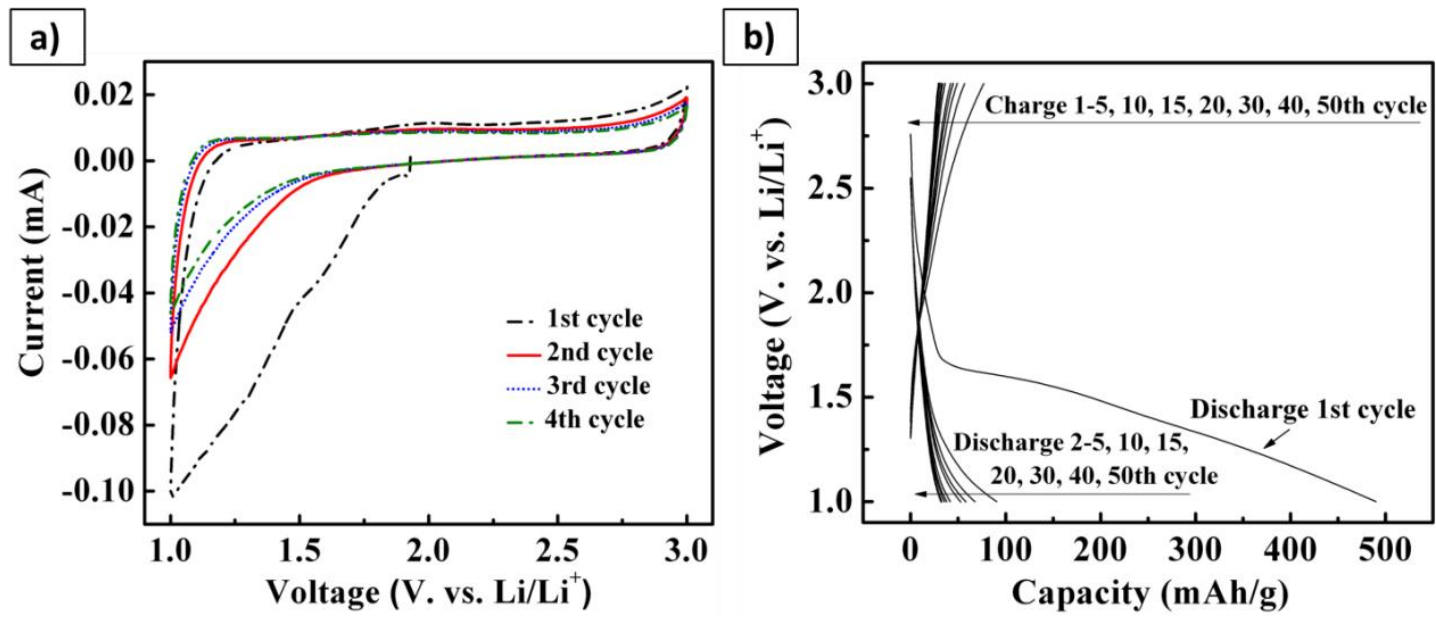

Figure 2.5 (a) Cyclic voltammograms of NGNSs as working electrode at a scan rate of $0.1 \mathrm{mV} \mathrm{s}^{-1}$ between 1.0 and $3.0 \mathrm{~V}$ (vs. $\mathrm{Li} / \mathrm{Li}^{+}$) and (b) Discharge/charge profile of NGNSs at $0.1 \mathrm{C}$ rate. 

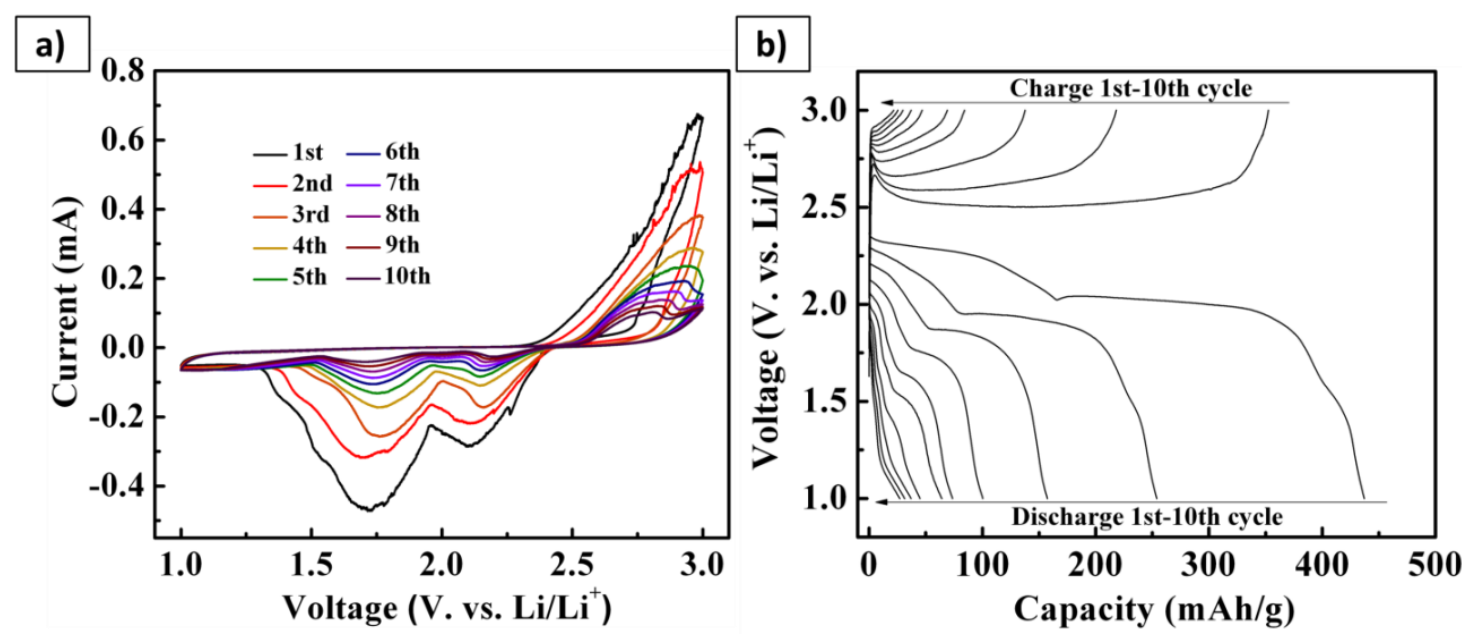

Figure 2.6 (a) Cyclic voltammograms of $\mathrm{S}$ particles as working electrode at a scan rate of $0.1 \mathrm{mV} \mathrm{s}^{-1}$ between 1.0 and $3.0 \mathrm{~V}$ (vs. $\mathrm{Li} / \mathrm{Li}^{+}$) and (b) Discharge/charge profile of $\mathrm{S}$ particles at $0.1 \mathrm{C}$ rate.

To further investigate charge transfer resistance of NGNSs/S composite cathode during cycling, EIS of Li-S cell before and after the 1st cycle (i.e., test at the end of the 1st cycle), and after the 5th cycle (i.e., test at the end of the 5th cycle) were conducted, as shown in Fig. 2.7. The impedance plots are composed of one semicircle in the high frequency region and near linear line in the low frequency region. The semicircles are assigned to the solid-electrolyte interface resistance and the charge transfer resistance of the NGNSs/S electrode. It can be seen that radii of the semicircles after the 1 st and 5 th cycles are larger than the radius before cycling, indicating that charge transfer kinetics become lower which may be due to the resistance of the irreversible deposition and aggregation of insulated $\mathrm{Li}_{2} \mathrm{~S}_{2} / \mathrm{Li}_{2} \mathrm{~S}$ layer on the surface of NGNSs/S electrode after cycling. The resistance of NGNSs/S changes from about $100 \Omega$ before the 1 st cycle to about $150 \Omega$ in the following cycles. However, the semicircle radii after the 1 st and 5 th cycles are almost unchanged, which implies that NGNSs/S cathode achieves a stable interfacial charge-transfer process during cycling [52]. The linear line relates to the 
diffusion kinetics of $\mathrm{Li}^{+}$within the electrodes. It can be seen that the slope of the linear line after 5th cycle turns to be steeper compared to the slopes before and after the 1st cycle, which indicates NGNSs/S cathode is in favor of rapid $\mathrm{Li}^{+}$transport with cycling.

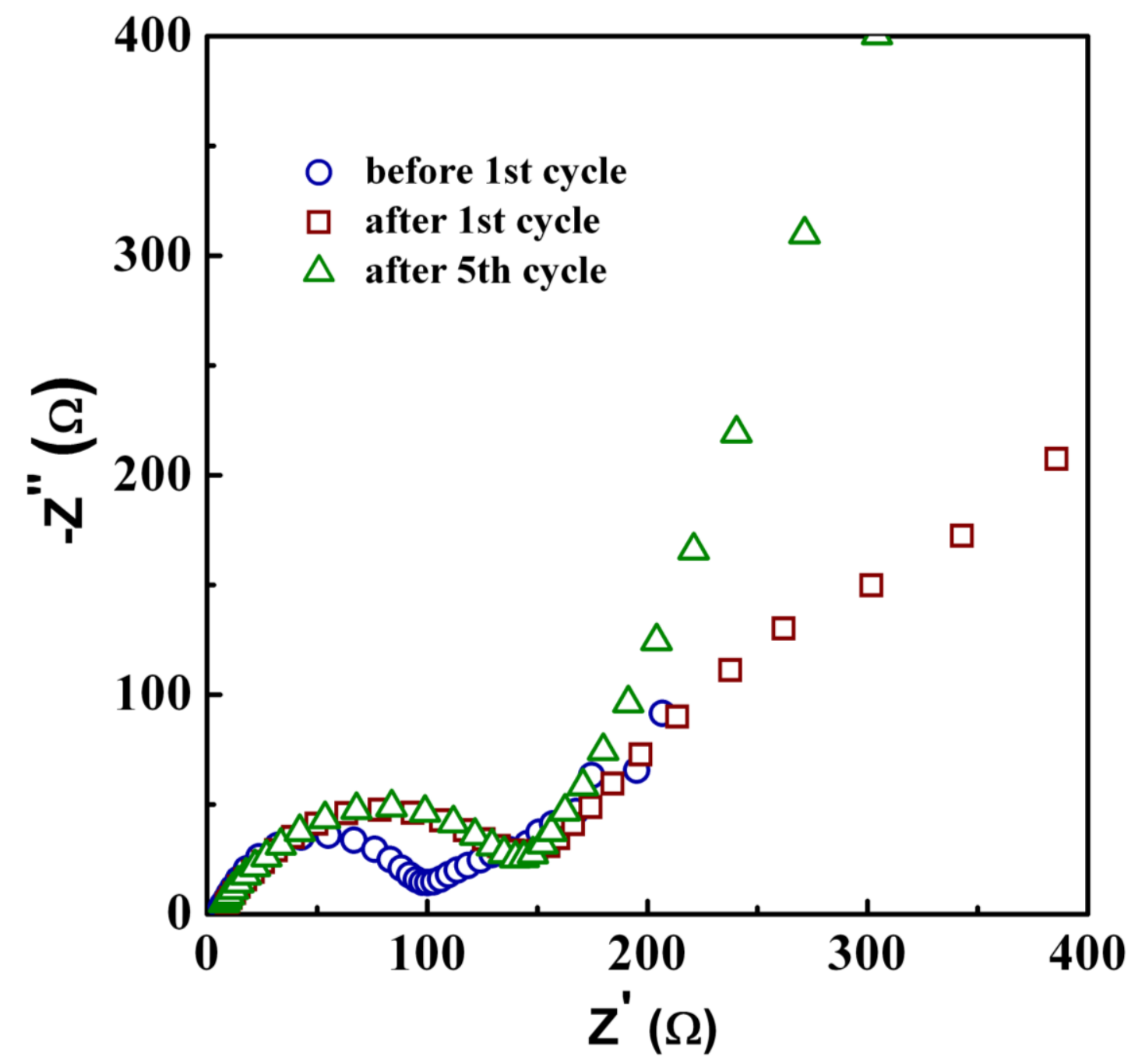

Figure 2.7 Nyquist plots of the Li-S cell with NGNSs/S composite cathode before the 1st, after the 1 st and 5 th cycles.

\subsection{Conclusions}

In summary, the NGNSs/S composite has been successfully synthesized by a facile chemical reaction deposition method. The NGNSs/S cathode exhibits good rate 
capability and good specific discharge capacity of $319.3 \mathrm{mAh} \mathrm{g}^{-1}$ at $0.1 \mathrm{C}$ after 20 cycles. The NGNSs apply as a framework formed by the 2D graphene layer could anchor sulfur particles, improve the conductivity of the electrode and enlarge the contact surface area to allow fast $\mathrm{Li}^{+}$transport.

\subsection{References}

[1] Y.X. Yin, S. Xin, Y.G. Guo, L.J. Wan, Angewandte Chemie International Edition, 52 (2013) 13186-13200.

[2] B. Papandrea, X. Xu, Y. Xu, C.-Y. Chen, Z. Lin, G. Wang, Y. Luo, M. Liu, Y. Huang, L. Mai, Nano Research, 9 (2016) 240-248.

[3] Y. Fu, C. Zu, A. Manthiram, Journal of the American Chemical Society, 135 (2013) 18044-18047.

[4] J.-Q. Huang, Q. Zhang, H.-J. Peng, X.-Y. Liu, W.-Z. Qian, F. Wei, Energy \& Environmental Science, 7 (2014) 347-353.

[5] R. Elazari, G. Salitra, Y. Talyosef, J. Grinblat, C. Scordilis-Kelley, A. Xiao, J. Affinito, D. Aurbach, Journal of The Electrochemical Society, 157 (2010) A1131-A1138.

[6] S.S. Zhang, Journal of Power Sources, 231 (2013) 153-162.

[7] N.A. Cañas, S. Wolf, N. Wagner, K.A. Friedrich, Journal of power sources, 226 (2013) 313-319.

[8] Y. Yang, G. Zheng, Y. Cui, Chemical Society Reviews, 42 (2013) 3018-3032.

[9] T. Lin, Y. Tang, Y. Wang, H. Bi, Z. Liu, F. Huang, X. Xie, M. Jiang, Energy \& Environmental Science, 6 (2013) 1283-1290.

[10] J.-Q. Huang, Q. Zhang, S.-M. Zhang, X.-F. Liu, W. Zhu, W.-Z. Qian, F. Wei, Carbon, 58 (2013) 99-106.

[11] X.a. Chen, Z. Xiao, X. Ning, Z. Liu, Z. Yang, C. Zou, S. Wang, X. Chen, Y. Chen, S. Huang, Advanced Energy Materials, 4 (2014) 1301988.

[12] X. Li, X. Li, M.N. Banis, B. Wang, A. Lushington, X. Cui, R. Li, T.-K. Sham, X. Sun, Journal of Materials Chemistry A, 2 (2014) 12866-12872. 
[13] X. Li, Q. Sun, J. Liu, B. Xiao, R. Li, X. Sun, Journal of Power Sources, 302 (2016) 174-179.

[14] J. Fanous, M. Wegner, J. Grimminger, A.n. Andresen, M.R. Buchmeiser, Chemistry of Materials, 23 (2011) 5024-5028.

[15] Y. Zhang, Z. Bakenov, Y. Zhao, A. Konarov, T.N.L. Doan, M. Malik, T. Paron, P. Chen, Journal of Power Sources, 208 (2012) 1-8.

[16] W. Zhou, Y. Yu, H. Chen, F.J. DiSalvo, H.c.D. Abruña, Journal of the American Chemical Society, 135 (2013) 16736-16743.

[17] W. Li, Q. Zhang, G. Zheng, Z.W. Seh, H. Yao, Y. Cui, Nano letters, 13 (2013) 55345540.

[18] X. Ji, S. Evers, R. Black, L.F. Nazar, Nature communications, 2 (2011) 325.

[19] S. Evers, T. Yim, L.F. Nazar, The Journal of Physical Chemistry C, 116 (2012) 19653-19658.

[20] Z.W. Seh, W. Li, J.J. Cha, G. Zheng, Y. Yang, M.T. McDowell, P.-C. Hsu, Y. Cui, Nature communications, 4 (2013) 1331.

[21] C. Barchasz, J.-C. Leprêtre, S. Patoux, F. Alloin, Journal of The Electrochemical Society, 160 (2013) A430-A436.

[22] L. Suo, Y.-S. Hu, H. Li, M. Armand, L. Chen, Nature communications, 4 (2013) 1481.

[23] J. Jin, Z. Wen, X. Liang, Y. Cui, X. Wu, Solid State Ionics, 225 (2012) 604-607.

[24] Z. Lin, Z. Liu, W. Fu, N.J. Dudney, C. Liang, Advanced Functional Materials, 23 (2013) 1064-1069.

[25] D.J. Lee, M. Agostini, J.W. Park, Y.K. Sun, J. Hassoun, B. Scrosati, ChemSusChem, 6 (2013) 2245-2248.

[26] S. Chen, F. Dai, M.L. Gordin, D. Wang, Rsc Advances, 3 (2013) 3540-3543.

[27] Y.-S. Su, A. Manthiram, Nature communications, 3 (2012) 1166.

[28] Y.-S. Su, A. Manthiram, Chemical Communications, 48 (2012) 8817-8819.

[29] C. Zu, Y.-S. Su, Y. Fu, A. Manthiram, Physical Chemistry Chemical Physics, 15 (2013) 2291-2297. 
[30] R. Singhal, S.-H. Chung, A. Manthiram, V. Kalra, Journal of Materials Chemistry A, 3 (2015) 4530-4538.

[31] I. Bauer, S. Thieme, J. Brückner, H. Althues, S. Kaskel, Journal of Power Sources, 251 (2014) 417-422.

[32] J. Balach, T. Jaumann, M. Klose, S. Oswald, J. Eckert, L. Giebeler, Advanced Functional Materials, 25 (2015) 5285-5291.

[33] U. Stoeck, J. Balach, M. Klose, D. Wadewitz, E. Ahrens, J. Eckert, L. Giebeler, Journal of Power Sources, 309 (2016) 76-81.

[34] J. Hassoun, J. Kim, D.-J. Lee, H.-G. Jung, S.-M. Lee, Y.-K. Sun, B. Scrosati, Journal of Power Sources, 202 (2012) 308-313.

[35] R. Demir-Cakan, M. Morcrette, F. Nouar, C. Davoisne, T. Devic, D. Gonbeau, R. Dominko, C. Serre, G. Férey, J.-M. Tarascon, Journal of the American Chemical Society, 133 (2011) 16154-16160.

[36] H. Yao, G. Zheng, P.-C. Hsu, D. Kong, J.J. Cha, W. Li, Z.W. Seh, M.T. McDowell, K. Yan, Z. Liang, Nature communications, 5 (2014) 3943.

[37] S. Thieme, J. Brückner, I. Bauer, M. Oschatz, L. Borchardt, H. Althues, S. Kaskel, Journal of Materials Chemistry A, 1 (2013) 9225-9234.

[38] H. Wang, Y. Yang, Y. Liang, J.T. Robinson, Y. Li, A. Jackson, Y. Cui, H. Dai, Nano letters, 11 (2011) 2644-2647.

[39] S. Evers, L.F. Nazar, Chemical communications, 48 (2012) 1233-1235.

[40] N. Li, M. Zheng, H. Lu, Z. Hu, C. Shen, X. Chang, G. Ji, J. Cao, Y. Shi, Chemical Communications, 48 (2012) 4106-4108.

[41] Y. Liu, J. Guo, J. Zhang, Q. Su, G. Du, Applied Surface Science, 324 (2015) 399404.

[42] Y. Cao, X. Li, I.A. Aksay, J. Lemmon, Z. Nie, Z. Yang, J. Liu, Physical chemistry chemical physics, 13 (2011) 7660-7665.

[43] Y.-X. Wang, L. Huang, L.-C. Sun, S.-Y. Xie, G.-L. Xu, S.-R. Chen, Y.-F. Xu, J.-T. Li, S.-L. Chou, S.-X. Dou, Journal of Materials Chemistry, 22 (2012) 4744-4750.

[44] R. Chen, T. Zhao, J. Lu, F. Wu, L. Li, J. Chen, G. Tan, Y. Ye, K. Amine, Nano letters, 13 (2013) 4642-4649. 
[45] L. Ji, M. Rao, H. Zheng, L. Zhang, Y. Li, W. Duan, J. Guo, E.J. Cairns, Y. Zhang, Journal of the American Chemical Society, 133 (2011) 18522-18525.

[46] C. Zu, A. Manthiram, Advanced Energy Materials, 3 (2013) 1008-1012.

[47] K. Chang, D. Geng, X. Li, J. Yang, Y. Tang, M. Cai, R. Li, X. Sun, Advanced Energy Materials, 3 (2013) 839-844.

[48] L.-S. Zhang, X.-Q. Liang, W.-G. Song, Z.-Y. Wu, Physical Chemistry Chemical Physics, 12 (2010) 12055-12059.

[49] Z. Wen, X. Wang, S. Mao, Z. Bo, H. Kim, S. Cui, G. Lu, X. Feng, J. Chen, Advanced materials, 24 (2012) 5610-5616.

[50] X.G. Sun, X. Wang, R.T. Mayes, S. Dai, ChemSusChem, 5 (2012) 2079-2085.

[51] F. Sun, J. Wang, H. Chen, W. Li, W. Qiao, D. Long, L. Ling, ACS applied materials \& interfaces, 5 (2013) 5630-5638.

[52] J. Yang, J. Xie, X. Zhou, Y. Zou, J. Tang, S. Wang, F. Chen, L. Wang, The Journal of Physical Chemistry C, 118 (2014) 1800-1807.

[53] P. Zhu, J. Song, D. Lv, D. Wang, C. Jaye, D.A. Fischer, T. Wu, Y. Chen, The Journal of Physical Chemistry C, 118 (2014) 7765-7771.

[54] J. Song, T. Xu, M.L. Gordin, P. Zhu, D. Lv, Y.B. Jiang, Y. Chen, Y. Duan, D. Wang, Advanced Functional Materials, 24 (2014) 1243-1250.

[55] X. Li, D. Geng, Y. Zhang, X. Meng, R. Li, X. Sun, Electrochemistry Communications, 13 (2011) 822-825.

[56] H.M. Jeong, J.W. Lee, W.H. Shin, Y.J. Choi, H.J. Shin, J.K. Kang, J.W. Choi, Nano letters, 11 (2011) 2472-2477.

[57] X. Wang, Z. Zhang, Y. Qu, Y. Lai, J. Li, Journal of Power Sources, 256 (2014) 361368.

[58] C. Wang, K. Su, W. Wan, H. Guo, H. Zhou, J. Chen, X. Zhang, Y. Huang, Journal of Materials Chemistry A, 2 (2014) 5018-5023.

[59] Y. Qiu, W. Li, W. Zhao, G. Li, Y. Hou, M. Liu, L. Zhou, F. Ye, H. Li, Z. Wei, Nano letters, 14 (2014) 4821-4827.

[60] Y. Li, J. Wang, X. Li, D. Geng, M.N. Banis, R. Li, X. Sun, Electrochemistry Communications, 18 (2012) 12-15. 
[61] R.G. Chaudhuri, S. Paria, Journal of colloid and interface science, 343 (2010) 439446.

[62] C. Zhang, R. Hao, H. Liao, Y. Hou, Nano Energy, 2 (2013) 88-97.

[63] D. Geng, S. Yang, Y. Zhang, J. Yang, J. Liu, R. Li, T.-K. Sham, X. Sun, S. Ye, S. Knights, Applied Surface Science, 257 (2011) 9193-9198.

[64] S. Zheng, F. Yi, Z. Li, Y. Zhu, Y. Xu, C. Luo, J. Yang, C. Wang, Advanced Functional Materials, 24 (2014) 4156-4163.

[65] C. Barchasz, F. Molton, C. Duboc, J.-C. Leprêtre, S. Patoux, F. Alloin, Analytical chemistry, 84 (2012) 3973-3980.

[66] S. Xiong, X. Kai, X. Hong, Y. Diao, Ionics, 18 (2012) 249-254.

[67] K. Kumaresan, Y. Mikhaylik, R.E. White, Journal of The Electrochemical Society, 155 (2008) A576-A582.

[68] S. Chen, X. Huang, H. Liu, B. Sun, W. Yeoh, K. Li, J. Zhang, G. Wang, Advanced Energy Materials, 4 (2014) 1301761. 


\section{NITROGEN-DOPED GRAPHENE NANOSHEETS AND SULFUR COMPOSITE}

\section{BASED CATHODE FOR ROOM-TEMPERATURE SODIUM-SULFUR BATTERY}

\subsection{Introduction}

Over the past two decades, rechargeable lithium-ion batteries have played an important role in portable electronics and electric vehicles [1-3]. However, there is growing concern regarding limited resource and rising price of lithium. Instead, sodium, with high abundance and suitable redox potential $(\sim 2.71 \mathrm{~V})$, could be a cost-effective alternative especially for renewable energy applications where weight and energy density are of minor importance. However, the large atomic size of $\mathrm{Na}^{+}$compared to $\mathrm{Li}^{+}$could introduce higher intercalation barrier when pair with popular graphite anode resulting in poor reversibility. Sulfur, as another abundant element on earth which has high theoretical capacity of $1675 \mathrm{mAh} \mathrm{g}^{-1}$ and high energy density of $2600 \mathrm{Wh} \mathrm{kg}^{-1}$, is becoming one of the most attractive cathode materials to replace traditional transition metal oxide cathodes [4]. In the sodium-sulfur (Na-S) system, the energy density as high as $760 \mathrm{Wh} \mathrm{kg}^{-1}$ can be achieved with reduction of sulfur to $\mathrm{Na}_{2} \mathrm{~S}_{3}$. However, low reactivity between sulfur and sodium leads to low active material utilization, which results in the cell performance with low capacity and energy density. Traditional high temperature Na-S batteries were originally developed by Ford Motor Company in the 1960s and have been widely used by NGK/TEPCO consortium in Japan for load-leveling stationary energy storage and peak-shaving in smart grid since 1980s [5]. These Na-S batteries are operated at temperature $300-350{ }^{\circ} \mathrm{C}$ to achieve low resistance $(2.5 \Omega \mathrm{cm}$ at $350{ }^{\circ} \mathrm{C}$ ) for $\mathrm{Na}^{+}$transfer through beta-alumina solid electrolyte tubes which has been also 
applied as electrical separator with high mechanical strength. However, there is safety concern at this temperature that the molten $\mathrm{S}, \mathrm{Na}$ and polysulfides are highly corrosive and failure of solid electrolyte could lead to fire and explosion. Besides, since the reactants are in liquid state, the reaction products $\mathrm{Na}_{2} \mathrm{~S}_{2}$ and $\mathrm{Na}_{2} \mathrm{~S}$ with high melting points $\left(\mathrm{T}_{\mathrm{m}}=470\right.$ and $1168{ }^{\circ} \mathrm{C}$ for $\mathrm{Na}_{2} \mathrm{~S}_{2}$ and $\mathrm{Na}_{2} \mathrm{~S}$, respectively) cannot be eventually formed, which leads to incomplete reduction reaction [6,7]. Best energy densities of $\sim 200 \mathrm{Wh} \mathrm{kg}^{-1}$ has been commercially achieved on the cell level.

In recent years, on the one hand, room temperature (RT) Li-S batteries have been intensively investigated and several critical issues have been identified [8-10], such as: low utilization of sulfur active material, poor cycle life and low storage efficiency, due to intermediate polysulfides dissolution in electrolytes forming "shuttle" phenomenon, volumetric expansion during cycling and the insulating nature of sulfur. On the other hand, since 2006, few RT Na-S works have been reported and effort has been devoted to achieve acceptable electrochemical performance [11, 12]. It has to be noted that the electrochemistry investigation of RT Na-S cells is still limited and the results are various which may due to the various experimental condition. Since solid beta-alumina electrolyte is not suitable in room temperature due to the low sodium-ion conductivity, RT Na-S batteries is required an electrolyte to ensure sufficient ion transport between $\mathrm{S}$ and $\mathrm{Na}$. Initial strategies have been involved in modifying the electrolytes to obtain high ionic conductivity for enhancing the cell performance, such as gel polymer electrolyte, solid PEO polymer electrolyte, and ether-based electrolyte [13-15]. The liquid electrolyte with sodium salt such as $\mathrm{NaCF}_{3} \mathrm{SO}_{3}$ or $\mathrm{NaClO}_{4}$ promotes the formation of the intermediate products polysulfides during the charge and discharge process. However, 
polysulfide shuttle effect in the electrolyte is becoming the major challenge, which limits the RT Na-S cell performance. Some strategies have been focused on developing advanced cell structures and configurations to prohibit the polysulfide diffusion to $\mathrm{Na}$ electrode, such as applying an ion selective Nafion-coating membrane as a separator [16], inserting a carbon-based interlayer between cathode and separator [17, 18], and using Na$\mathrm{S}$ reduction products(e.g. sodium polysulfide catholytes $\mathrm{or}_{2} \mathrm{Na}_{2} \mathrm{~S}$ ) as cathode materials $[19,20]$. Some works have even combined the strategies to take full advantages, such as applying Nafion-coating separator and polysulfide catholytes at the same time [21, 22]. However, these strategies involved with multi-synthesis procedures and high manufacturing cost. Other series works are employing carbon materials as matrix to improve the utilization of $\mathrm{S}$ and confine the polysulfides. So far as it concerns, the carbon materials conducted in Na-S batteries have been involved with carbon nanofiber, mesoporous carbon, microporous carbon and hard carbon [23-25]. Graphene, with a unique two-dimensional carbon structure, has been widely used in energy storage community since its discovery due to its exceptional electrical conductivity, high theoretical specific surface area, and high mechanical strength [26]. Nitrogen doping (Ndoping) is a simple but useful process for graphene modification because $\mathrm{N}$-doping easily manipulates local electronic structures, allowing for enhanced binding with ions. This feature can be applied in high-capacity energy storages [27, 28]. So far, some works involving with $\mathrm{N}$-doped graphene have been published in Li-ion and Li-S batteries [29$31]$.

In our previous work, we have reported an $\mathrm{N}$-doped graphene nanosheets/sulfur (NGNS/S) composite as cathode in lithium-sulfur batteries. The $\mathrm{N}$ functional groups 
doped on NGNS have been detected as Amino $\mathrm{N}$ and Pyridine N-oxide. In this contribution, we further conducted thermal treatment on the synthesized composite with the aim of encapsulating $\mathrm{S}$ into the graphene layers. By this approach, not only the electrical conductivity of the composite can be improved with anchoring $\mathrm{S}$ onto the graphene layer, but also the expansion between graphene layers by the infusion of sulfur particle can facilitate large size $\mathrm{Na}^{+}$transport to improve the cell efficiency, as shown in Figure 3.1. Meanwhile, the defects and active sites induced by $\mathrm{N}$ functional groups on NGNS have an impact on immobilization of polysulfides to avoid shuttle effect. It has to be noted that $\mathrm{S}$ loading is one of the crucial factors on the electrochemical performance. One of the Na-S studies revealed that the electrochemical performance turned out to be inferior when the sulfur content increased to $48 \%$. S loading below a certain level is beneficial for a good performance [23]. In this study, sulfur was combined with NGNS in high and low weight ratios. After electrochemical evaluation of both loadings, it can be concluded that low S loading NGNS/S composite exhibits a better electrochemical performance with capacity retention, cycle life and rate capability in comparison of high S loading NGNS/S composite. After 300 cycles testing, there is still acceptable capacity of $48 \mathrm{mAh} \mathrm{g}^{-1}$ existing and the Coulombic efficiency remained at $100 \%$. This study suggests that sulfur composite with certain level content and unique interior nanostructures can make a promising progress to develop high performance RT Na-S batteries. 


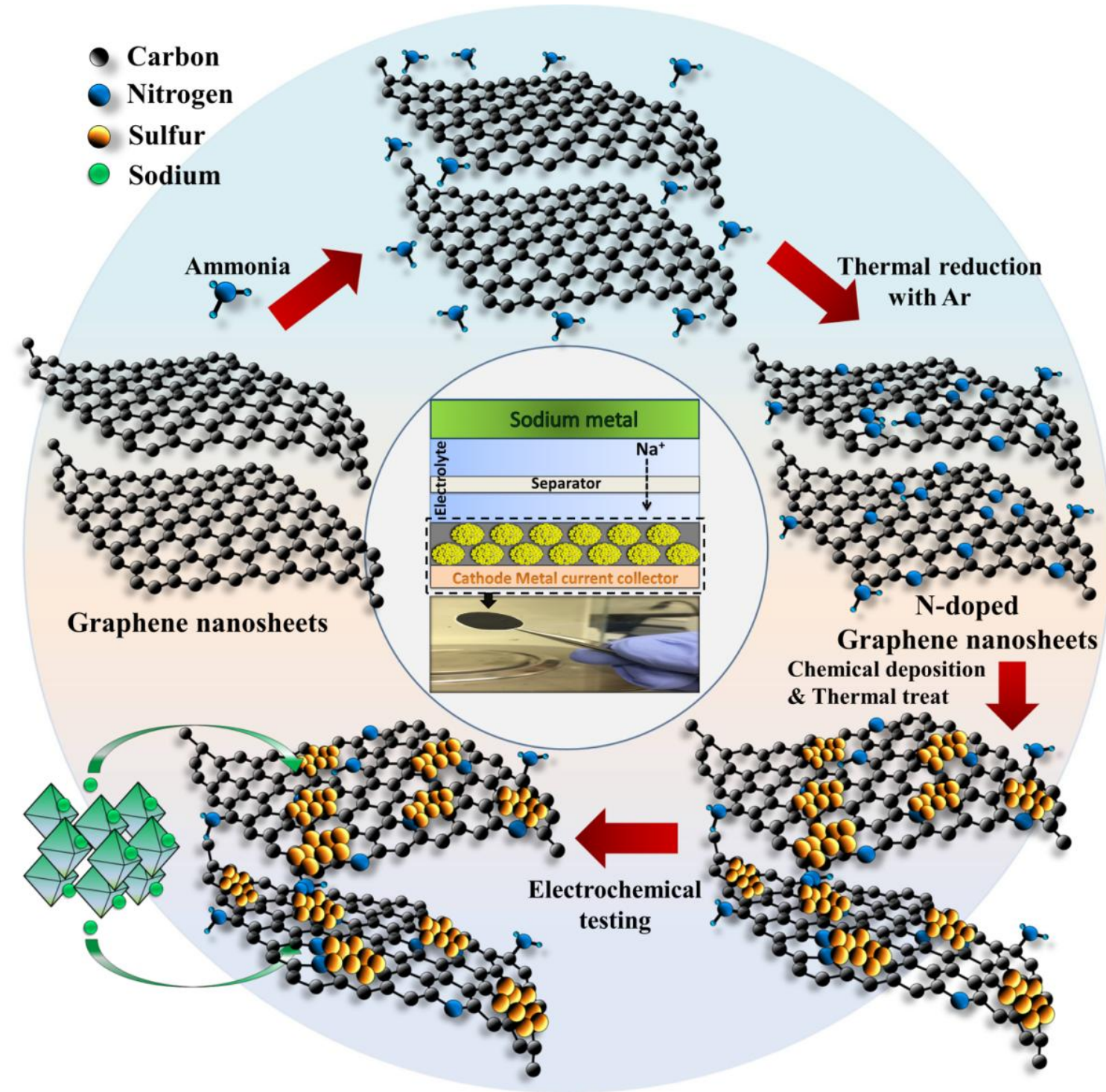

Figure 3.1 Schematic illustration of Nitrogen-doped Graphene nanosheets/Sulfur nanocomposites preparation and electrochemical testing as cathode material in roomtemperature Sodium-Sulfur batteries and typical room-temperature sodium-sulfur batteries configuration with actual working electrode photo (middle).

\subsection{Experimental Section}

\subsubsection{Preparation of NGNS}

The process of synthesizing NGNS is the same as our previous reported work.

First, graphite oxide was obtained by the oxidation of natural graphite in a modified 
Hummers method. Then, the thermal exfoliation of graphite oxide was conducted at 1050 ${ }^{\circ} \mathrm{C}$ for 30 s under nitrogen atmosphere to obtain graphene nanosheets (GNS). NGNS were prepared by treating the pristine GNS at the mixed gas of ammonia and argon at $900{ }^{\circ} \mathrm{C}$ for $5 \min [32-34]$.

\subsubsection{Preparation of NGNS/S nanocomposite}

NGNS/S nanocomposite was synthesized by a facile chemical reaction deposition method as our previous work and followed by low temperature heat treatment as one of the Li-S batteries works [35]. First, $3.16 \mathrm{~g} \mathrm{Na}_{2} \mathrm{~S}_{2} \mathrm{O}_{3}$ was dissolved in $500 \mathrm{ml}$ distilled water, followed by magnetic stirring for 30 minutes to prepare $0.04 \mathrm{M} \mathrm{Na} \mathrm{S}_{2} \mathrm{O}_{3}$ solution. Next, the as-synthesized NGNS ( 75 $\mathrm{mg}$ and $\sim 4 \mathrm{mg}$ ) were dispersed in the separately above solution (each $250 \mathrm{ml}$ ) to produce composites with low and high sulfur content loadings. The mixture was under sonication in an ice bath for $1 \mathrm{~h}$. To initiate precipitation of S homogeneously, $20 \mathrm{ml} \mathrm{10M}$ hydrochloric acid was dropped into the solution and it was continuously stirred. After stirring for $24 \mathrm{~h}$ to let the reaction proceed completely, the product was filtered and washed with distilled water several times to eliminate salt products as well as until $\mathrm{pH}$ reached 7 and finally dried in a vacuum oven at $60{ }^{\circ} \mathrm{C}$ for 24 h. After this, the as-synthesized samples moved into glove box and sealed in a vessel with Argon atmosphere. Next, the vessel was put into tube furnace, and heat treated under flowing argon with the controlled flow rate of $\sim 200 \mathrm{cc} \mathrm{s}^{-1}$ at $155^{\circ} \mathrm{C}$ for $12 \mathrm{~h}$. The heating rate was $5{ }^{\circ} \mathrm{C} \mathrm{min}^{-1}$. The final products of low and high $\mathrm{S}$ loading $\mathrm{NGNS/S}$ nanocomposite are referred as NGNS/S-H25 and NGNS/S-H86, respectively. Pristine S were also prepared with the same procedures and followed by the heat treatment as the 
same condition as NGNS/S. NGNS was under the heat treatment as well and refer as NGNSH. Both S and NGNSH were used as control samples.

\subsubsection{Characterization}

The crystal structure characterization of S, NGNSH, GNS and NGNS/S nanocomposites was examined by the X-ray diffraction (XRD) using a Siemens 500D X-ray Diffractometer with $\mathrm{Cu} \mathrm{K} \alpha$ radiation between 10 and $90^{\circ}$ at a scan rate of $2^{\circ} \min ^{-1}$. The chemical composition of GNS was determined by X-ray photoelectron spectroscopy (XPS) measurements with a Kratos Axis Ultra Al $(\alpha)$ X-ray photoelectron spectroscopy at $14 \mathrm{kV}$. The microstructure and morphology of NGNSH and NGNS/S nanocomposites were carried out by using a JEOL FE6330 field-emission scanning electron microscope (SEM) and a Phillips CM-200 Transmission Electron Microscope (TEM). The composition of the NGNS/S nanocomposite was analyzed by energy dispersive X-ray spectroscopy (EDS) attached on SEM. More detailed surface information was obtained by nitrogen adsorption/desorption isotherms at $77 \mathrm{~K}$ and calculated by Brunauer-EmmettTeller (BET) measurements using a TriStar II Micromeritics. The thermogravimetric analysis (TGA) was conducted by a SDT Q600 (USA) under nitrogen protection at a heating rate of $10^{\circ} \mathrm{C} / \mathrm{min}$ from room temperature to $450^{\circ} \mathrm{C}$.

\subsubsection{Electrochemical measurement}

CR2032-type coin cells were used for electrochemical characterization with the electrode materials of S, NGNSH, NGNS/S-H25 and NGNS/S-H86. The working electrodes were constructed from 70 wt. \% electrode materials, 15 wt. \% poly(vinylidene difluoride) (PVDF) binder, and 15 wt. \% Super P Li in an N-methyl-2-pyrrolidinone (NMP) solution. The well mixed slurry was uniformly tape casted onto the aluminum foil current 
collectors and the films were dried in an oven at $60{ }^{\circ} \mathrm{C}$ for $12 \mathrm{hrs}$. The coin cells were assembled in an argon-filled glove box with sodium metal as the counter and reference electrodes, and Celgard 2400 polypropylene film was used as the separator. The electrolyte was $0.8 \mathrm{NaClO}_{4}$ in $1: 1 \mathrm{v} / \mathrm{v}$ ethylene carbonate (EC) and diethyl carbonate (DEC) mixed solvent. The cyclic voltammetry (CV) data were collected with a biologic VMP3 at a scan rate of $0.1 \mathrm{mV} \mathrm{s}^{-1}$ at $1.0-3.0 \mathrm{~V}\left(\mathrm{vs} . \mathrm{Na} / \mathrm{Na}^{+}\right.$). Galavanostatic charge/discharge profiles along with cyclability and rate capability were conducted with constant current densities of $\mathrm{C}$ rates based on $\mathrm{S}\left(1 \mathrm{C}=1675 \mathrm{~mA} \mathrm{~g}^{-1}\right)$ at a cut-off potential of $1.0-3.0 \mathrm{~V}$ (vs. Na/Na ${ }^{+}$) under room temperature by Neware BTS-610 instrument. Electrochemical impedance spectroscopy (EIS) was conducted on the VMP3 in the frequency range from $100 \mathrm{kHz}$ to $10 \mathrm{mHz}$ with an input $\mathrm{AC}$ voltage amplitude of $10 \mathrm{mV}$. 3.3 Results and Discussion

SEM and TEM were used to characterize the morphology and structure of NGNSH and NGNS/S nanocomposites, as shown in Figures 3.2, 3.3 and 3.4. Figure 3.2a displays the morphology of NSNSH which was random planar sheets agglomerated as the disordered particles. From Figure 3.2a inset, it can be clearly observed that NGNSH layers are stacked together. The TEM image (Figure 3.2b) of NGNSH substrates shows a layered, two-dimensional structure. These thin and flexible planar sheets with the feature of high surface/volume ratio could provide a benefit for sulfur to disperse and enough spacing to buffer the strain from the volume change of $S$ during the cycling process. From Figure 3.2c, NGNS/S-H25 nanocomposite is generated with NGNS and sulfur to form 3d hierarchical voile-like structure. However, there is no observation of agglomerated sulfur particles or crystalline sulfur on the planar sheets. This phenomenon 
has also been proved by NGNS/S-H86 (Figure 3.4a). However, EDS results reveal the presence of element sulfur in the NGNS/S-H25 and NGNS/S-H86 (Figure 3.3d and 3.4c).
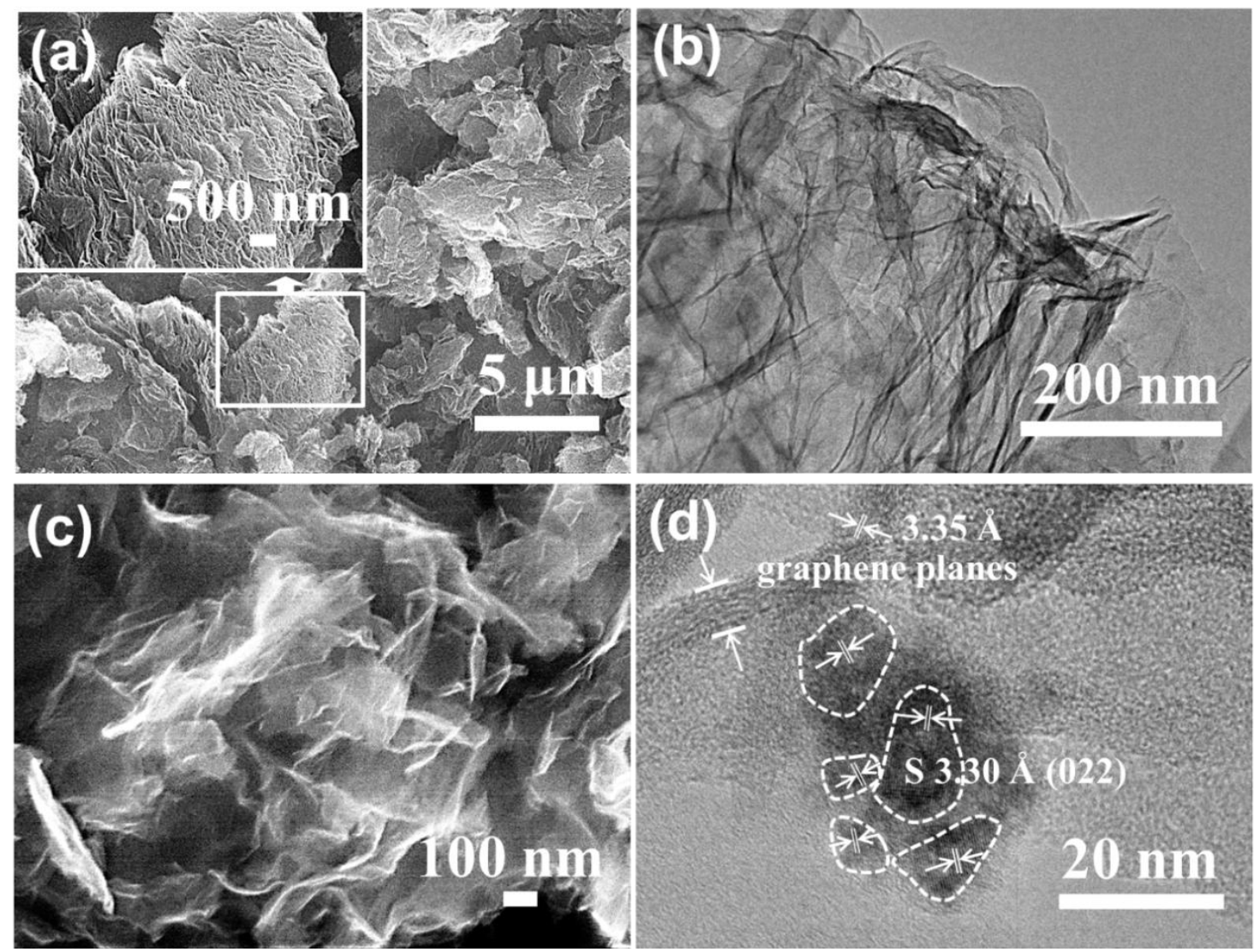

Figure 3.2 SEM images of (a) NGNSH, inset represents a typical layered structure of NGNSH and (c) NGNS/S-H25, (b) TEM image of NGNSH and (d) HRTEM image of NGNS/S-H25, respectively.

The EDS elemental mapping verifies that sulfur has formed well dispersed nanoparticles, indicating that sulfur has homogeneously spread throughout the NGNS due to the heat treatment process. To confirm the particle size of $\mathrm{S}$, high-resolution TEM has been conducted on NGNS/S-H25 nanocomposite, as shown in Figure 3.2d. It can be seen that one $S$ cluster attached to the graphene layer consists of five $S$ particles with the average size of $\sim 10 \mathrm{~nm}$. The measured lattice fringe with an interplanar distance of $3.30 \AA$ comes from (022) plane of monoclinic $S$. 


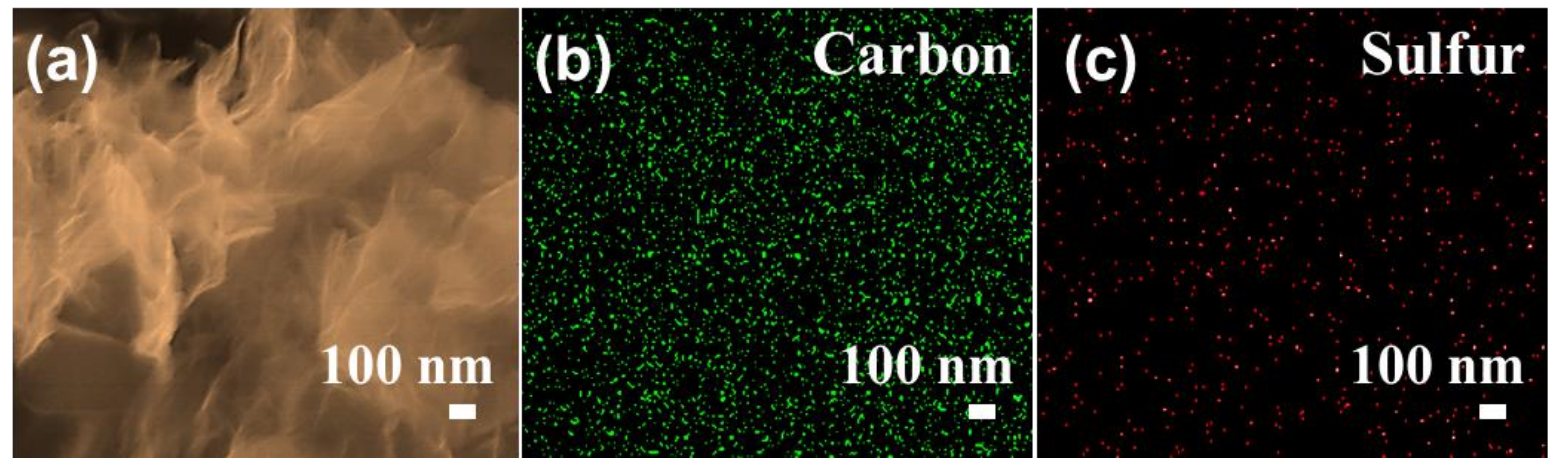

Figure 3.3 (a) SEM image of NGNS/S-H25 and corresponding EDS element mapping of (b) Carbon and (c) Sulfur.
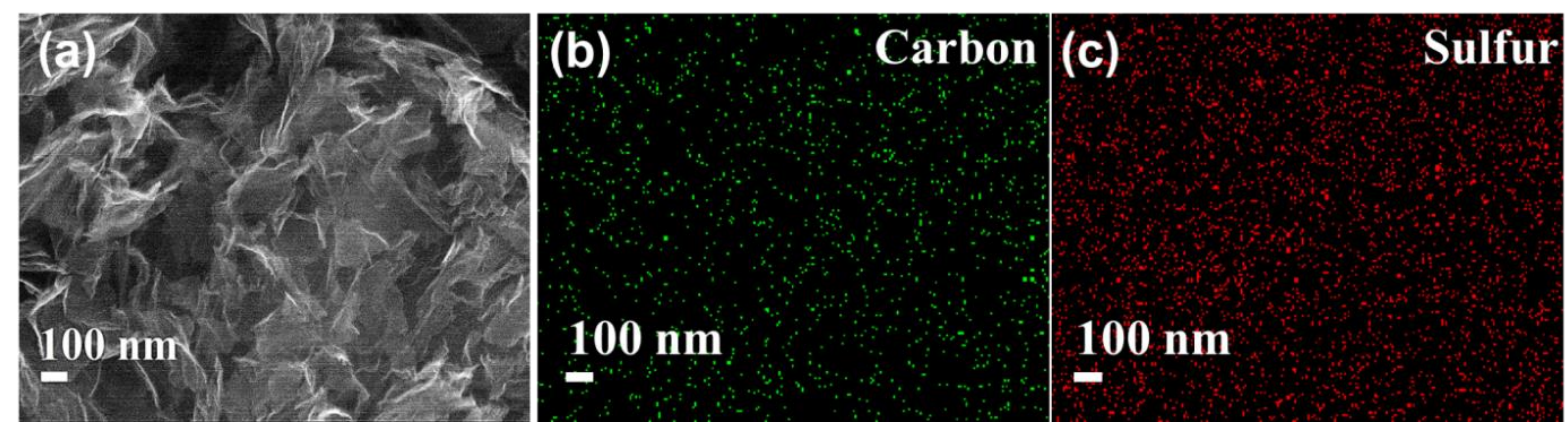

Figure 3.4 (a) SEM image of NGNS/S-H86 and corresponding EDS element mapping of (b) Carbon and (c) Sulfur.

The XRD patterns of S, GNSs, NGNS, as-synthesized NGNS/S-H25 and NGNS/S-H86 nanocomposites are presented in Figure 3.5. It is observed that the neat GNS exists a broad diffraction peak around $24^{\circ}$, corresponding to the characteristic $(002)$ diffraction peak of multi-layered graphene. Nevertheless, the pattern of NGNSH reveals the (002) peak position around $26^{\circ}$, showing that the peak position of NGNSH changed a little compared with GNS. This may be demonstrated that the nitrogen defect sites were doped into the GNS during the ammonia corrosion treatment process. This peak position movement can be observed on the pattern of NGNS/S-H25 as well. The XRD pattern of 


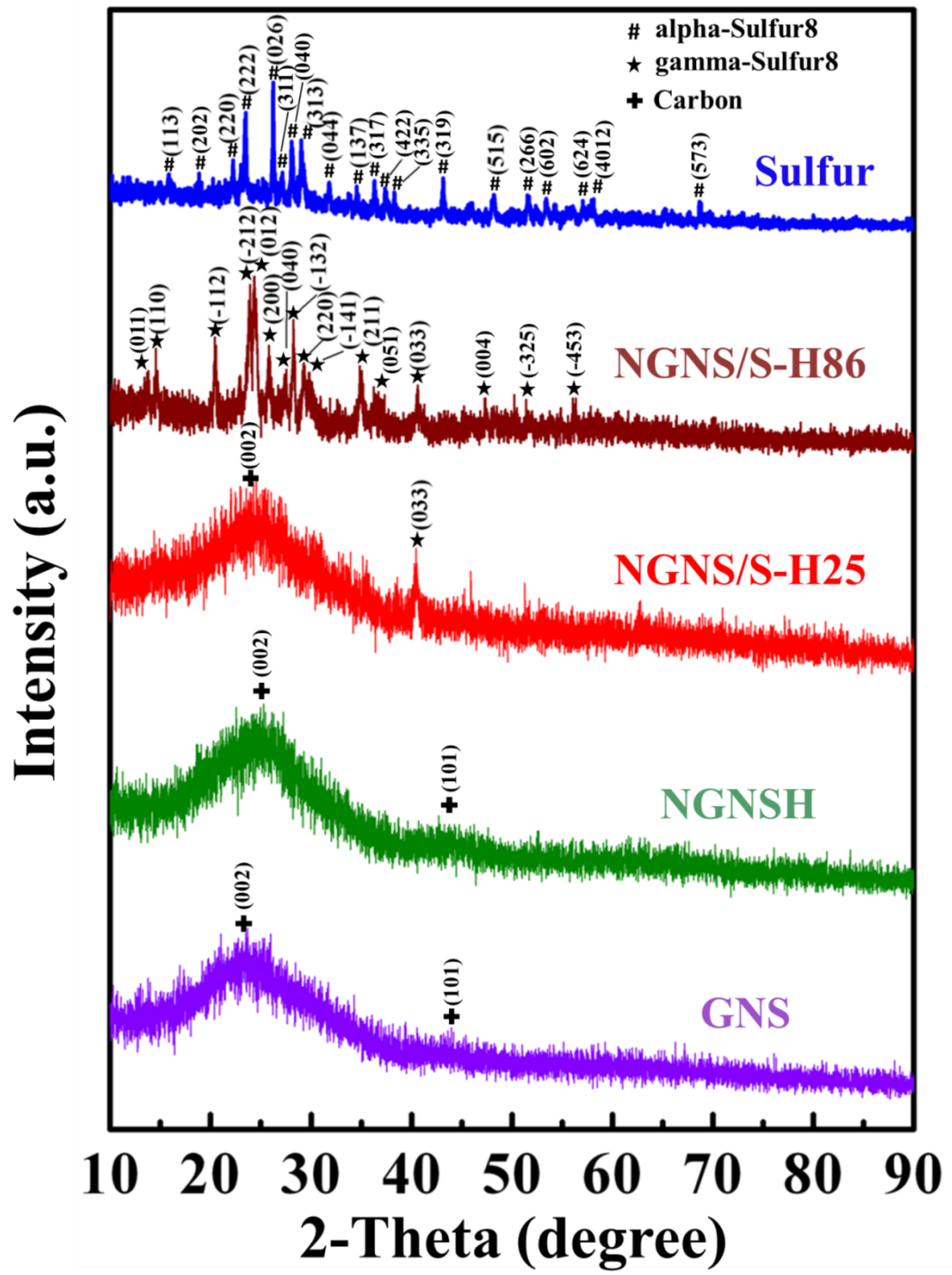

Figure 3.5 XRD patterns of GNS, NGNSH, NGNS/S-H25 nanocomposites, NGNS/SH86 nanocomposites and Sulfur, respectively. 
heat-treated sulfur generally exhibits a series of sharp and strong peaks, indicating a welldefined Fddd orthorhombic crystalline structure of alpha-Sulfur8 (JCPDS\#: 00-0080247). In comparison with sulfur, the NGNSs/S-H86 nanocomposite shows sharp peaks as well. However, most of the peaks have moved the position comparing with the sulfur pattern and based on the peak positions, it reveals that the sulfur particles in NGNSs/SH86 nanocomposite can be assigned to gamma-Sulfur8 with P2/c monoclinic crystalline structure (JCPDS\#: 01-071-0396). This phase transformation of sulfur can be attributed to the heat treatment and structural confinement of NGNS. Crystalline alpha-sulfur mostly converts to gamma-sulfur during this thermal progress and NGNS prohibits gamma-sulfur transferring back to alpha-sulfur during the cool down process. From XRD pattern of NGNS/S-H25, a major peak can be observed at $26^{\circ}$ which is assigned to (002) NGNS peak. Besides, only one sulfur peak is shown up which is matching (033) peak of gamma-Sulfur8, proving that the sulfur as gamma phase existing in NGNS/S-H25 nanocomposite as well. With the changing of XRD peak position, it can be concluded that 1) Nitrogen has been successfully doped in the NGNS layers. 2) Sulfur would be expected to melt and diffuse into layers with small particles, dispersed within the conductive matrix and occupy the nitrogen defect active sites of NGNS based on the observation of phase transformation of S. This progress may create certain interactions between the active sites on NGNS and the sulfur particles. 

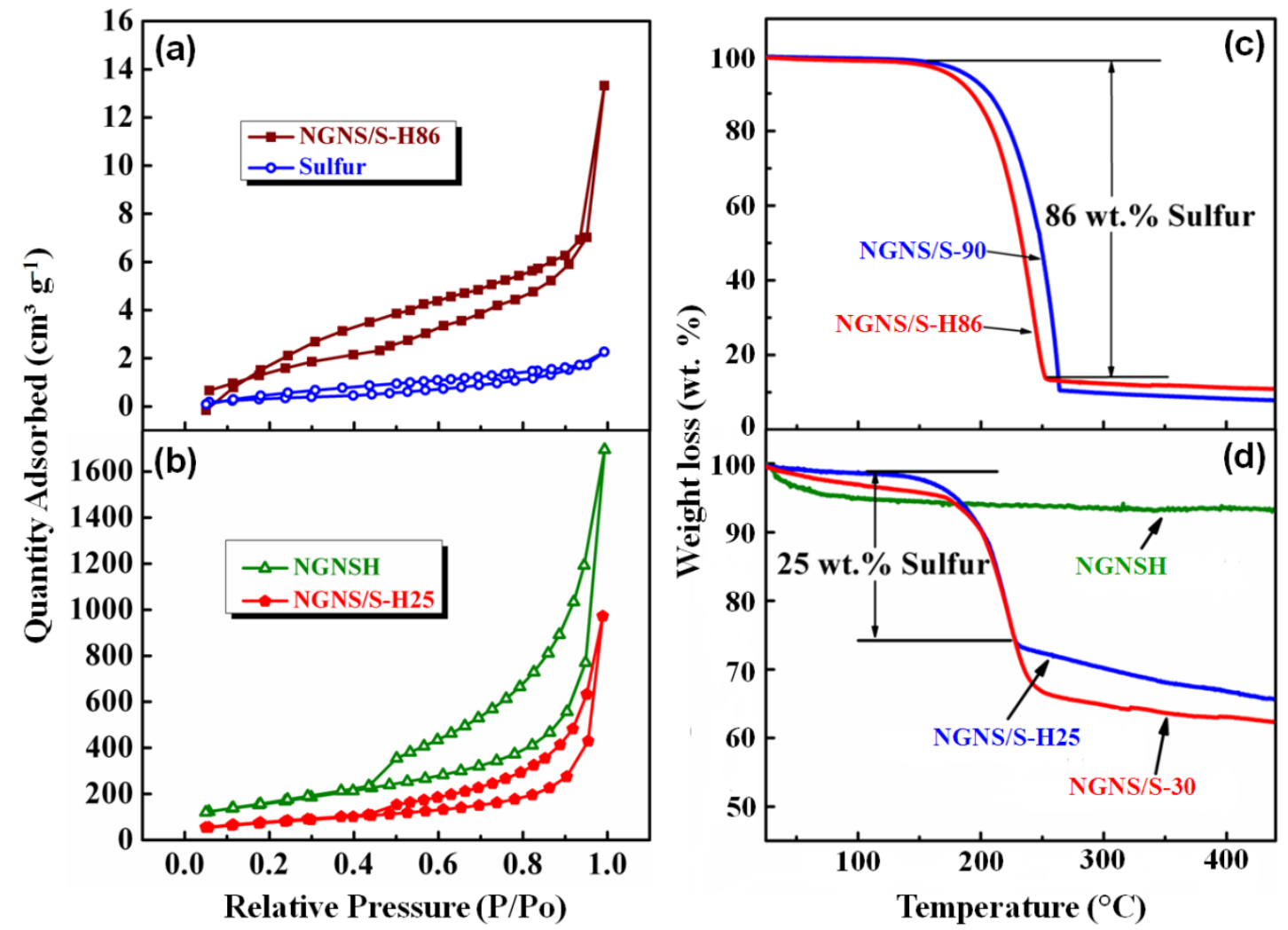

Figure 3.6 $\mathrm{N}_{2}$ adsorption-desorption isotherms of (a) NGNS/S-H86 and Sulfur, and (b) NGNSH and NGNS/S-H25, respectively. TGA analysis of (c) NGNS/S-H86 and NGNS/s-90, and (d) NGNSH, NGNS/S-H25, and NGNS/S-30, respectively.

Figure 3.6a and 3.6b show the surface area measurement results of NGNS/S-H86, sulfur, NGNSH and NGNS/S-H25, respectively. In Figure 3.6a, from the high loading level, the NGNS/S-H86 nanocomposite exhibits a surface area of $6.5 \mathrm{~m}^{2} \mathrm{~g}^{-1}$. This number is in the level with the surface area of sulfur, which is $1.2 \mathrm{~m}^{2} \mathrm{~g}^{-1}$. On the other hand, for NGNSH in Figure 3.6b, the surface area is around $570 \mathrm{~m}^{2} \mathrm{~g}^{-1}$. This large surface area supplies a promising space for the loading of sulfur and volume expansion during cycling. After low sulfur loading, the surface area of NGNS/S-H25 nanocomposite was calculated to be $272 \mathrm{~m}^{2} \mathrm{~g}^{-1}$. This decrease of surface area after sulfur loading confirms that the low loading sulfur content partially occupies the surface of NGNS layers. To 
further confirm the weight percentages of the synthesized samples, TGA was carried out in the temperature range of $25-450{ }^{\circ} \mathrm{C}$. It can be observed from Figure $3.6 \mathrm{c}$, the weight loss of prepared high S loading sample NGNS/S-90 is $90 \mathrm{wt}$ \% in the case of before heat treatment. After heat treatment, the high S loading content has been changed to $86 \mathrm{wt} . \%$. In Figure 3.6d, it can be observed that the NGNSH has a weight loss of 5 wt. \% with the temperature increasing process, which is due to the moisture evaporation. The low sulfur loading content has been obtained with 25 wt. \% for NGNS/S-H25 nanocomposite, comparing with $30 \mathrm{wt}$. \% of sulfur loading in the same sample before heat treatment.

(a)
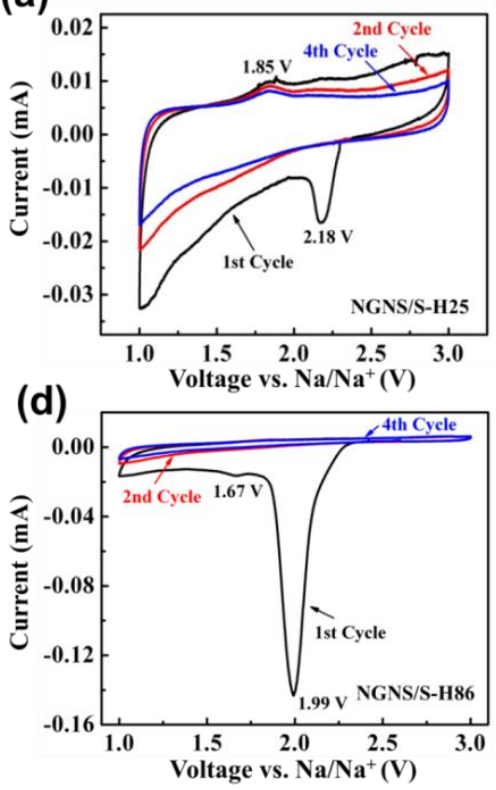

(b)
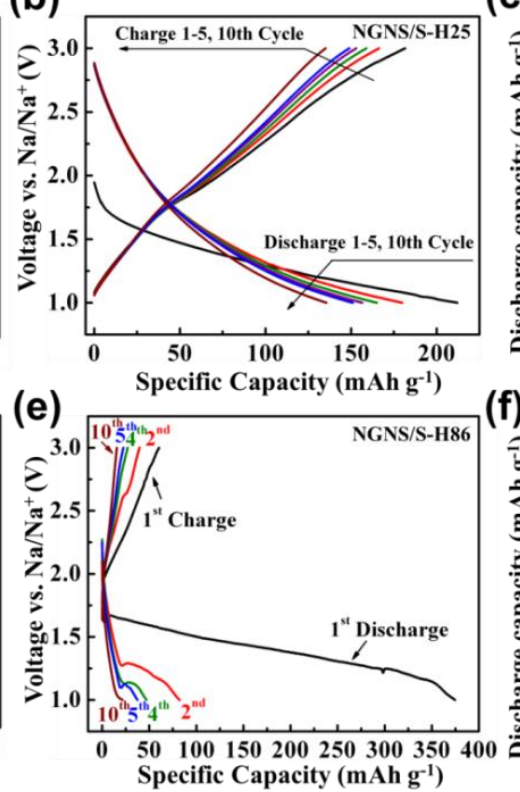
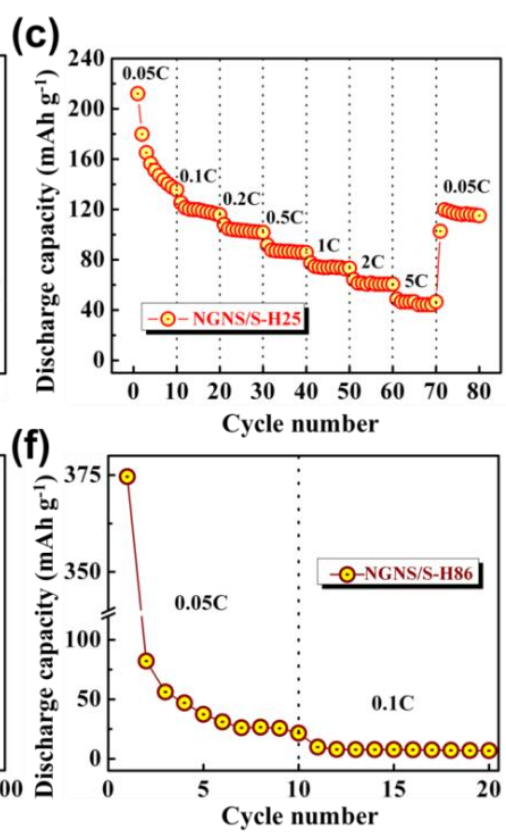

Figure 3.7 Electrochemical performance of NGNS/S-H25 and NGNS/S-H86 electrodes. CVs of (a) NGNS/S-H25 and (d) NGNS/S-H86 at a scan rate of $0.1 \mathrm{mV} \mathrm{s}^{-1}$ between 1.0 and $3.0 \mathrm{~V}$ vs. Na/Na ${ }^{+}$; Galvanostatic discharge/charge profiles of (b) NGNS/S-H25 and (e)NGNS/S-H86 at $0.05 \mathrm{C}$; Rate performances of (c) NGNS/S-H25 at various $\mathrm{C}$ rates and (f) $\mathrm{NGNS} / \mathrm{S}-\mathrm{H} 86$ at $0.05 \mathrm{C}$ and $0.1 \mathrm{C}$.

Half cells were prepared to evaluate the electrochemical performance of NGNS/S nanocomposites along with control samples of S (Figure 3.9) and NGNSH (Figure 3.8) in 
RT Na/S batteries. Figure 3.7a shows the CV profiles of the NGNS/S-H25 cathode for the initial 1st, 2nd and 4th cycles between 1.0-3.0 V (vs. Na/Na' ${ }^{+}$. From the 1st cycle, it can be observed that there is a sharp cathodic peak at potential of $2.18 \mathrm{~V}$. This is attributed to the formation of long chain polysulfides $\mathrm{Na}_{2} \mathrm{~S}_{\mathrm{n}}(4 \leq \mathrm{n} \leq 8)$ [14]. In the reverse oxidation process, there is an anodic peak appearing at $1.85 \mathrm{~V}$, indicating that $\mathrm{Na}_{2} \mathrm{~S}$ has been oxidized during this process. After the current sweeps back to the reduction progress, it is barely observed the cathodic peak, this may be due to the relatively large sizes of $\mathrm{Na}^{+}$and less efficient $\mathrm{Na}^{+}$diffusion into the cathode framework compared with the 1 st cycle. This similar phenomenon has been observed in a Phosphorus/Graphene anode for Na-ion batteries work as well [36]. However, from the 2nd to 4th cycles, the anodic peaks still exist, which suggests that the redox reaction still continues on the cathode side with cycling. Figure $3.7 \mathrm{~b}$ exhibits the charge/discharge profiles of NGNS/S-H25 at $0.05 \mathrm{C}$. It can be observed that in the 1 st cycle, charge/discharge capacities have been reached $212 \mathrm{mAh} \mathrm{g}^{-1}$ and $181 \mathrm{mAh} \mathrm{g}^{-1}$, respectively, in the voltage window of $1.0-3.0 \mathrm{~V}$ vs. $\mathrm{Na} / \mathrm{Na}^{+}$. From the discharge curves, there is no obvious plateau observed. From the charge curves, it can be examined that there is an oxidation plateau shown at $1.85 \mathrm{~V}$, which is consistent with the $\mathrm{CV}$ analysis as mentioned above. The rate capability testing of NGNS/S-H25 is shown in Figure 3.7c, several current rates were conducted from $0.05 \mathrm{C}$ to $5 \mathrm{C}$ and each rate was within 10 cycles. In each c-rate process, the discharge capacities at the 10th cycle are 136, 116, 102, 86, 73, 61 and $46 \mathrm{mAh} \mathrm{g}^{-1}$ at discharge rates of $0.05 \mathrm{C}, 0.1 \mathrm{C}, 0.2 \mathrm{C}, 0.5 \mathrm{C}, 1 \mathrm{C}, 2 \mathrm{C}$ and $5 \mathrm{C}$, respectively. During the 1 st cycle at $0.2 \mathrm{C}$, the discharge and charge capacities are 108 $\mathrm{mAh} \mathrm{g}^{-1}$ and $105 \mathrm{mAh} \mathrm{g}^{-1}$, respectively. These capacity values are substantially larger 
than on reported Na-ion batteries work with the values of $101 \mathrm{mAh} \mathrm{g}^{-1}$ delivered by an $\mathrm{N}$ doped carbon coating $\mathrm{Na}_{3} \mathrm{~V}_{2}\left(\mathrm{PO}_{4}\right)_{3}$ electrode at $0.2 \mathrm{C}$ [37]., it can be seen that the capacity shows a good retention in each rate from $0.1 \mathrm{C}$. It has to be noted that when the rate turns back to $0.05 \mathrm{C}$, the specific capacity recovers to $115 \mathrm{~mA} \mathrm{~g}^{-1}$ at the 80 th cycle, indicating that NGNS/S composite around 25 wt. \% sulfur ratio presents a stable rate capability. The electrochemical performance of control sample NSNSH is shown in Figure 3.8, testing as the same procedures as NGNS/S-H25. In Figure 3.8c, the rate capability of NGNSH shows the discharge capacities of $9,6,5,3,0.5,0.5$ and $0.6 \mathrm{~mA} \mathrm{~h}$ $\mathrm{g}^{-1}$ at the 10 th cycle of $0.05 \mathrm{C}, 0.1 \mathrm{C}, 0.2 \mathrm{C}, 0.5 \mathrm{C}, 1 \mathrm{C}, 2 \mathrm{C}$ and $5 \mathrm{C}$, respectively. The specific capacity recovers to $7 \mathrm{mAh} \mathrm{g}^{-1}$ as rate sets back to $0.05 \mathrm{C}$ as well. The NGNS/SH25 presents a much higher capacity than NGNSH.

(a)

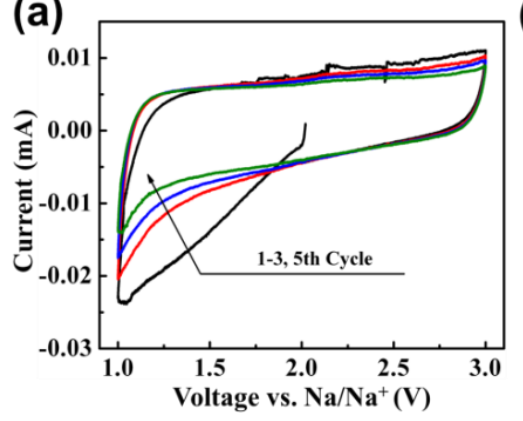

(b)

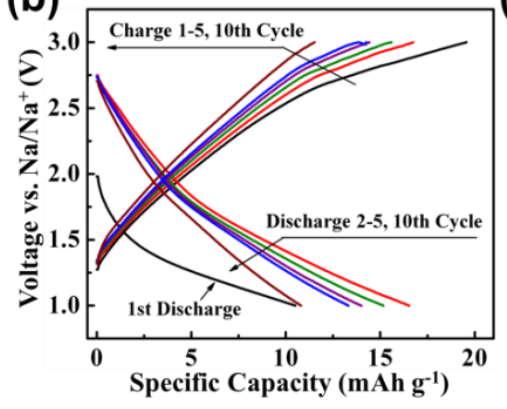

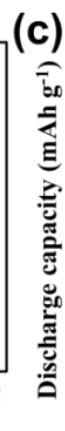

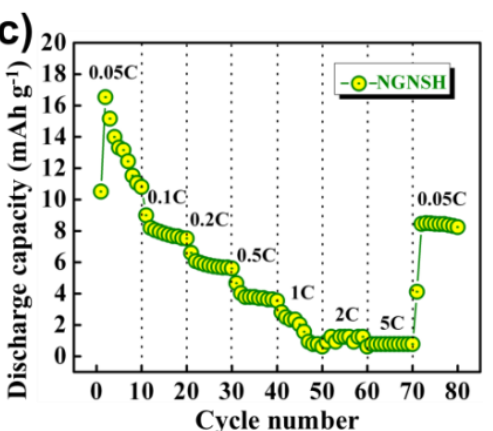

Figure 3.8 Electrochemical performance of NGNSH electrodes in Na-S cells: (a) cyclic voltammograms at a scan rate of $0.1 \mathrm{mV} \mathrm{s}^{-1}$ between 1.0 and $3.0 \mathrm{~V}$, (b) discharge/charge profile at a current rate of $0.05 \mathrm{C}$ and (c) rate capability at various current rates. 

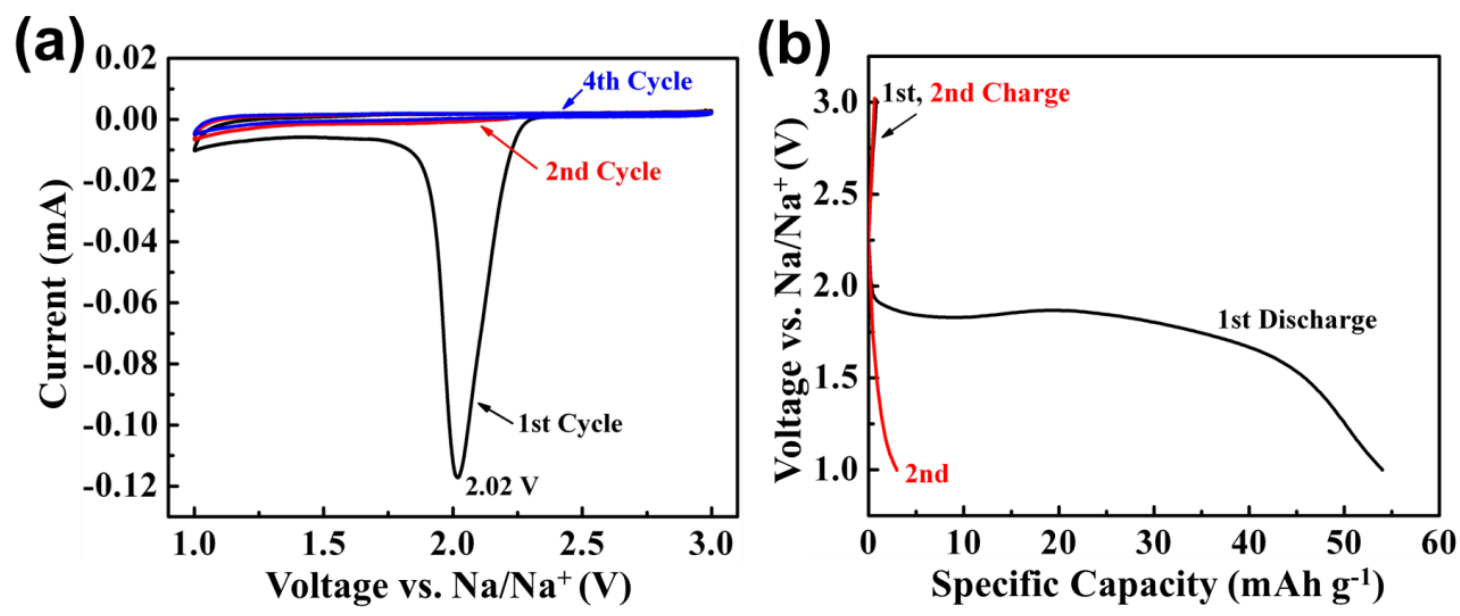

Figure 3.9 Electrochemical performance of $\mathrm{S}$ electrodes in Na-S cells: (a) cyclic voltammograms at a scan rate of $0.1 \mathrm{mV} \mathrm{s}^{-1}$ between 1.0 and $3.0 \mathrm{~V}$ and (b) discharge/charge profile at a current rate of $0.05 \mathrm{C}$.

The electrochemical performances of NGNS/S-H86 are presented in Figure 3.7d3.7f. Figure 3.7d shows the CV profile of NGNS/S-H86 in the 1st, 2nd and 4th cycles. During the cathodic process of the 1st cycle, there is one strong reduction peak observed at $1.99 \mathrm{~V}$. This reduction peak may be assigned to the reduction reaction of long chain polysulfides $\mathrm{Na}_{2} \mathrm{~S}_{\mathrm{n}}(4 \leq \mathrm{n} \leq 8)$ formation [17]. There is a small reduction peak observed at $1.67 \mathrm{~V}$. It may be attributed to the long chain polysulfides transfer to short chain polysulfides $\mathrm{Na}_{2} \mathrm{~S}_{\mathrm{n}}(2 \leq \mathrm{n}<4)$ or to the sulfides $\left(\mathrm{Na}_{2} \mathrm{~S}\right)$ [18]. During the anodic process of first cycle, there is no oxidation peaks shown up on the curve. For the following cathodic sweep, the reduction peaks cannot be observed which is consistent to the $\mathrm{CV}$ results of NGNS/S-H25. There is no oxidation peaks as well. Further investigation needs to be conducted on the redox process between $\mathrm{Na}$ and $\mathrm{S}$. In Figure 3.7e, the galvanostatic charge/discharge profile of NGNS/S-H86 composite cathode depicts the 1st, 2nd, 4th, 5th and 10 th cycles at a current rate of $0.05 \mathrm{C}$. A typical plateau is observed during the first discharge cycle, which is assigned to the formation of sodium polysulfides. A high 
discharge capacity of $375 \mathrm{mAh} \mathrm{g}^{-1}$ was obtained. During the second cycle, the discharge capacity decreases dramatically to $82 \mathrm{mAh} \mathrm{g}^{-1}$, nevertheless, there are plateaus observed on both charge $(2.63 \mathrm{~V})$ and discharge $(1.25 \mathrm{~V})$ curves, indicating that $\mathrm{Na}, \mathrm{S}$ and sodium polysulfides are converting during the cycling. For the following 4th, 5th and 10 th cycles, there are small plateaus existing on the discharge curves, revealing that $\mathrm{S}$ is continuously reduced to polysulfides. However, the reaction potential is getting lower and the capacities decrease during cycling. This may be due to the dissolution of polysulfides in the electrolyte and their shuttle between the electrodes [6]. From rate capability performance of NGNS/S-H86 in Figure 3.7f, it can be observed that at $0.05 \mathrm{C}$, the obtained capacities of NGNS/S-H86 decrease within the initial 6 cycles of 10, and it turns to be stable at $\sim 25 \mathrm{mAh} \mathrm{g}^{-1}$ in the following cycles. At $0.1 \mathrm{C}$ rate, the capacities values drop to $\sim 5 \mathrm{mAh}^{-1}$. From the above electrochemical performance analysis of NGNS/SH86, it can be concluded that the high loading of sulfur promotes the sulfur loss during the cycles and the $\mathrm{N}$-doped active sites on graphene could not prevent the dissolution of polysulfide efficiently.

Table 3.1 Fitting results of the Nyquist plots.

\begin{tabular}{ccccc}
\hline Sample & Cycle Number & $\mathbf{R}_{\mathbf{e}}[\mathbf{\Omega}]$ & $\mathbf{R}_{\mathbf{f}}[\mathbf{\Omega}]$ & $\mathbf{R}_{\mathbf{c t}}[\mathbf{\Omega}]$ \\
\hline \multirow{2}{*}{ NGNS/S-H25 } & 0 & 10.7 & 441.5 & 478.6 \\
& 300 & 3.0 & 398.4 & 6.5 \\
NGNS/S-H86 & 0 & 15.2 & 27219 & 309.5 \\
& 300 & 67.5 & 1739 & 9.0 \\
\hline
\end{tabular}




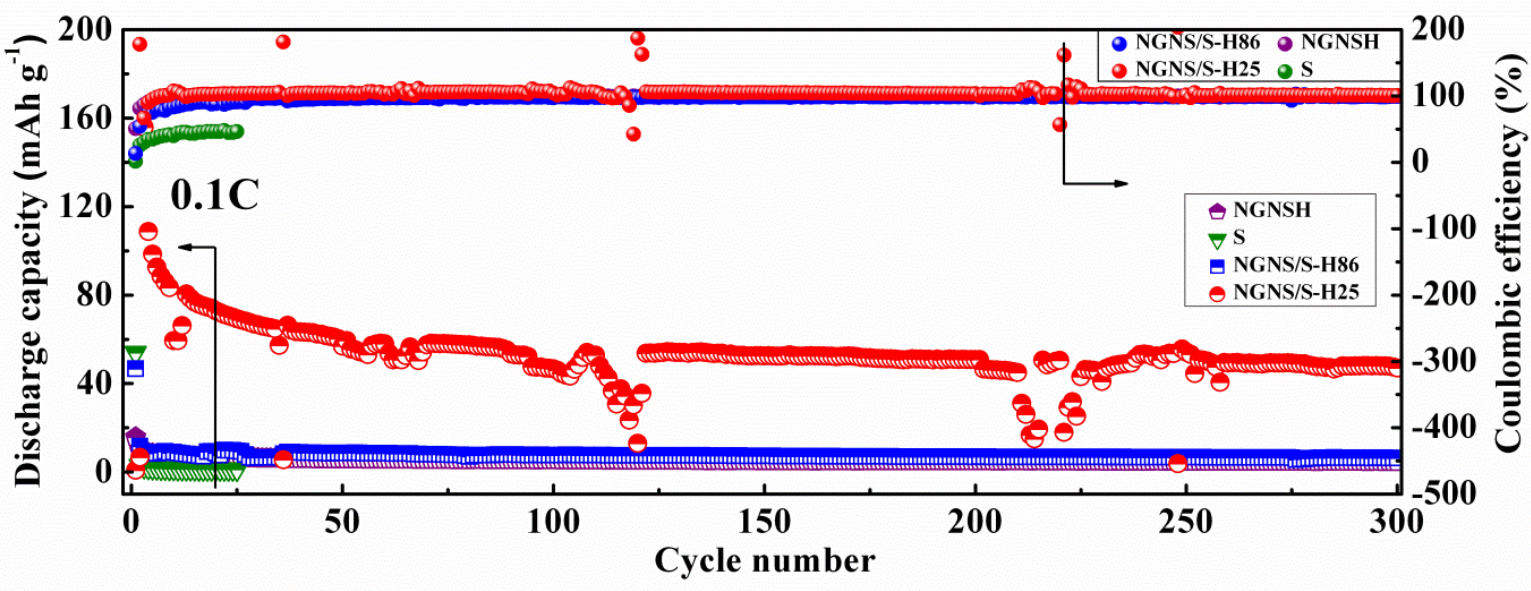

Figure 3.10 Cycling performances and Coulombic efficiencies of NGNSH, S, NGNS/SH86 and NGNS/S-H25 electrodes at 0.1C, respectively.

To further investigate the electrochemical performance, cycling test has been carried out on NGNSH, S, NGNS/S-H86 and NGNS/S-H25, respectively, as shown in Figure 3.10. It can be observed that the NGNS/S-H25 composite electrode exhibits a better cycling performance upon 300 cycles at $0.1 \mathrm{C}$ compared with other electrode materials. There is a relatively high discharge capacity retention of $48 \mathrm{mAh} \mathrm{g}^{-1}$ and high Coulombic efficiency of $100 \%$ retaining at the 300 th cycle. The performance obtained in this work is attributed to the following factors: First, the NGNSs provide a conductive network for anchoring the small sulfur particles. Intimate contact of insulating sulfur was established with the conductive NGNS. Second, there is enough accommodation space providing between the interlayer graphene to reserve for the volumetric expansion of sulfur during cycling and the established porous network affords rapid sodium ion transfer to the active material as well. This also provides more surface contact area between active material and electrolyte, accelerating the electrochemical reactions, and further increases the charge/discharge efficiency. Thirdly, the functional groups and $\mathrm{N}$ - 
doped active sites of NGNS interlinked strongly with sulfur and trap to stable intermediate polysulfides during the cycling, minimizing the mass loss of the active material. Thus, we can conclude that this good electrochemical performance of NGNS/S$\mathrm{H} 25$ is the output of the synergic contribution between NGNS and S particles.
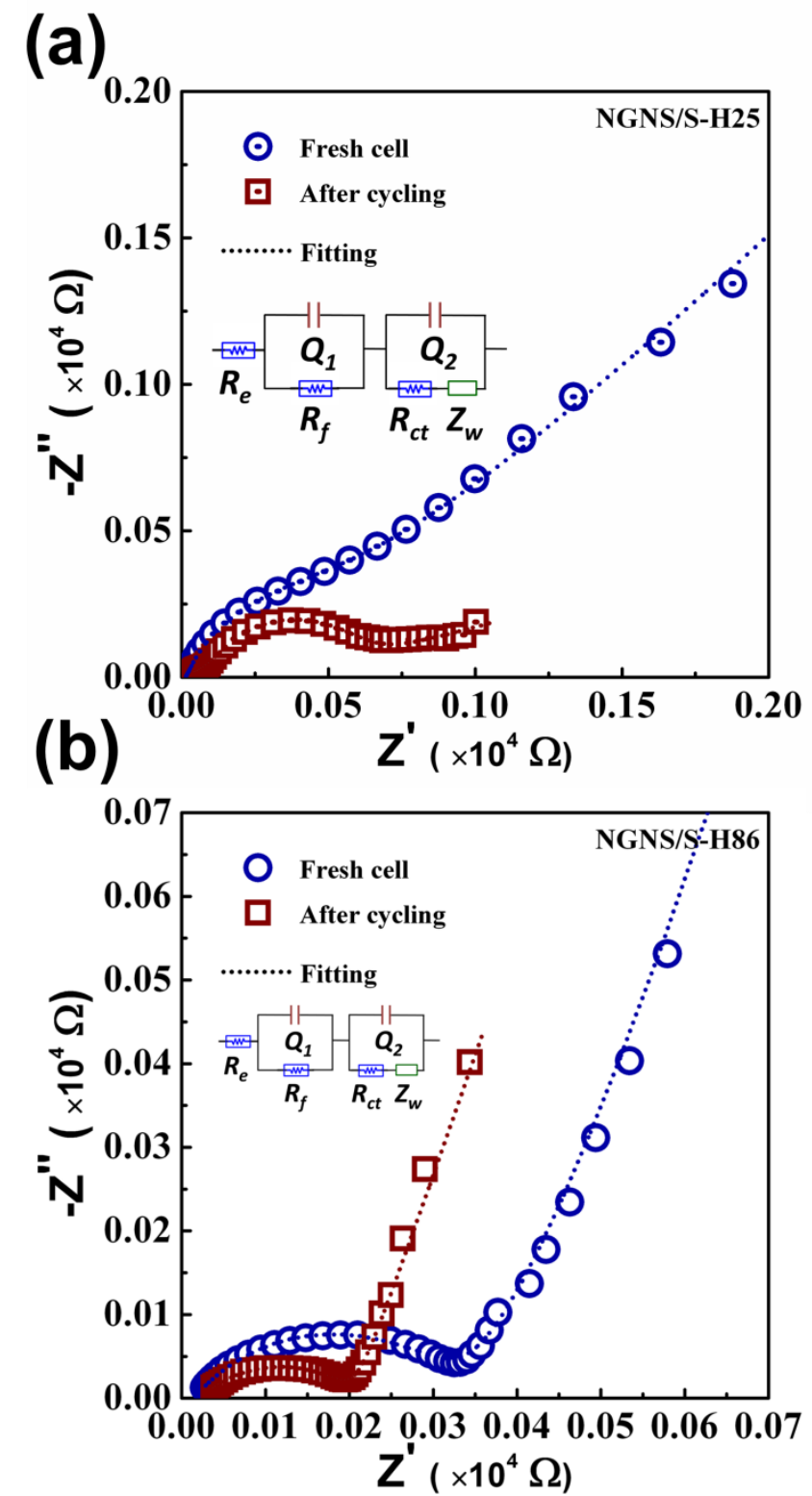

Figure 3.11 (a) Nyquist plots of NGNS/S-H25 working electrode before 1st cycle and after 300 cycles. (b) Nyquist plots of NGNS/S-H86 working electrode before 1st cycle and after 300 cycles. 


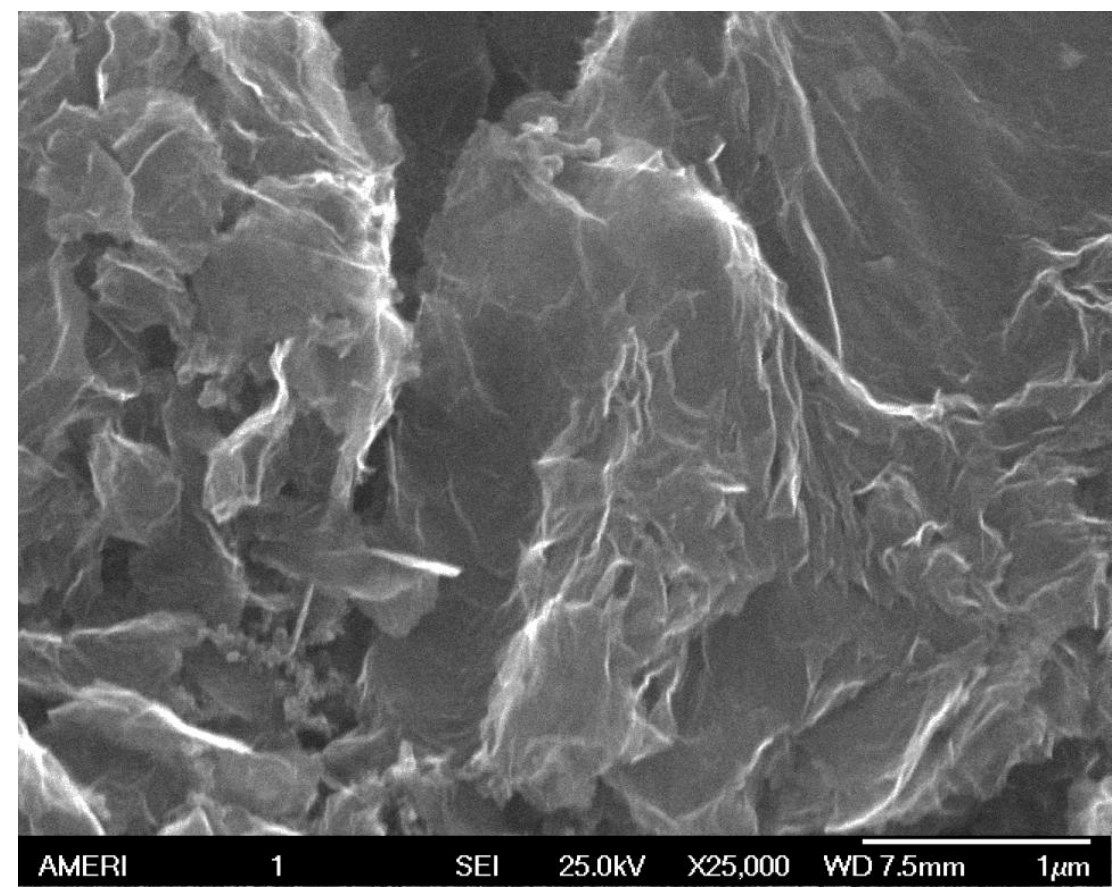

Figure 3.12 SEM image of the surface of NGNS/S-H25 nanocomposite working electrode after 300 cycles.

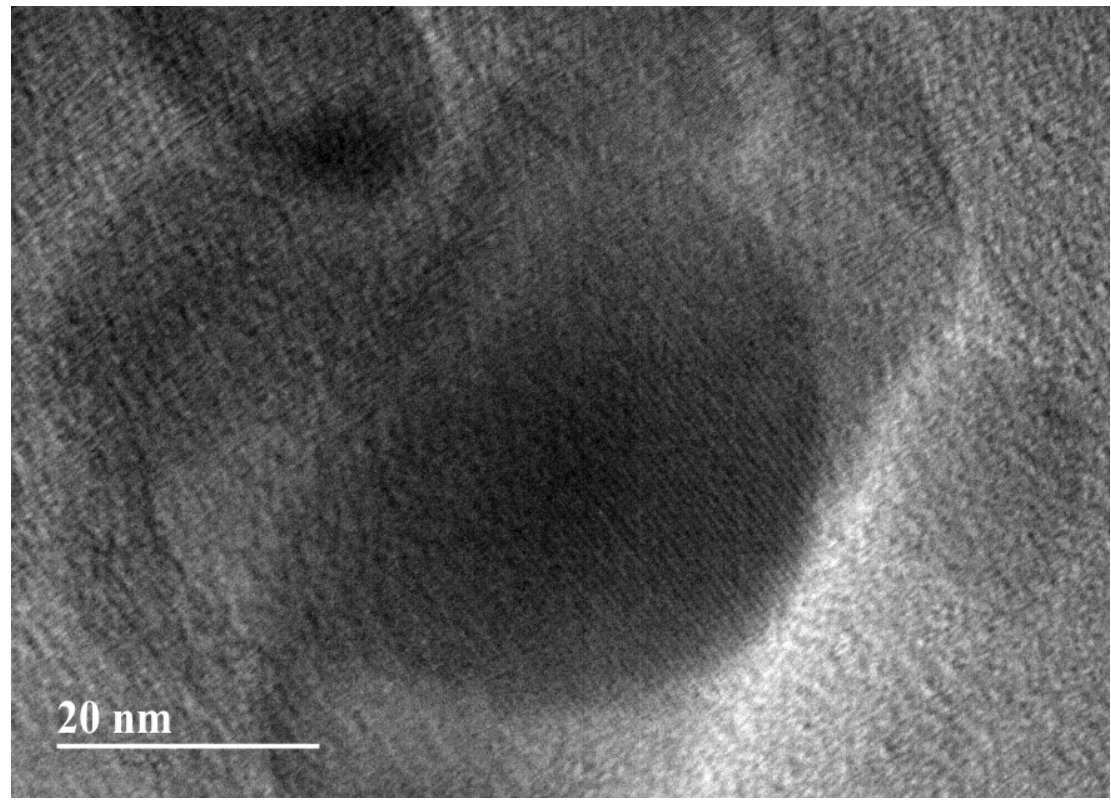

Figure 3.13 TEM image of NGNS/S-H25 nanocomposite working electrode after 300 cycles. 
To further examine the charge transfer resistance and $\mathrm{Na}^{+}$diffusion kinetics, EIS has been conducted on the NGNS/S-H25 cell before and after cycling. Figure 3.11 presents the Nyquist plots of NGNS/S-H25 electrode. Fitting has been conducted as well based on the equivalent circuit and fitting results is summarized in Table 3.1. From Figure 3.11, it can be observed that the semicircle of NGNS/S-H25 after cycling in the high-frequency region is smaller than that of fresh cell, which indicates a better chargetransfer condition after cycling. In the equivalent circuit, where $R_{e}$ represents the electrolyte resistance, $\mathrm{R}_{\mathrm{f}}$ represents the surface related resistance, $\mathrm{R}_{\mathrm{ct}}$ represents the charge transfer resistance, $\mathrm{Q}_{1}$ and $\mathrm{Q}_{2}$ represent related constant phase elements and $\mathrm{Z}_{\mathrm{w}}$ represent s the Warburg element [38]. From the summarized fitting results in Table 3.1, the values of $\mathrm{R}_{\mathrm{e}}, \mathrm{R}_{\mathrm{f}}$ and $\mathrm{R}_{\mathrm{ct}}$ after cycling are $3.0 \Omega, 398.4 \Omega$ and $6.5 \Omega$, respectively. The corresponding values of fresh cell are $10.7 \Omega, 441.5 \Omega$ and $478.6 \Omega$, respectively. The charge transfer resistance turns to be much lower after cycling, indicating the enhanced $\mathrm{Na}^{+}$transfer kinetics. The coin cell of NGNS/S-H25 was fully charged to $3.0 \mathrm{~V}$ after cycling and disassembled in the glove box. The NGNS/S-H25 electrode was rinsed with DEC, dried under vacuum at room temperature and further characterized by SEM. Figure 3.12 shows the SEM image of the surface of NGNS/S-H25 working electrode, it can be seen that there are pores and large agglomerates of reaction products existing in the elecrtrode. The NGNS layered structure can be observed, indicating a well remaining conductive matrix after cycle performance. Figure 3.13 shows the high resolution TEM image of NGNS/S-H25 nanocomposite after 300th cycle, it can be seen that the cluster contains several particles. However, the reaction products still cannot be determined by 
this HRTEM image. The possible reaction product might be sulfur. However, since the low reactivity between sulfur and sodium, it may also be reaction intermediates such as $\mathrm{Na}_{2} \mathrm{~S}_{3}$ or $\mathrm{Na}_{2} \mathrm{~S}_{2}$ [39]. Future examinations such as EDS and SAED need to be further carried out to confirm the final reaction products between $\mathrm{S}$ and $\mathrm{Na}$ at ambient temperature.

\subsection{Conclusions}

In summary, we have demonstrated NGNS interlinked with $\mathrm{S}$ nanocomposites as electrode materials for RT Na-S batteries. In this kind of nanocomposites, sulfur has been phase-transferred from alpha-S8 to gamma-S8, formed small nanoparticles with average size of $\sim 10 \mathrm{~nm}$ and anchored onto the NGNS layers during the thermal treatment progress. The NGNS/S with low loading sulfur content exhibits an excellent rate and cycling performance, indicating that the defects and active sites introduced by $\mathrm{N}$ functional groups play an effective role in interlinking sulfur and confining polysulfide dissolution in the organic electrolytes in RT Na-S batteries. This significant improvement can also be attributed to the conductive network established by both S and NGNS for fast flexible $\mathrm{Na}^{+}$transport during cycling. The high loading sulfur content exhibits an inferior electrochemical performance, indicating that low sulfur loading level leads a good way for high performance of RT Na-S batteries.

\subsection{References}

[1] J.-M. Tarascon, M. Armand, Nature, 414 (2001) 359-367.

[2] A.S. Arico, P. Bruce, B. Scrosati, J.-M. Tarascon, W. Van Schalkwijk, Nature materials, 4 (2005) 366-377. 
[3] X. Li, A. Dhanabalan, C. Wang, Advanced Energy Materials, 2 (2012) 174-174.

[4] P.G. Bruce, S.A. Freunberger, L.J. Hardwick, J.-M. Tarascon, Nature materials, 11 (2012) 19-29.

[5] F. Gross, F. Harbach, R. Knodler, R. Langpape, S. Mennicke, L. Weiler, In: Journal Of The Electrochemical Society, Electrochemical Soc Inc 10 South Main Street, Pennington, Nj 08534, 1984, Pp. C290-C290.

[6] S. Wenzel, H. Metelmann, C. Rai, A.K. Dürr, J. Janek, P. Adelhelm, Journal of Power Sources, 243 (2013) 758-765.

[7] R. Okuyama, H. Nakashima, T. Sano, E. Nomura, Journal of power sources, 93 (2001) 50-54.

[8] X. Ji, K.T. Lee, L.F. Nazar, Nature materials, 8 (2009) 500-506.

[9] X. Ji, S. Evers, R. Black, L.F. Nazar, Nature communications, 2 (2011) 325.

[10] S. Evers, L.F. Nazar, Accounts of chemical research, 46 (2012) 1135-1143.

[11] C.-W. Park, J.-H. Ahn, H.-S. Ryu, K.-W. Kim, H.-J. Ahn, Electrochemical and solid-state letters, 9 (2006) A123-A125.

[12] J. Wang, J. Yang, Y. Nuli, R. Holze, Electrochemistry communications, 9 (2007) 3134.

[13] C.-W. Park, H.-S. Ryu, K.-W. Kim, J.-H. Ahn, J.-Y. Lee, H.-J. Ahn, Journal of power sources, 165 (2007) 450-454.

[14] J.-S. Kim, H.-J. Ahn, I.-P. Kim, K.-W. Kim, J.-H. Ahn, C.-W. Park, H.-S. Ryu, Journal of Solid State Electrochemistry, 12 (2008) 861-865.

[15] H. Ryu, T. Kim, K. Kim, J.-H. Ahn, T. Nam, G. Wang, H.-J. Ahn, Journal of Power Sources, 196 (2011) 5186-5190.

[16] I. Bauer, M. Kohl, H. Althues, S. Kaskel, Chemical Communications, 50 (2014) 3208-3210.

[17] X. Yu, A. Manthiram, The journal of physical chemistry letters, 5 (2014) 1943-1947.

[18] X. Yu, A. Manthiram, ChemElectroChem, 1 (2014) 1275-1280.

[19] X. Yu, A. Manthiram, The Journal of Physical Chemistry C, 118 (2014) 2295222959. 
[20] X. Yu, A. Manthiram, Chemistry-A European Journal, 21 (2015) 4233-4237.

[21] X. Yu, A. Manthiram, Advanced Energy Materials, 5 (2015).

[22] X. Yu, A. Manthiram, Chemistry of Materials, (2016).

[23] T.H. Hwang, D.S. Jung, J.-S. Kim, B.G. Kim, J.W. Choi, Nano letters, 13 (2013) 4532-4538.

[24] S. Zheng, P. Han, Z. Han, P. Li, H. Zhang, J. Yang, Advanced Energy Materials, 4 (2014).

[25] S. Xin, Y.X. Yin, Y.G. Guo, L.J. Wan, Advanced Materials, 26 (2014) 1261-1265.

[26] R. Agrawal, C. Chen, Y. Hao, Y. Song, C. Wang, Graphene-based Energy Devices, (2015) 171-214.

[27] X. Wang, X. Li, L. Zhang, Y. Yoon, P.K. Weber, H. Wang, J. Guo, H. Dai, Science, 324 (2009) 768-771.

[28] J. Xu, M. Wang, N.P. Wickramaratne, M. Jaroniec, S. Dou, L. Dai, Advanced Materials, 27 (2015) 2042-2048.

[29] C. Wang, K. Su, W. Wan, H. Guo, H. Zhou, J. Chen, X. Zhang, Y. Huang, Journal of Materials Chemistry A, 2 (2014) 5018-5023.

[30] Y. Qiu, W. Li, W. Zhao, G. Li, Y. Hou, M. Liu, L. Zhou, F. Ye, H. Li, Z. Wei, Nano letters, 14 (2014) 4821-4827.

[31] D. Xie, W. Tang, X. Xia, D. Wang, D. Zhou, F. Shi, X. Wang, C. Gu, J. Tu, Journal of Power Sources, 296 (2015) 392-399.

[32] X. Li, D. Geng, Y. Zhang, X. Meng, R. Li, X. Sun, Electrochemistry Communications, 13 (2011) 822-825.

[33] D. Geng, Y. Chen, Y. Chen, Y. Li, R. Li, X. Sun, S. Ye, S. Knights, Energy \& Environmental Science, 4 (2011) 760-764.

[34] Y. Li, J. Wang, X. Li, D. Geng, M.N. Banis, R. Li, X. Sun, Electrochemistry Communications, 18 (2012) 12-15.

[35] S. Chen, X. Huang, H. Liu, B. Sun, W. Yeoh, K. Li, J. Zhang, G. Wang, Advanced Energy Materials, 4 (2014). 
[36] J. Song, Z. Yu, M.L. Gordin, S. Hu, R. Yi, D. Tang, T. Walter, M. Regula, D. Choi, X. Li, Nano letters, 14 (2014) 6329-6335.

[37] W. Shen, C. Wang, Q. Xu, H. Liu, Y. Wang, Advanced Energy Materials, 5 (2015).

[38] D.J. Kim, R. Ponraj, A.G. Kannan, H.-W. Lee, R. Fathi, R. Ruffo, C.M. Mari, D.K. Kim, Journal of Power Sources, 244 (2013) 758-763.

[39] Adelhelm, P., Hartmann, P., Bender, C. L., Busche, M., Eufinger, C., Janek, J. Beilstein journal of nanotechnology, 6(1) (2015) 1016-1055. 


\section{STUDIES ON INTRINSIC PHASE-DEPENDENT ELECTROCHEMICAL}

PROPERTIES OF MNS NANOCRYSTALS AS ANODES FOR LITHIUM-ION

\section{BATTERIES}

\subsection{Introduction}

Transition metal sulfides, such as copper sulfides, iron sulfides, cobalt sulfides, nickel sulfides and molybdenum sulfides, have recently received much attention owing to their diverse crystal structures and potential applications in solar cells, sensors, thermoelectric devices, fuel cells, supercapacitors and lithium-ion batteries (LIBs) [1-13]. In general, most transition metal sulfides $\mathrm{M}_{\mathrm{x}} \mathrm{S}_{\mathrm{y}}$, analogous to typical transition metal oxides, could be associated with two lithiation reaction mechanisms. One is a lithium insertion reaction to form an intermediate $\mathrm{Li}_{n} \mathrm{M}_{\mathrm{x}} \mathrm{S}_{\mathrm{y}}$, followed by a conversion reaction to form the metallic nanoparticles $\mathrm{M}$ and $\mathrm{Li}_{2} \mathrm{~S}$ alloy. The overall $\mathrm{M}_{\mathrm{x}} \mathrm{S}_{\mathrm{y}}$ lithiation/delithiation mechanism can be described as $\mathrm{M}_{\mathrm{x}} \mathrm{S}_{\mathrm{y}}+2 \mathrm{yLi}^{+}+2 \mathrm{ye}-\mathrm{yLi}_{2} \mathrm{~S}+\mathrm{xM}$ [14-17]. On the one hand, the nanosized metal particles, as reported in the case of other transition metal oxides (such as $\mathrm{NiO}[18,19], \mathrm{Fe}_{3} \mathrm{O}_{4}$ [20] and $\mathrm{ZnO}$ [21]), have a positive effect on the electrochemical reaction activity. On the other hand, typical sulfide electrodes exhibit poor cycle life due to their low electrical conductivity and relatively large volume expansion during lithiation/delithiation process [22-25], which hinders the sulfides in commercial energy storage application.

Among the sulfides, manganese sulfide $(\mathrm{MnS})$ with widely varied nanostructures (e.g., nanorod, nanocube, nanowire, nanosaw and nanosphere) has been regarded as one of the promising anode materials due to its relatively high theoretical capacity of 616 $\mathrm{mAh} \mathrm{g}^{-1}$ (Graphite: $372 \mathrm{mAh} \mathrm{g}^{-1}$ ) [26-30]. Generally, MnS has three different phases: RS- 
MnS or $\alpha-M n S$ with a cubic rock-salt crystal structure $(a=b=c=5.224 \AA$ ), ZB-MnS or $\beta$ MnS with a cubic zinc-blende crystal structure $(\mathrm{a}=\mathrm{b}=\mathrm{c}=5.615 \AA)$ and WZ-MnS or $\gamma-\mathrm{MnS}$ with a hexagonal wurtzite crystal structure ( $a=b=3.979 \AA$ and $c=6.446 \AA)$ [17], as shown in insets of Fig. 1. Both metastable tetrahedrally coordinated phases ZB-MnS and WZMnS are stable below $100{ }^{\circ} \mathrm{C}$ and can transform into octahedrally coordinated phase RS$\mathrm{MnS}$ at $100-400{ }^{\circ} \mathrm{C}$ or at high pressure [31]. So far, few works about single phase RSMnS with polyhedron [32] and hollow microbox [33] structures as well as WZ-MnS with nanosaws [28] structure as anode materials in LIBs have been investigated. For example, Zhang et al. [32] first synthesized and utilized stable RS-MnS submicrocrystals for LIBs and the large particle RS-MnS in size of $2 \mu \mathrm{m}$ manifested capacity of $339.6 \mathrm{mAh} \mathrm{g}^{-1}$ at the 20th cycle, indicating the particle size and the degree of crystallinity played key roles in the electrochemical performance of RS-MnS submicrocrystals. In another work, it was found that RS-MnS microboxes with high crystallinity and structural integrity exhibited a much better specific capacity of $495 \mathrm{mAh} \mathrm{g}^{-1}$ compared with RS-MnS porous microcubes of $340 \mathrm{mAh} \mathrm{g}^{-1}$ at the 100th cycle, which implies that not only crystallinity, but also contact surface area is a crucial factor [33]. Furthermore, Chen et al. [34] focused on improving electrical conductivity and structural stability by compositing $\mathrm{MnS}$ with graphene and at the 30th cycle, MnS composite electrode delivered the specific discharge and charge capacities of $987 \mathrm{mAh} \mathrm{g}^{-1}$ and $976 \mathrm{mAh} \mathrm{g}^{-1}$, repectively.

It is well known that selecting nanoscale active materials and making composite electrodes are generally accepted strategies to improve charge-transfer and interfacial charge storage [35-37]. However, a thorough investigation of MnS phase-dependent electrochemical performance remains missing to date. We believe a detailed 
understanding of structural transformation and intrinsic performance of the $\mathrm{MnS}$ with different crystallinity will be essential to further develop high performance electrode materials. In our recent work, RS-MnS, ZB-MnS and WZ-MnS nanocrystals (NCs) with well-controlled morphology and dimensionality have been successfully synthesized via a facile one-pot solvothermal route [27, 30]. Herein, three single phase MnS samples have been fabricated and evaluated as anode materials in LIBs. It was found that the capacities of as-assembled RS-MnS, ZB-MnS and WZ-MnS electrodes showed a decreasing trend in the initial $\sim 40$ cycles and gradually increased in the following cycles. At the 600th cycle, RS-MnS, ZB-MnS and WZ-MnS electrodes exhibited the capacities of $232.5 \mathrm{mAh}$ $\mathrm{g}^{-1}, 287.9 \mathrm{mAh} \mathrm{g}^{-1}$ and $79.8 \mathrm{mAh} \mathrm{g}^{-1}$, respectively. Further studies revealed that reduced particle size and decreased charge transfer impedance were beneficial for $\mathrm{Li}^{+}$transport during charge-discharge process, and further beneficial for capacity increase.

\subsection{Experimental Section}

\subsubsection{Material synthesis}

For a typical synthesis procedure of RS-MnS NCs, a mixture of $0.063 \mathrm{~g}(0.5$ mmol) anhydrous $\mathrm{MnCl}_{2}$ powder, $0.038 \mathrm{~g}$ (0.5 mmol) Thioacetamide (TAA, 99\%), 1.0 $\mathrm{ml}$ oleic acid (OA, 90\%) and $5.0 \mathrm{ml}$ oleylamine (OLA, 70\%) was added to a 50-ml three neck flask. This mixture was heated to $80{ }^{\circ} \mathrm{C}$ for 60 min under nitrogen flow. The solution was then slowly heated to $250{ }^{\circ} \mathrm{C}\left(5^{\circ} \mathrm{C} / \mathrm{min}\right)$ and kept for $30 \mathrm{~min}$, then cooled to room temperature naturally. To synthesize $\mathrm{ZB}-\mathrm{MnS} \mathrm{NCs}, 0.063 \mathrm{~g}$ of anhydrous $\mathrm{MnCl}_{2}$ and $4.0 \mathrm{ml}$ of OLA were first added to a $50-\mathrm{ml}$ three necked flask. The mixture was heated to $140{ }^{\circ} \mathrm{C}$ under nitrogen flow, and pink $\mathrm{MnCl}_{2}$ powder was completely dissolved under stirring. After the mixture was cooled down to room temperature, a clear mixture 
solution of $1.0 \mathrm{ml}$ OLA and $0.038 \mathrm{~g}$ TAA prepared in a glovebox was added into the flask. After that, the clear red solution was transferred to a 10-ml Teflon-lined autoclave. The autoclave was kept in a furnace at $200{ }^{\circ} \mathrm{C}$ for $30 \mathrm{~min}$. To synthesize WZ-MnS NCs, the autoclave was kept in a furnace at $250{ }^{\circ} \mathrm{C}$ for $30 \mathrm{~min}$ while other conditions were the same as the parameters used for synthesizing ZB-MnS NCs. All the samples were isolated using methanol and acetone, followed by centrifuging for $10 \mathrm{~min}$ at $10000 \mathrm{rpm}$. Subsequently, the residual samples were redispersed in toluene for microscopy characterization.

\subsubsection{Characterization}

X-ray diffraction (XRD) was used to determine the crystallographic structures of as-synthesized MnS powders and disassembled MnS electrodes after cycling. Data were collected from a Shimadzu XRD-6000 diffractometer and a Siemens D-5000 diffractometer both working with $\mathrm{Cu}-\mathrm{K} \alpha$ targets. Transmission electron microscopy (TEM) images, High-resolution transmission electron microscopy (HRTEM) images and selected area electron diffraction (SAED) patterns of as-synthesized MnS NCs and TEM images as well as HRTEM images of disassembled MnS electrodes were obtained with a JEOL JEM-2200FS transmission electron microscope with an emission gun operating at an acceleration voltage of $200 \mathrm{kV}$.

\subsubsection{Electrochemical measurements}

The 2032 coin cells were assembled to examine the electrochemical performance of $\mathrm{MnS}$ NCs. As-synthesized MnS samples (70 wt\%) were mixed into slurry with conductive carbon black (15 wt\%) and polyvinylidene fluoride (PVDF) binder (15 wt\%) 
in N-methyl-2-pyrrolidinone (NMP) solvent. Then, the slurry was cast onto disc shaped copper foils, followed by transferring the electrodes into a vacuum oven and dried at $80{ }^{\circ} \mathrm{C}$ for $12 \mathrm{~h}$. The coin cells were assembled in an argon-filled glovebox with $\mathrm{MnS}$ samples as working electrodes and lithium foils as counter and reference electrodes. Celgard 2400 polypropylene was used as separators and 1 M lithium bis(perfluoroethylsulfonyl)imide (LiBETI) dissolved in ethylene carbonate (EC), diethyl carbonate (DEC) and ethyl methyl carbonate (EMC) in the volume ratio of 1:1:1 was used as electrolyte. Cyclic voltammetry (CV) was conducted on the VMP3 multi-channel potentiostat at the scanning rate of $0.2 \mathrm{mV} \mathrm{s}^{-1}$ in the voltage range of $0.01-3 \mathrm{~V}$ vs. $\mathrm{Li} / \mathrm{Li}^{+}$. Both galvanostatic charge-discharge cyclability test at a current density of $0.1 \mathrm{~A}$ $\mathrm{g}^{-1}$ and rate capability test at various current densities of $0.1,0.2,0.5,1$ and $2 \mathrm{~A} \mathrm{~g}^{-1}$ were carried out on the NEWARE BTS-610 Battery Test System in the voltage window between $0.01 \mathrm{~V}$ and $3 \mathrm{~V}$ vs. $\mathrm{Li} / \mathrm{Li}^{+}$. Electrochemical impedance spectroscopy (EIS) measurement was performed before and after cell cycling on VMP3 at an input AC signal of $10 \mathrm{mV}$ amplitude within the frequency range of $100 \mathrm{kHz}$ to $10 \mathrm{mHz}$. All the electrochemical characterization procedures were performed at room temperature.

\subsection{Results and Discussion}

The crystallographic structures of as-synthesized $\mathrm{MnS}$ powders were examined by XRD. Fig. 4.11 shows the XRD diffraction patterns of three different phases of MnS. It can be observed that all the diffraction peaks are in good agreement with the JCPDS standard values. Five characteristic peaks can be observed in curve (a) corresponding to the (111), (200), (220), (222) and (400) planes, which can be indexed to cubic RS-MnS phase with a space group of Fm-3m(225) (JCPDS No.65-2919, curve (b)). Three 
diffraction peaks in curve (c) can be assigned to the planes of (111), (220) and (311) in cubic ZB-MnS phase with a F-43m(216) space group (JCPDS No.40-1288, curve (d)). The diffraction peaks in the curve (e) can be indexed to hexagonal WZ-MnS phase with planes of (100), (002), (101), (110), (103) and (112), and a P63mc(186) space group (JCPDS No. 40-1289, curve (f)). There are no impurity peaks detected in any of the three patterns, indicating that the synthesized samples are pure RS-MnS, ZB-MnS and WZ$\mathrm{MnS}$ single phase, respectively.

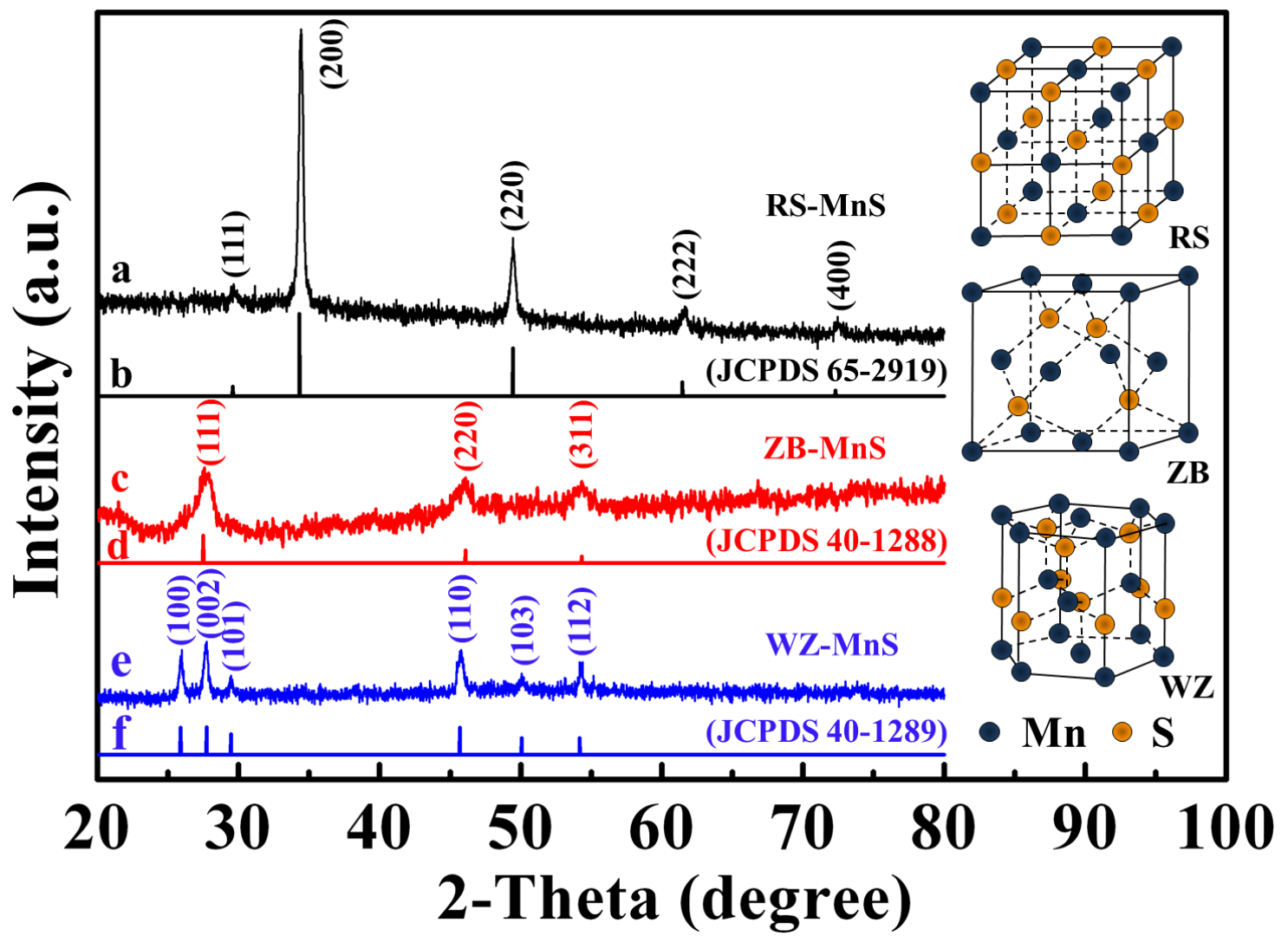

Figure 4.1 XRD patterns and corresponding JCPDS files of $(a, b)$ RS-MnS, (c, d) ZB-MnS and (e, f) WZ-MnS. The insets illustrate the crystalline structures of RS-, ZB- and WZ-MnS, respectively.

The morphology and crystalline structure of as-prepared RS-MnS, ZB-MnS and WZ-MnS NCs were characterized by TEM and HRTEM, respectively. The phases of 
these three kinds of MnS samples were also identified by the SAED patterns. As shown in Fig. 4.3a, RS-MnS is in a nanocube shape with an average particle size of $\sim 25 \mathrm{~nm}$. As in Fig. 4.3b, the HRTEM image of a typical RS-MnS NC, it can be observed that periodic lattice fringe with an interplanar distance of $2.64 \AA$ comes from (200) plane of cubic RSMnS. The SAED (Fig. 4.3c) pattern shows four diffraction rings, which can be indexed as pure RS-MnS, indicating high crystallinity of as-synthesized RS-MnS NCs.

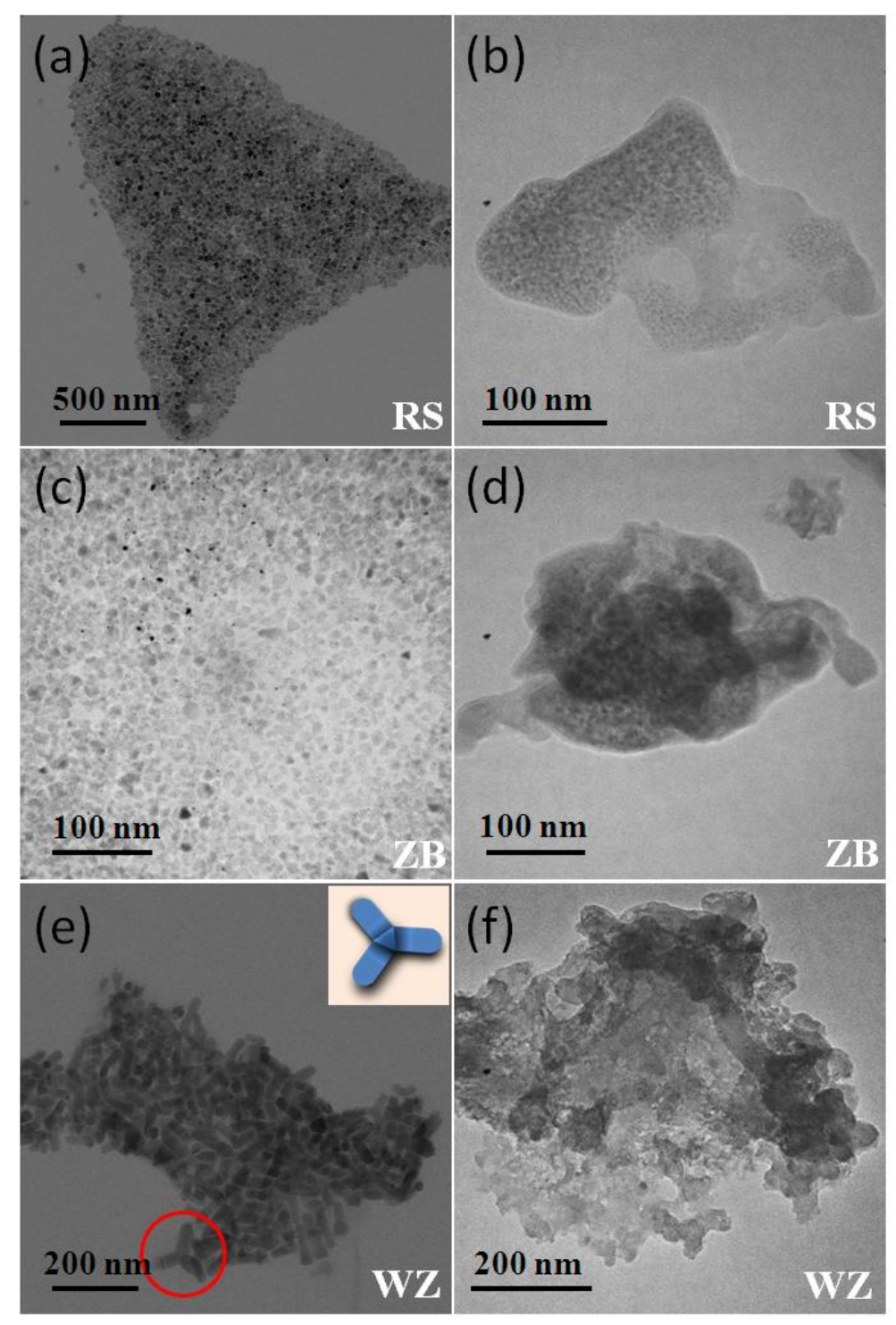

Figure 4.2 TEM images in low magnification of as-synthesized (a) RS-MnS, (c) ZB-MnS and (e) WZ-MnS NCs before cycling, and disassembled (b) RS-MnS, (d) ZB-MnS and 
(f) WZ-MnS electrodes after cycling, respectively. (e inset) The schematic image illustrates a 3-branch multipod-like morphology of WZ-MnS.

Fig. 4.3d-f show the TEM image, HRTEM image and corresponding SAED pattern of ZB-MnS. It can be clearly seen from Fig. 4.3d that ZB-MnS NCs are in irregular shapes with particle size distribution from $5 \mathrm{~nm}$ to $25 \mathrm{~nm}$ and an average size of $\sim 10 \mathrm{~nm}$. From the HRTEM image (Fig. 4.3e), the measured lattice spacing of $3.23 \AA$ is consistent with the (111) plane of cubic ZB-MnS. The SAED pattern (Fig. 4.3f) further confirms the existence of single phase ZB-MnS NCs. From Fig. 4.3g, it can be observed that the WZ-MnS NCs display anisotropic nanorod structure. Some of the nanorods are assembled into 2-branch V-shape and some are in 3-branch Y-shape. The lattice fringe from HRTEM image (Fig. 4.3h) taken on a typical individual nanocrystal shows the inter-plane spacing of $3.22 \AA$, which is attributed to the (002) plane of hexagonal WZ$\mathrm{MnS}$ phase. The diffraction concentric rings from the SAED pattern (Fig. 4.3i) correspond well with the (100), (002), (101), (110), (103) and (112) planes of the hexagonal structured WZ-MnS. The TEM, HRTEM and SAED results indicate that highly crystalline single phase RS-, ZB- and WZ-MnS NCs were successfully fabricated, which are in good agreement with the results obtained from the XRD patterns in Fig. 4.1. 


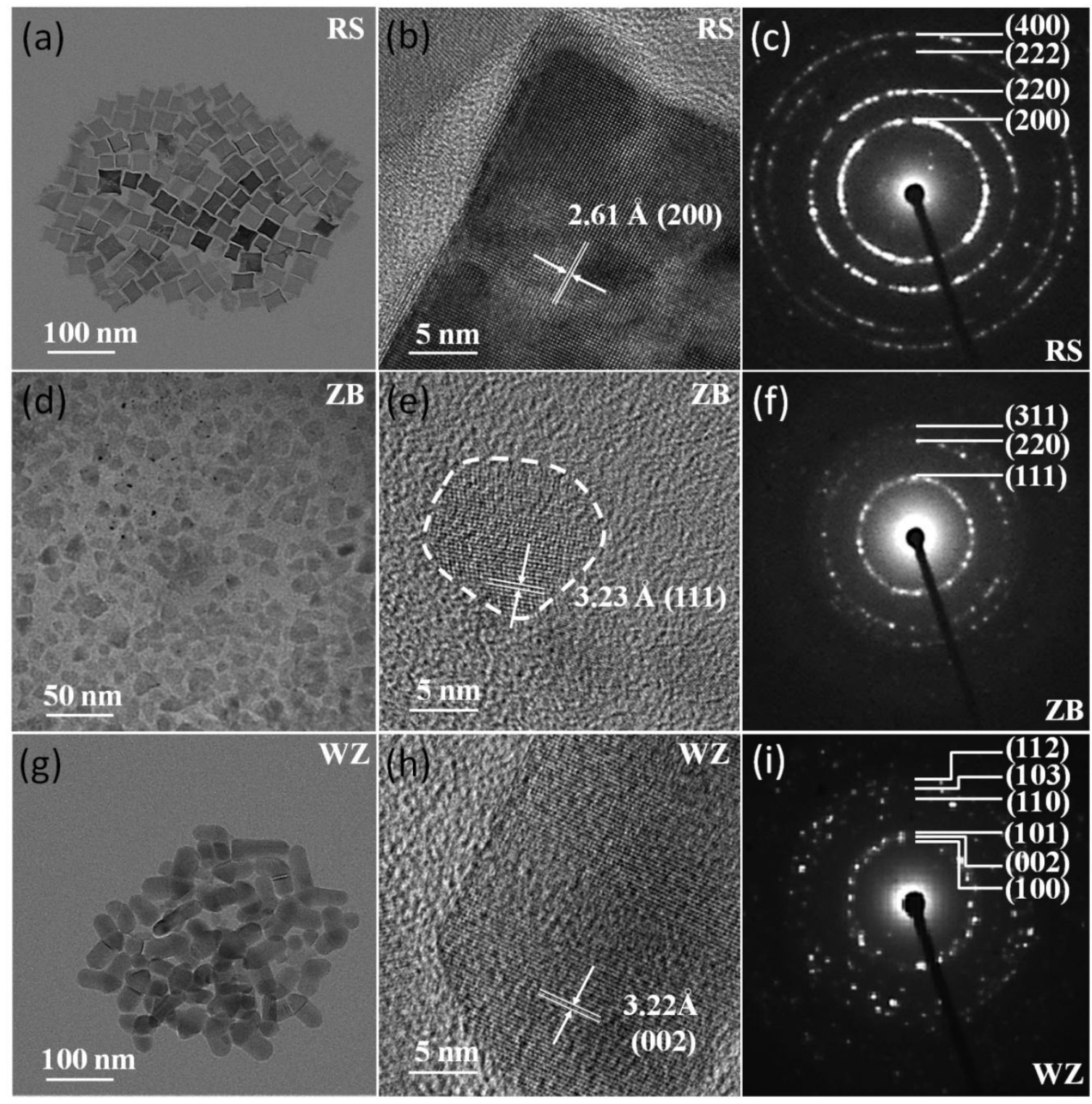

Figure 4.3 TEM images, HRTEM images and SAED patterns of as-synthesized (a,b,c) RS-MnS, (d,e,f) ZB-MnS and (g,h,i) WZ-MnS, respectively.

The electrochemical properties of RS-, ZB- and WZ-MnS NCs as anode materials for LIBs were investigated. From the CV curves of RS-MnS (Fig. 4.4a), two peaks can be observed during the cathodic process of the first cycle. One reduction peak is observed at 1.59 $\mathrm{V}$, which could be ascribed to the process of $\mathrm{Li}^{+}$insertion into the $\mathrm{MnS}$ lattice to form intermediate $\mathrm{Li}_{\mathrm{x}} \mathrm{MnS}$ phase [38]. In the voltage range of $0.01-1.0 \mathrm{~V}$, there is a 
broad shoulder observed on the curve, which could be assigned to the conversion process of $\mathrm{Mn}^{2+}$ to $\mathrm{Mn}$ [28]. Meanwhile, the other minor reduction peak is observed at around $0.75 \mathrm{~V}$ in this range for RS-MnS, representing the non-aqueous electrolyte decomposition and solid electrolyte interphase (SEI) formation process [39]. During the anodic process of first cycle, there are four oxidation peaks centered around $1.04 \mathrm{~V}, 1.42 \mathrm{~V}, 1.92 \mathrm{~V}$ and $2.37 \mathrm{~V}$, respectively, observed on anodic branch of RS-MnS, indicating the delithiation process of RS-MnS. The oxidation peaks at around $1.04 \mathrm{~V}$ and $1.42 \mathrm{~V}$ might be attributed to the conversion reaction of $\mathrm{Mn}$ to $\mathrm{Mn}^{2+}$, and the following two peaks at around $1.92 \mathrm{~V}$ and 2.37 $\mathrm{V}$ may be due to $\mathrm{Li}^{+}$extraction from the $\mathrm{MnS}$ lattice process [28]. From the second cycle and onward, one cathodic peak shifts its position from initial $1.59 \mathrm{~V}$ to 1.42V for RS-MnS. From Fig. 4.4b, three reduction peaks at around $1.41 \mathrm{~V}, 0.75 \mathrm{~V}$ and $0.50 \mathrm{~V}$ can be observed during the first cathodic process of ZB-MnS. In the upcoming cycles, the reduction peak at $1.41 \mathrm{~V}$ shifts to $1.49 \mathrm{~V}$. During the first anodic process, the ZB-MnS shows three oxidation peaks at $1.08 \mathrm{~V}, 1.96 \mathrm{~V}$ and $2.36 \mathrm{~V}$, respectively. The CV behavior indicates that most related CV peaks on RS-MnS curve can also be observed for the case of ZB-MnS. In Fig. 4.4c, two major reduction peaks at $1.41 \mathrm{~V}$ and $1.61 \mathrm{~V}$ can be observed during the first cathodic process of WZ-MnS. These two reduction peaks transformed to one peak at $1.46 \mathrm{~V}$ in the following cycles. Meanwhile, several minor peaks can be observed in the low potential region $(0.01-1.0 \mathrm{~V})$, indicating the complex conversion process of WZ-MnS along with the formation of SEI in the first cycle. Similar to RS-MnS, four oxidation peaks at $1.08 \mathrm{~V}, 1.36 \mathrm{~V}, 1.96 \mathrm{~V}$ and $2.38 \mathrm{~V}$ can be observed from the first anodic process of WZ-MnS. The peak at $1.96 \mathrm{~V}$ shifts to $1.91 \mathrm{~V}$ on the second cycle. Consequently, for the three kinds of MnS electrodes, more or less, there are 
some peak shifts after the first cycle. One possible reason to explain the peak shift could be the change of reaction kinetics due to the SEI formation [40]. It has to be noted that some reduction (e.g., RS $1.59 \mathrm{~V}$ and ZB $1.41 \mathrm{~V}$ ) and oxidation (e.g., RS $1.42 \mathrm{~V}$ and WZ $1.36 \mathrm{~V}$ ) peaks are not always obvious in all three different phases, indicating the reaction kinetics at different growth sectors might be slightly varied. In the subsequent cycles after the first cycle, the reduction and oxidation peaks most likely remain at the same position. However, the intensities gradually decrease, indicating the weakening of the redox reaction. The $\mathrm{CV}$ results seem to be in good agreement with the proposed electrochemical reaction process of $\mathrm{MnS}$ based on the conversion mechanism with intermediate $\mathrm{Li}_{\mathrm{x}} \mathrm{MnS}$ phase $[28,38]$ :

$$
\text { Insertion reaction: } \mathrm{MnS}+\mathrm{xLi}^{+}+\mathrm{xe}^{-} \leftrightarrow \mathrm{Li}_{\mathrm{x}} \mathrm{MnS}
$$

$$
\text { Conversion reaction: } \quad \mathrm{Li}_{2-x} \mathrm{MnS}+\mathrm{xLi}^{+}+\mathrm{xe}^{-} \leftrightarrow \mathrm{Mn}+\mathrm{Li}_{2} \mathrm{~S}
$$
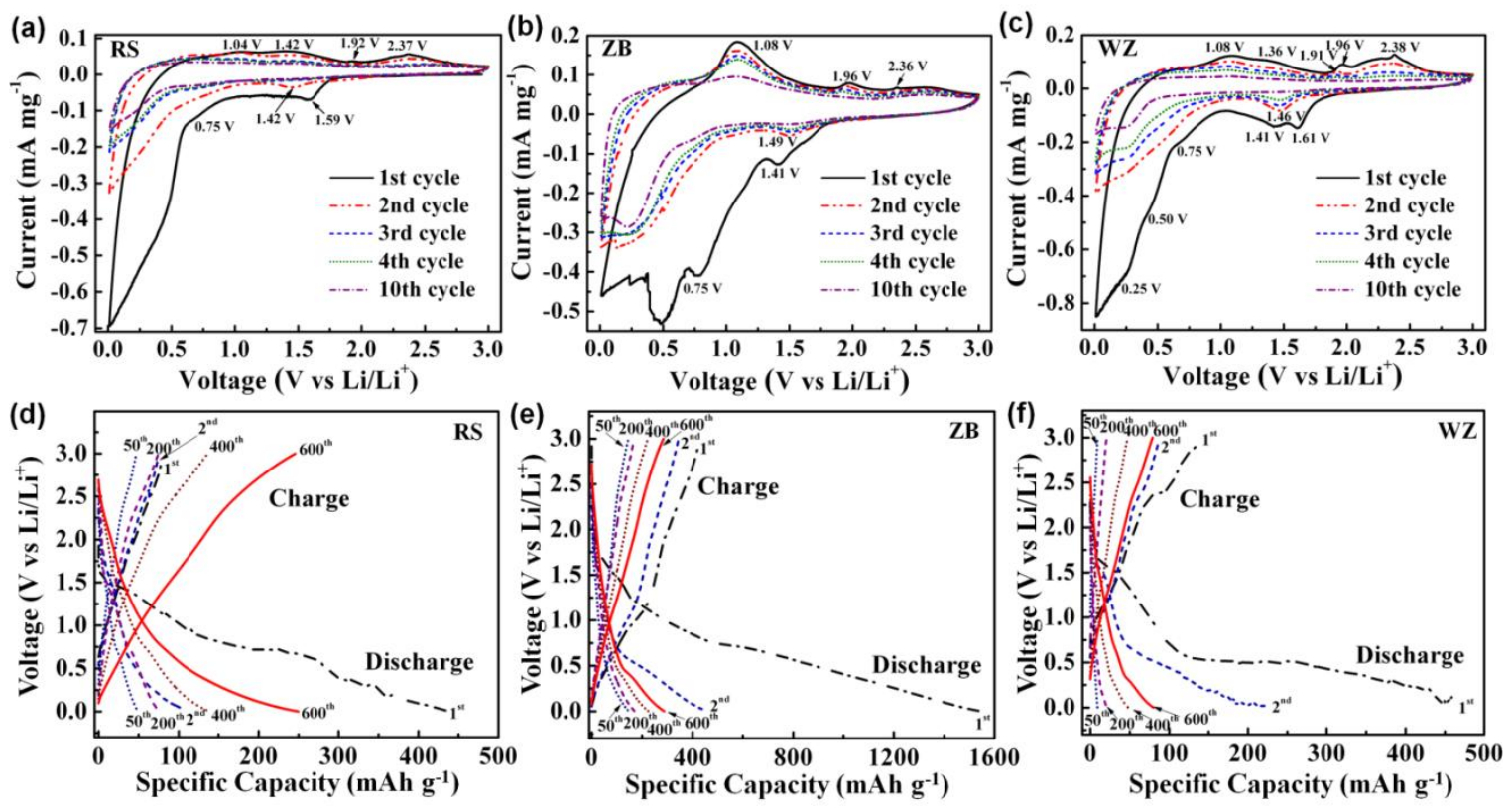

Figure 4.4 (a-c) Cyclic voltammetry at a scanning rate of $0.2 \mathrm{mV} \mathrm{s}^{-1}$ and (d-f) galvanostatic discharge/charge curves at a current density of $0.1 \mathrm{~A} \mathrm{~g}^{-1}$ of RS-, ZB- and WZ-MnS in the voltage range of $0.01-3 \mathrm{~V}$ vs. $\mathrm{Li} / \mathrm{Li}^{+}$, respectively. 
Fig. 4.4d-f present the galvanostatic discharge/charge profiles of RS-MnS, ZBMnS and WZ-MnS samples as working electrodes in LIBs. As shown in Fig. 4.4d, the first reduction plateau can be observed at $1.5 \mathrm{~V}$ on the first discharge curve of RS-MnS, which may be attributed to $\mathrm{Li}^{+}$insertion into $\mathrm{MnS}$ lattice to form $\mathrm{Li}_{x} \mathrm{MnS}$ [14]. With voltage decreasing, the second reduction plateau is observed at $0.75-0.5 \mathrm{~V}$ attributed to conversion reaction of $\mathrm{Mn}^{2+}$ to $\mathrm{Mn}$ and the formation of SEI process [41]. Furthermore, there is no obvious plateau shown up on the RS-MnS charge curve of the first cycle. On the following discharge/charge curves of the 2nd, 50th, 200th, 400th and 600th cycles, there are no obvious plateaus observed. This implies that the formation of SEI layer mainly takes place in the first cycle, which is in good agreement with the CV results. From Fig. 4.4e, it can be seen that the discharge behavior of the ZB-MnS in the first cycle is similar to RS-MnS with the reduction plateaus at around $1.5 \mathrm{~V}$ and $0.75 \mathrm{~V}$. There is an oxidation plateau at around $1.0 \mathrm{~V}$ on the first charge curve, which is corresponding to the first oxidation peak on the CV curve of ZB-MnS in Fig. 4.4b. In Fig. 4.4f, it shows that there are two reduction plateaus at around $1.5 \mathrm{~V}$ and $0.5 \mathrm{~V}$ on the discharge curve of WZ$\mathrm{MnS}$ in the first cycle. There is an oxidation plateau at around $2.3 \mathrm{~V}$ on the first charge curve, which may represent the $\mathrm{Li}^{+}$extraction from WZ-MnS lattice process [28]. In following cycles up to at the 600th cycle, small plateaus on the discharge/charge curves can still be observed for WZ-MnS, indicating the similar lithiation/delithiation process as occurred in the first cycle. With the voltage decreasing to $0.01 \mathrm{~V}$, The RS-MnS, ZB-MnS and WZ-MnS electrodes deliver the first discharge capacities of $438.8 \mathrm{mAh} \mathrm{g}^{-1}, 1545.1$ $\mathrm{mAh} \mathrm{g}^{-1}$ and $463 \mathrm{mAh} \mathrm{g}^{-1}$, respectively. The first charge capacities of RS-MnS, ZB-MnS and WZ-MnS are $80.5 \mathrm{mAh} \mathrm{g}^{-1}, 430.6 \mathrm{mAh} \mathrm{g}^{-1}$ and $144.7 \mathrm{mAh} \mathrm{g}^{-1}$, respectively, 
corresponding to Coulombic efficiencies of $18.3 \%, 27.9 \%$ and $31.2 \%$, respectively. In comparison, typical capacity loss ranging from $33 \%$ to $41 \%$ of $\mathrm{MnS}$ or $\mathrm{MnS} / \mathrm{carbon}$ composites as electrodes were reported in studies [28, 32, 34, 38]. The irreversible capacity loss may be attributed to the formation of SEI on the surface of MnS particles [41].

(a)

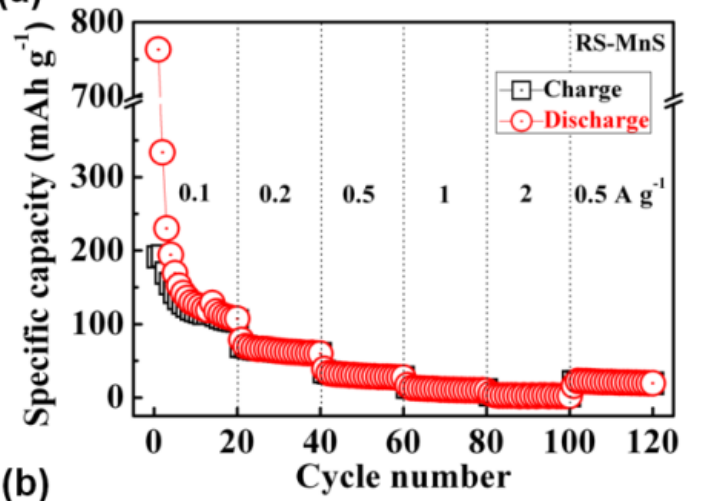

(b)
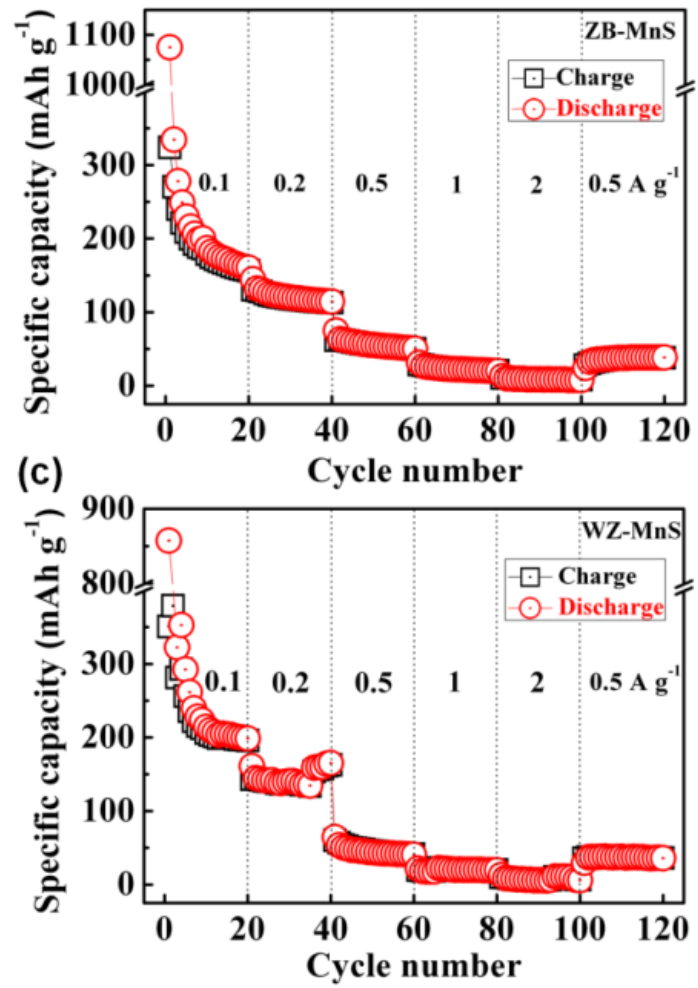

Figure 4.5 Rate capability of (a) RS-MnS, (b) ZB-MnS and (c) WZ-MnS at current densities of $0.1,0.2,0.5,1$ and $2 \mathrm{~A} \mathrm{~g} \mathrm{~g}^{-1}$, respectively. 
From Fig. 4.5, it can be seen the capacities decrease with the current rates increase for RS-MnS, ZB-MnS and WZ-MnS electrodes. However, the capacity remains stable upon cycling under different current densities. When the current density set back to $0.5 \mathrm{~A} \mathrm{~g}^{-1}$, the capacities can be recovered to the initial numbers. The RS-MnS, ZB-MnS and WZ-MnS samples exhibit a good rate capability.

(a)

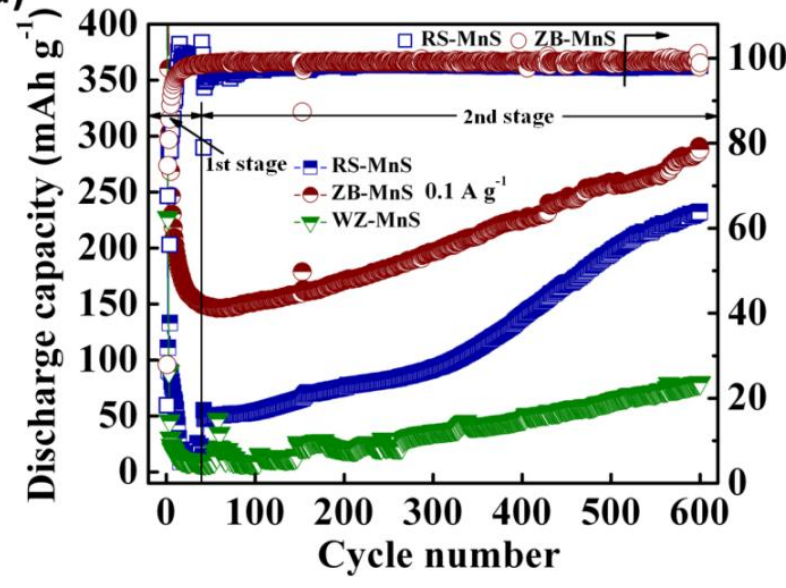

(b)

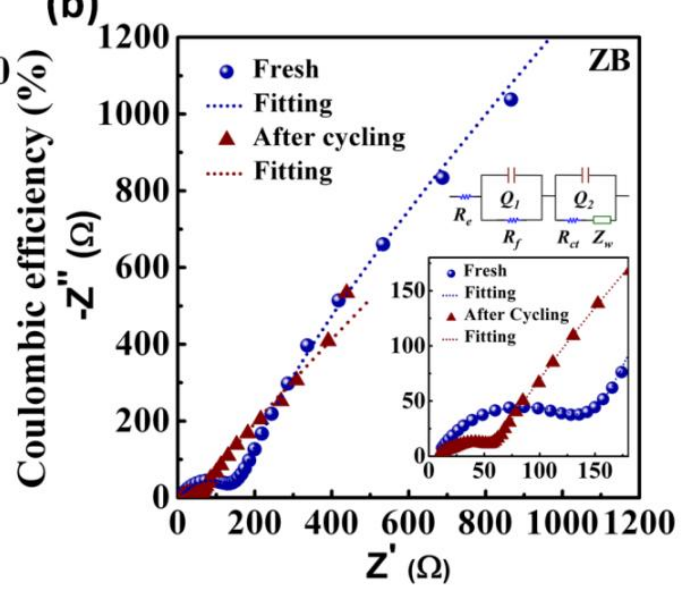

Figure 4.6 (a) Cycling performance of RS-, ZB- and WZ-MnS electrodes and corresponding Coulombic efficiencies of RS- and ZB-MnS at a current density of $0.1 \mathrm{~A}$ $\mathrm{g}^{-1}$, respectively; (b) Nyquist plots of fresh cell and cell after cyclability test with ZB$\mathrm{MnS}$ as anode in LIBs. Figure insets give equivalent circuit model for the fitting of the Nyquist plots and enlarged semicircles in high frequency range (below).

Fig. 4.6a shows the galvanostatic cycling performance of $\mathrm{MnS}$ electrodes with different phases. The capacity trend with cycling exhibits two distinctive stages. First stage is an abrupt decrease in capacities with increased cycle numbers during the first $\sim 40$ cycles. The discharge capacities of RS-MnS, ZB-MnS and WZ-MnS decrease to the lowest values of $11.4 \mathrm{mAh} \mathrm{g}^{-1}, 146.2 \mathrm{mAh} \mathrm{g}^{-1}$ and $8.1 \mathrm{mAh} \mathrm{g}^{-1}$ at around the 40th cycle, respectively. In contrast, the second stage shows a gradual increase of discharge capacity during the following cycles. At the 600th cycle, the discharge capacities of RS-MnS, ZBMnS and WZ-MnS cells reach to $232.5 \mathrm{mAh} \mathrm{g}^{-1}, 287.9 \mathrm{mAh} \mathrm{g}^{-1}$ and $79.8 \mathrm{mAh} \mathrm{g}^{-1}$, 
respectively, corresponding to Coulombic efficiencies of $98.2 \%, 98.9 \%$ and $98.7 \%$, respectively. The capacity of $\mathrm{WZ}-\mathrm{MnS}$ is in the continuous increasing trend even up to the 1000th cycle. Further effort needs to be done to understand this unusual capacity increase phenomenon.
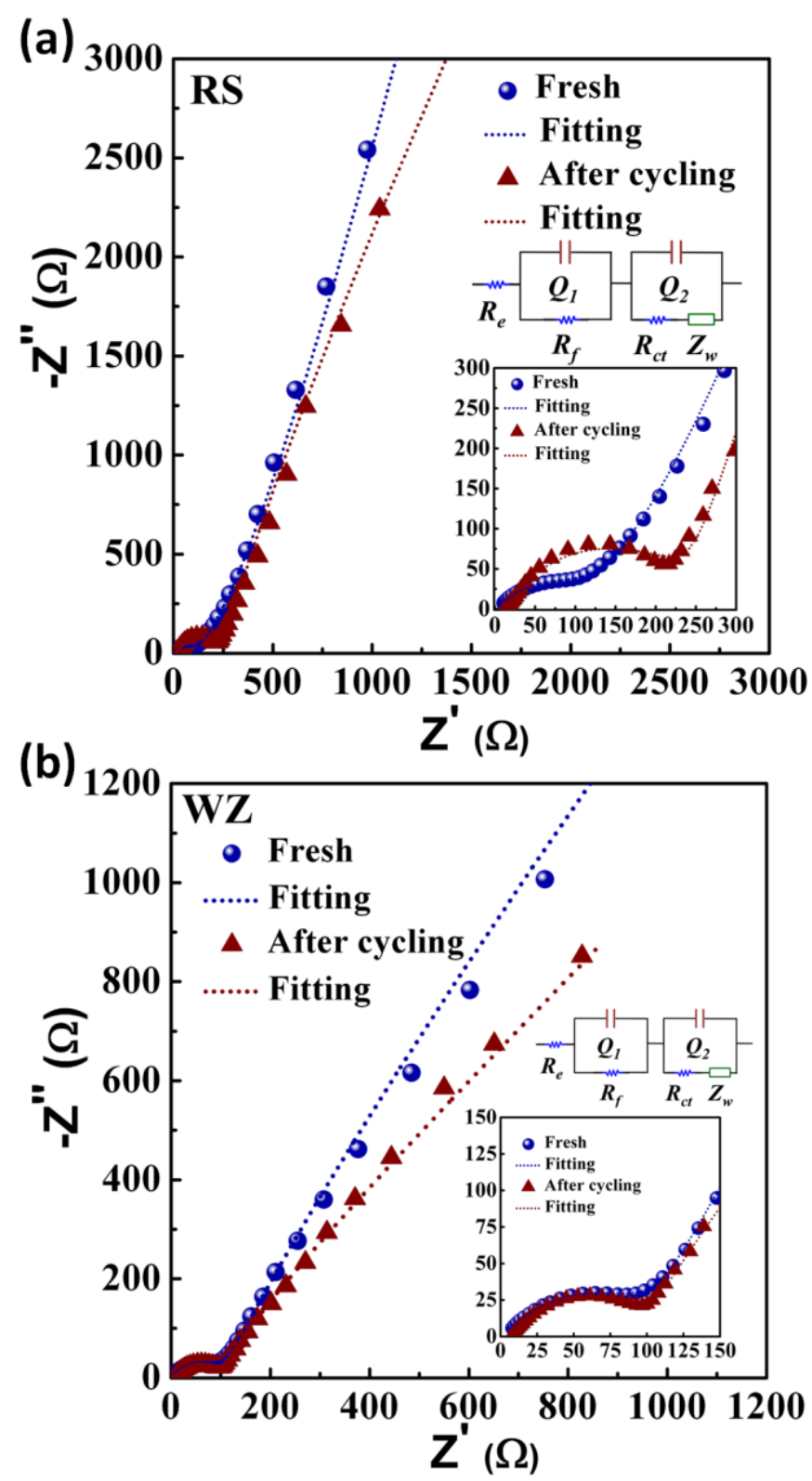

Figure 4.7 Nyquist plots of (a) RS-MnS and (b) WZ-MnS as anode materials in LIBs before and after cycling. Figure insets give equivalent circuit model for the fitting of the Nyquist plots and enlarged semicircles in high frequency range (below). 
To provide insights on the change of charge transfer resistance and $\mathrm{Li}^{+}$diffusion kinetics during cyclability test, EIS has been conducted on the three kinds of MnS before and after cycling. Fig. 4.6b shows the Nyquist plots of the ZB-MnS electrodes, which are fitted by an equivalent circuit (Fig. 4.6b inset). Fitting results of RS, ZB and WZ-MnS are summarized in Table 4.1. In Fig. 4.6b, it can be seen that both Nyquist plots consist of one semicircle in the high-frequency region and a linear straight line in the low frequency region. Obviously, the semicircle's diameter of ZB-MnS after cycling is smaller than that of ZB-MnS fresh cell, indicating an enhanced charge-transfer process after cycling. The slopes of the linear straight lines show almost the same value of $\sim 60^{\circ}$ (angle of linear line to $\mathrm{x}$ axis), indicating a retaining of similar $\mathrm{Li}^{+}$diffusion behavior in the $\mathrm{MnS}$ electrode [42]. In the equivalent circuit, where $R_{\mathrm{e}}$ denotes the electrolyte resistance, $R_{\mathrm{f}}$ denotes the surface related resistance, $\mathrm{R}_{\mathrm{ct}}$ denotes the charge transfer resistance, $\mathrm{Q}_{1}$ and $\mathrm{Q}_{2}$ represent related constant phase elements, and $Z_{\mathrm{w}}$ is the Warburg element [43]. It has to be noted that $R_{\mathrm{f}}$ after cycling is mainly associated with SEI layer at the surface of electrode materials. From the summarized fitting results as shown in Table 4.1, the values of $R_{e}, R_{f}$ and $\mathrm{R}_{\mathrm{ct}}$ of $\mathrm{ZB}-\mathrm{MnS}$ after cycling are $6.6 \Omega, 63.9 \Omega$ and $4.8 \Omega$, which are smaller than the corresponding values of $7.0 \Omega, 144.9 \Omega$ and $197.2 \Omega$ for the fresh ZB-MnS cell, indicating a lower charge transfer resistance and $\mathrm{Li}^{+}$diffusion resistance after cycling. This gives evidence that ZB-MnS electrode exhibits better electrical conductivity after cycling which may enhance the kinetics of $\mathrm{Li}^{+}$insertion/extraction process, leading to the capacity increase. 


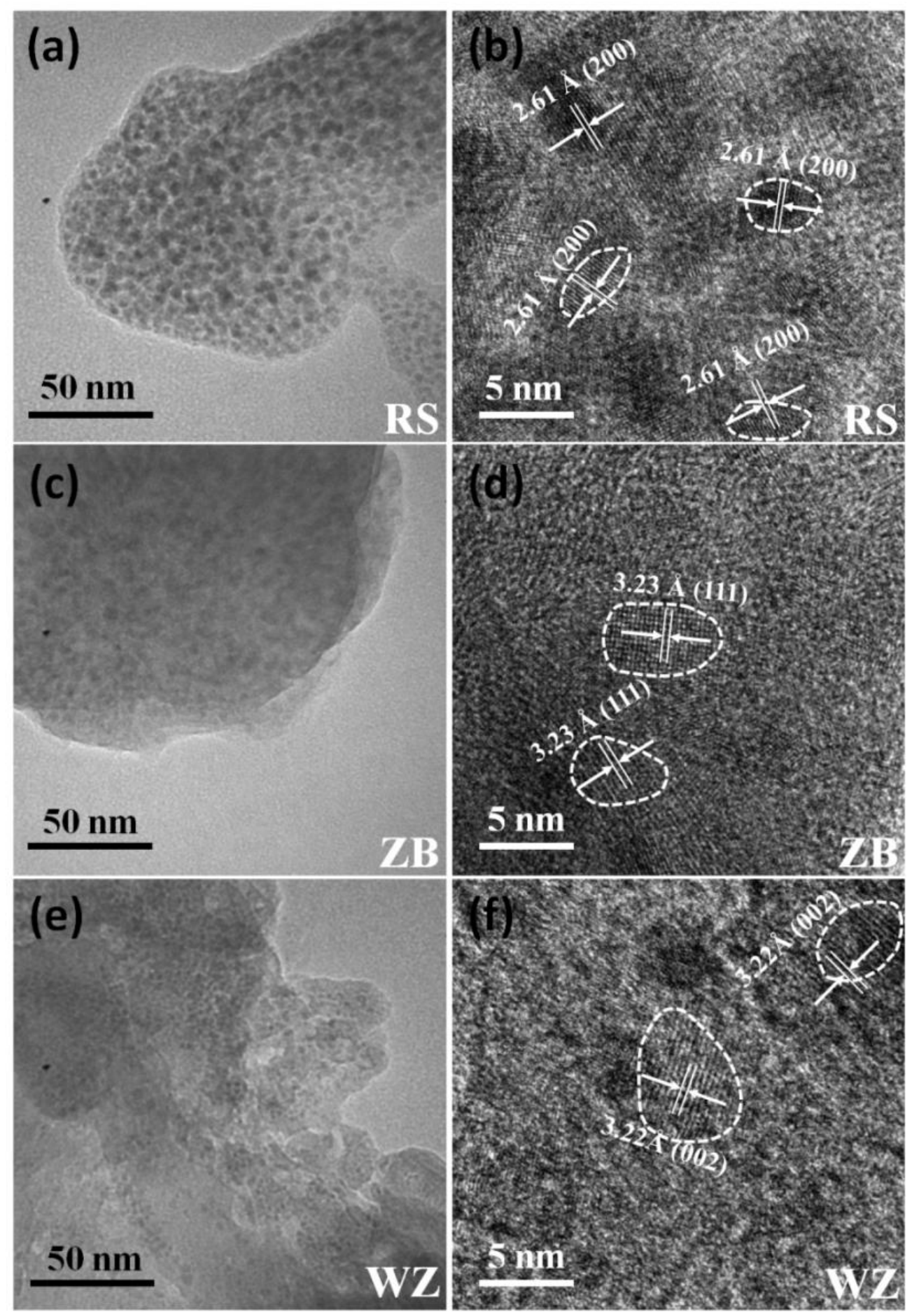

Figure 4.8 TEM and HRTEM images of disassembled (a,b) RS-MnS, (c,d) ZB-MnS and $(\mathrm{e}, \mathrm{f}) \mathrm{WZ}-\mathrm{MnS}$ electrode materials after cycling (charged to $3 \mathrm{~V}$ ).

To further understand the capacity increase mechanism after 40 cycles, three coin cells were fully charged to $3.0 \mathrm{~V}$ after cycling and then disassembled in the glovebox. 
Next, the electrodes were rinsed with diethyl carbonate and dried under vacuum at room temperature. Fig. 4.8a-f show the TEM and HRTEM images of the disassembled electrodes (RS, ZB and WZ-MnS in Fig. 4.8a-b, 4.8c-d and 4.8e-f, respectively). From the low resolution TEM images (Fig. 4.8a, 4.8c and 4.8e), it can be found that MnS NCs are surrounded by amorphous structure materials which are carbon black and binder PVDF. The morphologies of disassembled MnS have significantly changed, compared to the ones of as-synthesized MnS NCs (e.g., nanocube and nanorod). As shown in HRTEM images (Fig. 4.8b, 4.8d and 4.8f), all three kinds of MnS NCs break down to much smaller NCs after cycling. The average size of crystalline particles is $\sim 5 \mathrm{~nm}$. It has been found that lattice fringes with interplanar spacing remain the same as various initial MnS samples (RS-MnS with $2.61 \AA$, ZB-MnS with $3.23 \AA$ and WZ-MnS with $3.22 \AA$ ). This indicates that various MnS NCs still kept the same crystalline structures after cycling.

Table 4.1 Fitting results of the Nyquist plots using the equivalent circuit.

\begin{tabular}{llccc}
\hline & Samples & $R_{e}[\Omega]$ & $R_{f}[\Omega]$ & $R_{c t}[\Omega]$ \\
\hline \multirow{3}{*}{$\begin{array}{c}\text { Before } \\
\text { cycling }\end{array}$} & RS-MnS & 3.8 & 190.7 & 124.1 \\
& ZB-MnS & 7.0 & 144.9 & 197.2 \\
& WZ-MnS & 2.8 & 106.9 & 107.5 \\
\hline \multirow{2}{*}{$\begin{array}{c}\text { After } \\
\text { cycling }\end{array}$} & RS-MnS & 14.5 & 232.2 & 22.1 \\
& ZB-MnS & 6.6 & 63.9 & 4.8 \\
& WZ-MnS & 6.9 & 103.2 & 27.5 \\
\hline
\end{tabular}



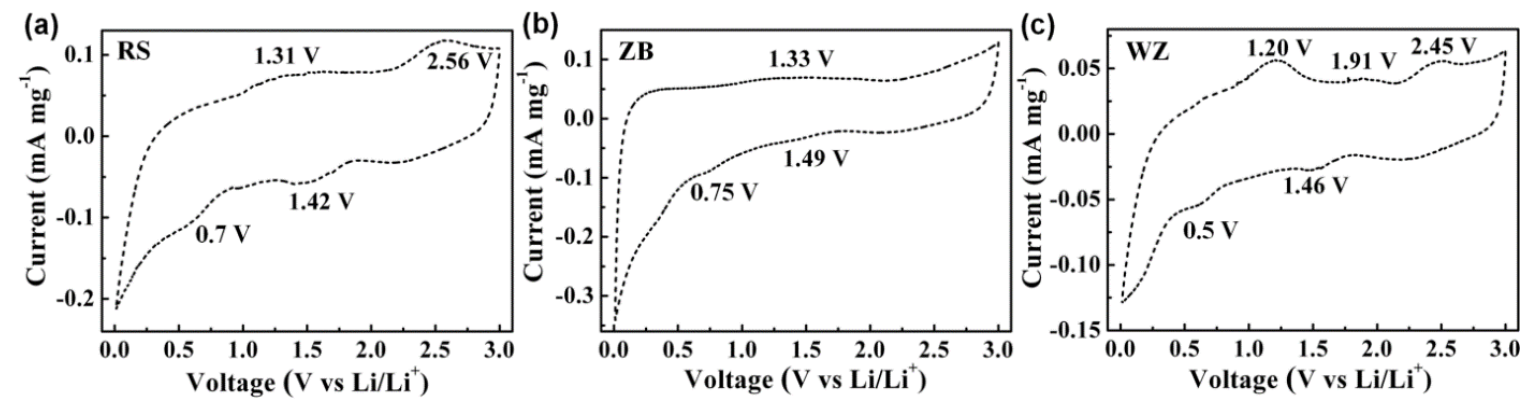

Figure 4.9 Cyclic voltammetry of (a) RS-, (b) ZB- and (c) WZ-MnS after cycling at the scanning rate of $0.2 \mathrm{mV} \mathrm{s}^{-1}$ in the voltage range of $0.01-3 \mathrm{~V} \mathrm{vs.} \mathrm{Li} / \mathrm{Li}^{+}$.

Cyclic voltammetry of the three MnS cells with three different phases have been taken after cyclability test, as shown in Fig. 4.9. During the cathodic process, there is still one reduction peak observed from the high voltage range (over $1.0 \mathrm{~V}$ ), and all the peaks remain at the same position (RS-MnS with $1.42 \mathrm{~V}$, ZB-MnS with $1.49 \mathrm{~V}$ and WZ- MnS with $1.46 \mathrm{~V}$ ) compared with corresponding peaks in Fig. 4.4a-c. Meanwhile, there are also reduction peaks observed from the low voltage range (RS-MnS $0.7 \mathrm{~V}, \mathrm{ZB}-\mathrm{MnS} 0.75$ $\mathrm{V}$ and WZ- MnS 0.5 V). During the anodic process, two oxidation peaks at $1.31 \mathrm{~V}$ and $2.56 \mathrm{~V}$ show up for RS-MnS (Fig. 4.9a). Only one broad oxidation peak centered at $\sim 1.33$ $\mathrm{V}$ is observed on ZB-MnS curve (Fig. 4.9b). There are three oxidation peaks $(1.20 \mathrm{~V}$, $1.91 \mathrm{~V}$ and $2.45 \mathrm{~V}$ ) on WZ-MnS curve (Fig. 4.9c), which are more or less similar to the discussed oxidation process. Although there are shifts of the reduction and oxidation peaks compared to the first 10 cycles of MnS CV behavior, most likely electrochemical reaction of three $\mathrm{MnS}$ samples still proceed through the insertion and conversion mechanisms after cycling. 


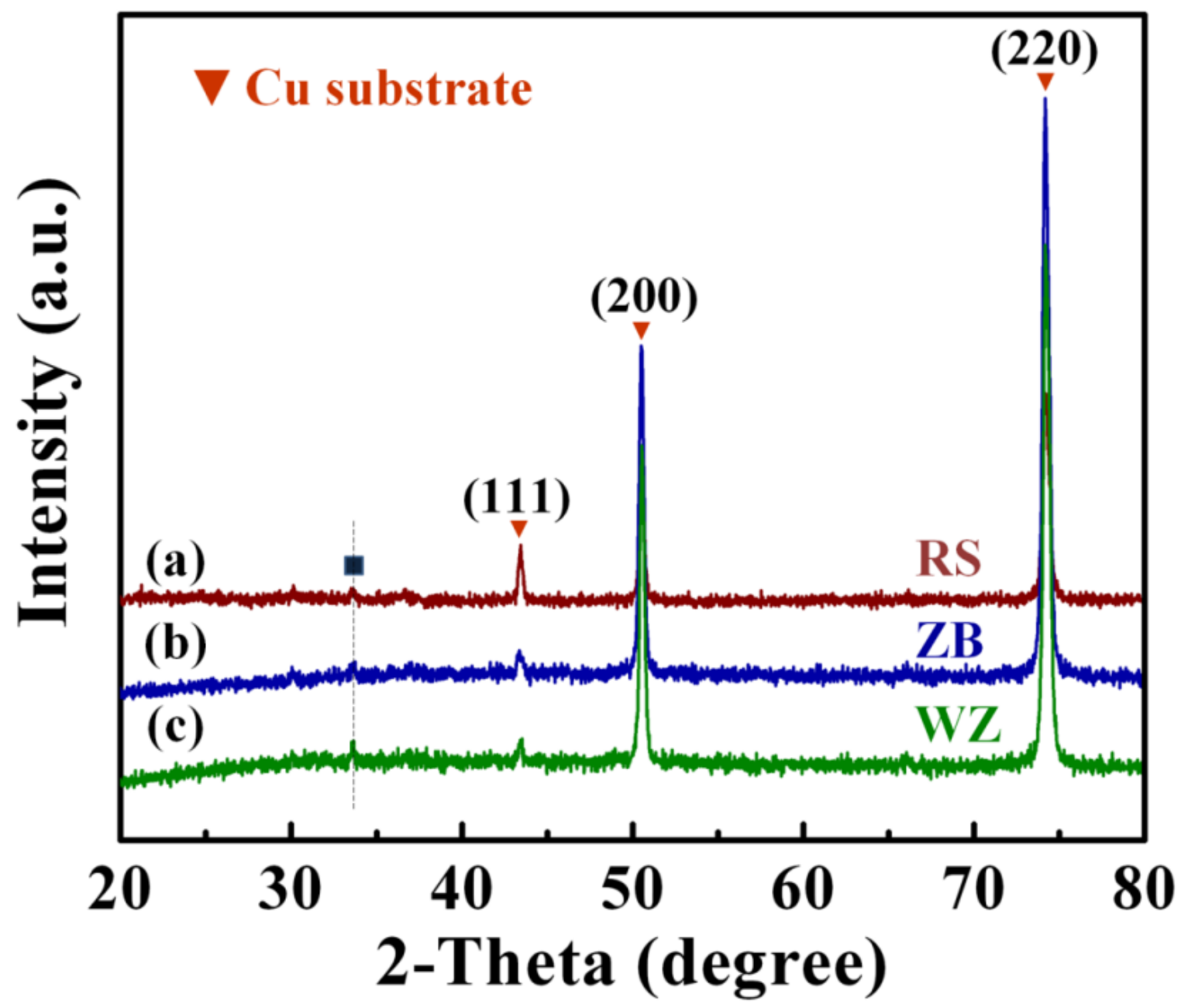

Figure 4.10 XRD patterns of disassembled (a) RS-MnS, (b) ZB-MnS and (c) WZ-MnS electrodes after cycling, charged to $3 \mathrm{~V}$.

XRD has been conducted on the RS-MnS, ZB-MnS and WZ-MnS electrodes after cyclability test. From Figure 4.10, it can be observed that three diffraction peaks shown up in curves (a), (b) and (c) corresponding to the (111), (200) and (220) planes, respectively, which are assigned to the copper substrate. There are new peaks (marked as square) shown up on all three patterns at the same position, which are hardly distinguished. 
The capacity trend during cyclability test can be discussed as follows. On the one hand, the capacity decrease in the course of initial $\sim 40$ cycles could be related to several factors, such as: the SEI formation, volumetric expansion and contraction introducing loss of active materials, metal nanoparticle aggregation, structure degradation, impedance change at the interface, as well as incomplete insertion reaction. On the other hand, similar phenomenon of capacity increase has been reported with some other electrode materials as well, such as carbon materials [44, 45], transition metal oxide [46-49] and transition metal sulfide $[1,24]$. At mean time, a few possible mechanisms have been proposed, such as: 1) Active materials partially lose crystallinity and transform to amorphous-like structure [47], 2) Gel-like polymeric film continual growth by catalytic activity of metal particles [42] and 3) Electrochemical milling effect during cycling [46]. In our case, the reduction peaks in the low voltage range can be observed in the CV curve of MnS electrodes after cycling (Figure 4.9), which could be associated to catalytic metal particles induced SEI formation. One explanation of capacity increase is due to the electrochemical milling effect which results in decreased particles size and enhanced the interfacial area, leading to sufficient electrode/electrolyte interface for more effective $\mathrm{Li}^{+} /$electron transport and extra interfacial charge storage. In addition, from EIS results, low charge transfer resistance after cycling may also contribute to capacity increase because of improved $\mathrm{Li}^{+}$kinetics. The other reason of capacity increase could be possibly due to MnS nanocrystals partially losing their crystallinity and transform to amorphous structure [50-58]. This can also results in the improvement of $\mathrm{Li}^{+}$kinetics. From the TEM results, it may not be confirmed that the amorphous structure materials are still $\mathrm{MnS}$. 
Further investigation, such as in-situ TEM, needs to be carried out to examine the mechanism of capacity increase and improvement of $\mathrm{Li}^{+}$diffusion kinetics.

\subsection{Conclusions}

In summary, we have successfully synthesized RS-MnS, ZB-MnS and WZ-MnS NCs with different morphologies via a facile solvothermal approach. The structural and morphological characterizations indicate that the obtained products exhibited high purity and excellent crystallinity. When evaluated as anode materials in LIBs, RS-, ZB- and WZ-MnS have achieved the capacities of $232.5 \mathrm{mAh} \mathrm{g}^{-1}, 287.9 \mathrm{mAh} \mathrm{g}^{-1}$ and $79.8 \mathrm{mAh}$ $\mathrm{g}^{-1}$ at the 600th cycle, respectively, retained with Coulombic efficiencies over $98 \%$. Notably, all the MnS samples showed an anomalous cycling performance as the capacity increases with the increase of cycle numbers, which may be attributed to the better kinetics and enhanced interfacial charge storage. Moreover, ZB-MnS delivered better electrochemical performance compared to RS-MnS and WZ-MnS.

\subsection{References}

[1] Y. Du, Z. Yin, J. Zhu, X. Huang, X.-J. Wu, Z. Zeng, Q. Yan, H. Zhang, Nat. Commun. 3 (2012) 1177.

[2] C. Xu, Y. Zeng, X. Rui, N. Xiao, J. Zhu, W. Zhang, J. Chen, W. Liu, H. Tan, H.H. Hng, ACS nano 6 (2012) 4713-4721.

[3] C. Zhu, Y. Wen, P.A. van Aken, J. Maier, Y. Yu, Adv. Funct. Mater. 25 (2015) 23352342.

[4] Q. Wang, L. Jiao, Y. Han, H. Du, W. Peng, Q. Huan, D. Song, Y. Si, Y. Wang, H. Yuan, J. Phys. Chem. C 115 (2011) 8300-8304.

[5] W. Zhou, X. Cao, Z. Zeng, W. Shi, Y. Zhu, Q. Yan, H. Liu, J. Wang, H. Zhang, Energy Environ. Sci. 6 (2013) 2216-2221. 
[6] K. Chang, D. Geng, X. Li, J. Yang, Y. Tang, M. Cai, R. Li, X. Sun, Adv. Energy Mater. 3 (2013) 839-844.

[7] C. Zhu, X. Mu, P.A. van Aken, Y. Yu, J. Maier, Angew. Chem. Int. Ed. 53 (2014) 2152-2156.

[8] C.-W. Kung, H.-W. Chen, C.-Y. Lin, K.-C. Huang, R. Vittal, K.-C. Ho, ACS nano 6 (2012) 7016-7025.

[9] G. Dennler, R. Chmielowski, S. Jacob, F. Capet, P. Roussel, S. Zastrow, K. Nielsch, I. Opahle, G.K. Madsen, Adv. Energy Mater. 4 (2014) 1301581.

[10] T. Zhu, H.B. Wu, Y. Wang, R. Xu, X.W.D. Lou, Adv. Energy Mater. 2 (2012) 14971502 .

[11] S. Peng, L. Li, H. Tan, R. Cai, W. Shi, C. Li, S.G. Mhaisalkar, M. Srinivasan, S. Ramakrishna, Q. Yan, Adv. Funct. Mater. 24 (2014) 2155-2162.

[12] Q. Su, G. Du, J. Zhang, Y. Zhong, B. Xu, Y. Yang, S. Neupane, K. Kadel, W. Li, ACS nano 7 (2013) 11379-11387.

[13] D. Xie, W. Tang, X. Xia, D. Wang, D. Zhou, F. Shi, X. Wang, C. Gu, J. Tu, J. Power Sources 296 (2015) 392-399.

[14] J. Yan, H. Huang, J. Zhang, Z. Liu, Y. Yang, J. Power Sources 146 (2005) 264-269.

[15] N. Yamakawa, M. Jiang, C.P. Grey, Chem. Mater. 21 (2009) 3162-3176.

[16] F. Liao, J. Światowska, V. Maurice, A. Seyeux, L.H. Klein, S. Zanna, P. Marcus, Appl. Surf. Sci. 283 (2013) 888-899.

[17] X. Rui, H. Tan, Q. Yan, Nanoscale 6 (2014) 9889-9924.

[18] X. Li, A. Dhanabalan, K. Bechtold, C. Wang, Electrochem. Commun. 12 (2010) 1222-1225.

[19] X. Li, A. Dhanabalan, C. Wang, J. Power Sources 196 (2011) 9625-9630.

[20] Y. Yu, A. Dhanabalan, L. Gu, C. Wang, Nanosci. Nanotechnol. Lett. 4 (2012) 983988.

[21] J. Wu, C. Chen, Y. Hao, C. Wang, Colloids Surf. A Physicochem. Eng. Asp. 468 (2015) 17-21. 
[22] Y. Zhao, J. Feng, X. Liu, F. Wang, L. Wang, C. Shi, L. Huang, X. Feng, X. Chen, L. $\mathrm{Xu}$, Nat. Commun. 5 (2014) 4565.

[23] B. Luo, Y. Fang, B. Wang, J. Zhou, H. Song, L. Zhi, Energy Environ. Sci. 5 (2012) 5226-5230.

[24] J. Xie, S. Liu, G. Cao, T. Zhu, X. Zhao, Nano Energy 2 (2013) 49-56.

[25] M.Y. Son, J.H. Choi, Y.C. Kang, J. Power Sources 251 (2014) 480-487.

[26] Y. Gui, L. Qian, X. Qian, Mater. Chem. Phys. 125 (2011) 698-703.

[27] X. Yang, Y. Wang, Y. Sui, X. Huang, T. Cui, C. Wang, B. Liu, G. Zou, B. Zou, Langmuir 28 (2012) 17811-17816.

[28] J. Beltran-Huarac, J. Palomino, O. Resto, J. Wang, W.M. Jadwisienczak, B.R. Weiner, G. Morell, RSC Adv. 4 (2014) 38103-38110.

[29] J. Beltran-Huarac, O. Resto, J. Carpena-Nuñez, W.M. Jadwisienczak, L.F. Fonseca, B.R. Weiner, G. Morell, ACS Appl. Mater. Interfaces 6 (2014) 1180-1186.

[30] X. Yang, Y. Wang, K. Wang, Y. Sui, M. Zhang, B. Li, Y. Ma, B. Liu, G. Zou, B. Zou, J. Phys. Chem. C 116 (2012) 3292-3297.

[31] S. Wang, K. Li, R. Zhai, H. Wang, Y. Hou, H. Yan, Mater. Chem. Phys. 91 (2005) 298-300.

[32] N. Zhang, R. Yi, Z. Wang, R. Shi, H. Wang, G. Qiu, X. Liu, Mater. Chem. Phys. 111 (2008) 13-16.

[33] L. Zhang, L. Zhou, H.B. Wu, R. Xu, X.W.D. Lou, Angew. Chem. 124 (2012) 73797382.

[34] D. Chen, H. Quan, X. Luo, S. Luo, Scr. Mater. 76 (2014) 1-4.

[35] Y. Yu, L. Gu, C. Wang, A. Dhanabalan, P.A. van Aken, J. Maier, Angew. Chem. Int. Ed. 48 (2009) 6485-6489.

[36] M. Beidaghi, C. Wang, Adv. Funct. Mater. 22 (2012) 4501-4510.

[37] X. Li, A. Dhanabalan, C. Wang, Adv. Energy Mater. 2 (2012) 174-174.

[38] Y. Liu, Y. Qiao, W.-X. Zhang, Z. Li, X.-L. Hu, L.-X. Yuan, Y.-H. Huang, J. Mater. Chem. 22 (2012) 24026-24033. 
[39] S.M. Lee, J.K. Lee, Y.C. Kang, Chem. Asian J. 9 (2014) 590-595.

[40] C. Wang, A.J. Appleby, F.E. Little, Electrochim. Acta 46 (2001) 1793-1813.

[41] X. Xu, S. Ji, M. Gu, J. Liu, ACS Appl. Mater. Interfaces 7 (2015) 20957-20964.

[42] Z. Fan, J. Liang, W. Yu, S. Ding, S. Cheng, G. Yang, Y. Wang, Y. Xi, K. Xi, R.V. Kumar, Nano Energy 16 (2015) 152-162.

[43] Y. Zhang, P. Zhu, L. Huang, J. Xie, S. Zhang, G. Cao, X. Zhao, Adv. Funct. Mater. 25 (2015) 481-489.

[44] X. Li, D. Geng, Y. Zhang, X. Meng, R. Li, X. Sun, Electrochem. Commun. 13 (2011) 822-825.

[45] L. Qie, W.M. Chen, Z.H. Wang, Q.G. Shao, X. Li, L.X. Yuan, X.L. Hu, W.X. Zhang, Y.H. Huang, Adv. Mater. 24 (2012) 2047-2050.

[46] Y. Yu, Y. Shi, C.-H. Chen, Nanotechnology 18 (2007) 055706.

[47] Y. Shi, B. Guo, S.A. Corr, Q. Shi, Y.-S. Hu, K.R. Heier, L. Chen, R. Seshadri, G.D. Stucky, Nano Lett. 9 (2009) 4215-4220.

[48] Z.-S. Wu, W. Ren, L. Wen, L. Gao, J. Zhao, Z. Chen, G. Zhou, F. Li, H.-M. Cheng, ACS nano 4 (2010) 3187-3194.

[49] M.F. Hassan, Z. Guo, Z. Chen, H. Liu, Mater. Res. Bull. 46 (2011) 858-864.

[50] M. Fayette and R. D. Robinson, J. Mater. Chem. A 2 (2014) 5965-5978.

[51] Y. He, M. Gu, H. Xiao, L. Luo, Y. Shao, F. Gao, Y. Du, S.X. Mao, C. Wang, Angew. Chem. Int. Ed. 55 (2016) 6244-6247.

[52] Y.C. Lu, C.Ma, A J.lvarado, N.Dimov, Y.S. Meng, S. Okada, J. Mater. Chem. A 3(2015) 16971-16977.

[53] H. Liu, S. Chen, G. Wang, S.Z. Qiao, Chem. Eur. J. 9 (2013) 16897-16901.

[54] C.M. Hayner, X. Zhao, H.H. Kung, Annu. Rev. Chem. Biomol. Eng. 3 (2012) 445471.

[55] Z. Liu, H. Deng, P.P. Mukherjee, ACS Appl. Mater. Interfaces, 7 (2015) 4000-4009.

[56] N. Mahmood, T. Tang, Y. Hou, Adv. Energy Mater. (2016) 
[57] J. Zai, X. Qian, K. Wang, C. Yu, L. Tao, Y. Xiao, J. Chen, CrystEngComm 14 (2012) 1364-1375.

[58] G. Yushin, W.U. Feixiang, H. Kim, Georgia Tech Research Corporation, U.S. Patent Application, 14/628 (2015) 153. 


\section{SUMMARY}

This dissertation presents fabrication, characterization and evaluation of sulfur based electrode materials for lithium ion batteries, lithium sulfur and room temperature sodium sulfur batteries. Sulfur is one of the most promising candidates for cathode materials due to its high capacity and energy density, low cost and eco-friendly. However, the practical application of sulfur and sulfides still needs further development to approach theoretical capacity with low process cost. This dissertation with the aim to tackle the challenges that constrain the electrochemical performance of sulfur-based electrode materials and the major conclusions are briefly summarized below:

First of all, for the lithium-sulfur batteries work, we have successfully synthesized the NGNSs/S composite by a facile chemical reaction deposition method. When evaluated as electrodes in Li-S batteries, the NGNSs/S cathode exhibits good rate capability and good specific discharge capacity after 20 cycles. It can be concluded that the NGNSs as a framework formed by the 2D graphene layer could anchor sulfur particles, improve the conductivity of the electrode and enlarge the contact surface area to allow fast $\mathrm{Li}^{+}$ transport, which are the main reasons for the enhanced electrochemical performance of sulfur as cathode.

Second of all, for the sodium-sulfur batteries work, NGNS was further used to interlink with S nanocomposites as electrode materials for RT Na-S batteries. In this kind of nanocomposites, sulfur has been phase-transferred from alpha-S8 to gamma-S8, formed small nanoparticles with average size of $\sim 10 \mathrm{~nm}$ and anchored onto the NGNS layers during the thermal treatment progress. The NGNS/S with low loading sulfur content exhibits an excellent rate and cycling performance, indicating that the defects and 
active sites introduced by $\mathrm{N}$ functional groups play an effective role in interlinking sulfur and confining polysulfide dissolution in the organic electrolytes in RT Na-S batteries. This significant improvement can also be attributed to the conductive network established by both $\mathrm{S}$ and NGNS for fast flexible $\mathrm{Na}^{+}$transport during cycling. The high loading sulfur content exhibits an inferior electrochemical performance, indicating that low sulfur loading level leads a good way for high performance of RT Na-S batteries.

In the last part of this thesis, for the MnS work, we have successfully synthesized RS-MnS, ZB-MnS and WZ-MnS NCs with different morphologies via a facile solvothermal approach. The structural and morphological characterizations indicate that the obtained products exhibited high purity and excellent crystallinity. As evaluation carrying out in LIBs, RS-, ZB- and WZ-MnS have achieved the capacities of $232.5 \mathrm{mAh}$ $\mathrm{g}^{-1}, 287.9 \mathrm{mAh} \mathrm{g}^{-1}$ and $79.8 \mathrm{mAh} \mathrm{g}^{-1}$ at the 600th cycle, respectively, retained with Coulombic efficiencies over 98\%. Remarkably, all the MnS samples showed an unusual cycling performance as the capacity increases with the increase of cycle numbers, which may be attributed to the better kinetics and enhanced interfacial charge storage. Moreover, ZB-MnS delivered better electrochemical performance compared to RS-MnS and WZ-MnS.

Nanostructured sulfur composites have archived high specific capacity of sulfur with cycling efficiency and rate capability performance. However, the syntheses process is costly on time and materials. The impact factor of sulfur content in the composite is also needed to be considered since it can dramatically reduce the energy density of sulfur cathode-based batteries. Other challenge is that, the dissolution of polysulfide into the liquid electrolyte in one aspect facilitates the conversion reaction between the insulating 
sulfur and lithium. In another aspect, the shuttle effect still exists during the reaction. Future work need to focus on how to tackle the pro and con of the polysulfides dissolution. One of the high demanded crucial work will be the development of liquid electrolyte which can suspend the dissolution of polysulfides and meanwhile stabilize the polysulfides. Although the work of sulfur as cathode so far is still under investigation with enormous effort and far away from the requirements of practical application. This dissertation presented promising solutions and investigations, and hopefully, it can offer approaches to facilitate sulfur as cathode in practical applications in the near future. 


\section{YONG HAO}

2002-2006

2008-2011

2011-2016
B.A., Mineral Processing

China University of Mining and Technology (Beijing), Beijing, China

M.S., Materials Science

Kunming University of Science and Technology, Kunming, China

Ph.D. Candidate, Materials Science and Engineering Florida International University, Miami, USA

\section{PUBLICATIONS AND PRESENTATIONS}

Yong Hao, Xifei Li, Xueliang Sun and Chunlei Wang, Nitrogen-doped graphene nanosheets/sulfur composite as lithium-sulfur batteries cathode, Materials Science \& Engineering B, 2016/4, DOI:10.1016/j.mseb.2016.04.009

Yong Hao, Chunhui Chen, Xinyi Yang, Guanjun Xiao, Bo Zou and Chunlei Wang, Studies on intrinsic phase-dependent electrochemical properties of $\mathrm{MnS}$ anodes for lithium-ion batteries, Journal of Power Sources, 2016. (under review)

Yong Hao, Xifei Li, Xueliang Sun and Chunlei Wang, Nitrogen-doped graphene nanosheets enhanced chemical interlink of sulfur as cathode material for roomtemperature sodium-sulfur battery. (to be submitted)

Jujun Yuan, Chunhui Chen, Yong Hao, Xianke Zhang, Bo Zou, Richa Agrawal, Chunlei Wang, $\mathrm{SnO}_{2}$ /polypyrrole hollow spheres with improved cycle stability as lithium-ion battery anodes, Journal of Alloys and Compounds, 2016. (under review)

Richa Agrawal, Yong Hao, Yin Song, Chunhui Chen, Chunlei Wang, Hybridization of lithium-ion batteries and electrochemical capacitors: fabrication and challenges, Proc. SPIE : Sensing, Technology \& Applications. 2015/5, 94930B:1-7 
Richa Agrawal, Chunhui Chen, Yong Hao, Yin Song, and Chunlei Wang. Graphene for Supercapacitors, Editor: Rashid bin Mohd Yusoff, John Wiley \& Sons, Inc., 2015. DOI: 10.1002/9783527690312.ch6. ISBN: 978-3-527-33806-1

Jun $\mathrm{Wu}$, Chunhui Chen, Yong Hao, Chunlei Wang, Enhanced electrochemical performance of nanosheet $\mathrm{ZnO}$ /reduced graphene oxide composites as anode for lithiumion batteries, Colloids and Surfaces A. 2014/12, 468, 17-21

Yin Song, Richa Agrawal, Yong Hao, Chunhui Chen, Chunlei Wang, C-MEMS based microsupercapacitors and microsensors, ECS Transactions, 2014, 61(7) 55-64

Chunhui Chen, Richa Agrawal, Yong Hao and Chunlei Wang. ECS Journal of Solid State Science and Technology, 2013, 2 (10), M3074-M3077

Yong Hao, Chunhui Chen, Chunlei Wang, Composite of sulfur/nitrogen-doped graphene nanosheets as the cathode of Lithium-Sulfur batteries, 2014 MRS Spring meeting, San Francisco, April 21-25, 2014 (Poster)

Yong Hao, Chunhui Chen, Chunlei Wang, Composite of sulfur/nitrogen-doped graphene nanosheets as the cathode of Lithium-Sulfur batteries, 2014 Nanoflorida, University of Miami, Miami, September 24-25, 2014 (Poster)

Yong Hao, Chunhui Chen, Richa Agrawal, Yin Song, Chunlei Wang, Carbon Nanotube and Conductive Polymer Dual Protection for Improving Sulfur Cathode Performance, 2014 MRS Fall meeting, Boston, Nov 30- Dec 5, 2014 (Poster)

Yong Hao, Chunhui Chen, Bo Zou and Chunlei Wang, Manganese Sulfide as anode material for Lithium-ion batteries, 2016 MRS Spring meeting, Phoenix, Arizona, March 28-April 1, 2016 (Poster)

Yong Hao, Xifei Li and Chunlei Wang, Nitrogen-doped graphene nanosheets/sulfur as cathode material for room-temperature sodium-sulfur battery, 2016 MRS Spring meeting, Phoenix, Arizona, March 28-April 1, 2016 (Poster)

Yong Hao, Xifei Li and Chunlei Wang, Nitrogen-doped graphene/sulfur composite as cathode material for room-temperature sodium-sulfur battery, ECS Spring Meeting 2016, San Diego, CA, May 29-June 3, 2016 (oral) 